Portland State University

PDXScholar

3-1-2018

Rammed Earth in the Portland Metro Area

Samuel D. Richmann

Portland State University

Follow this and additional works at: https://pdxscholar.library.pdx.edu/honorstheses

Let us know how access to this document benefits you.

Recommended Citation

Richmann, Samuel D., "Rammed Earth in the Portland Metro Area" (2018). University Honors Theses.

Paper 509.

https://doi.org/10.15760/honors.514

This Thesis is brought to you for free and open access. It has been accepted for inclusion in University Honors Theses by an authorized administrator of PDXScholar. Please contact us if we can make this document more accessible: pdxscholar@pdx.edu. 


\title{
Rammed Earth in the Portland Metro Area
}

\author{
By \\ Samuel Richmann \\ An undergraduate honors thesis submitted in partial fulfillment of the \\ requirements for the degree of \\ Bachelor of Science \\ in \\ University Honors \\ and \\ Civil Engineering
}

Thesis Adviser

Evan Kristof

Portland State University

2018 


\section{$\underline{\text { TABLE OF CONTENTS }}$}

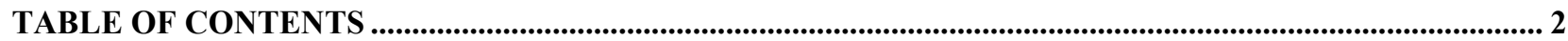

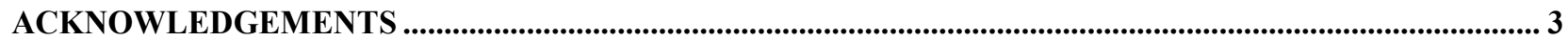

ABSTRACT …....................................................................................................................................................... 4

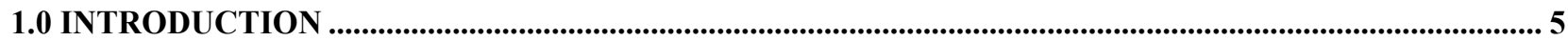

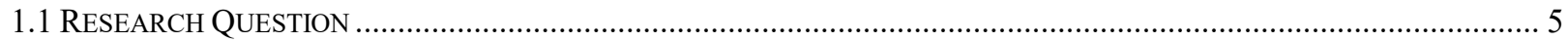

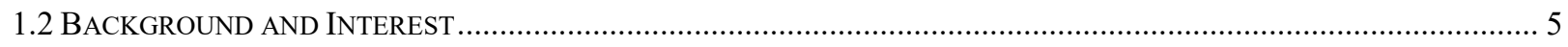

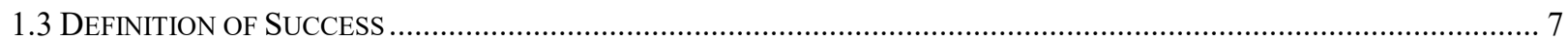

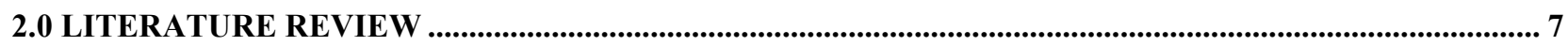

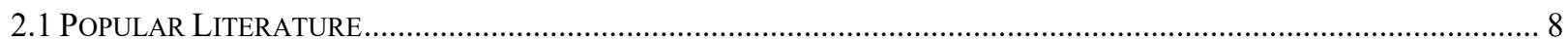

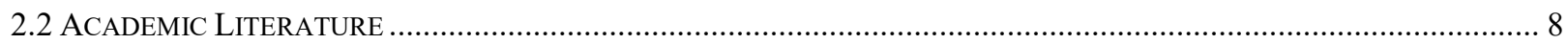

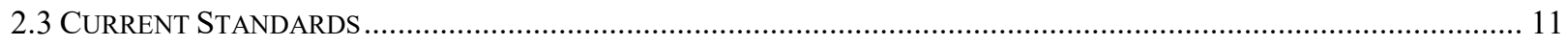

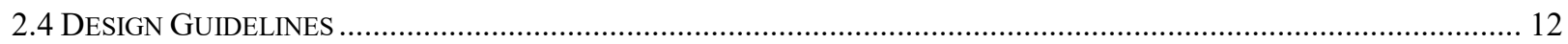

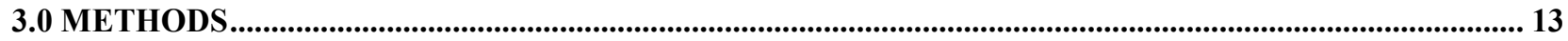

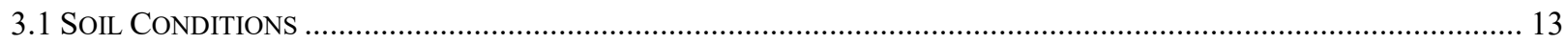

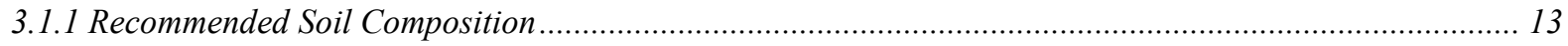

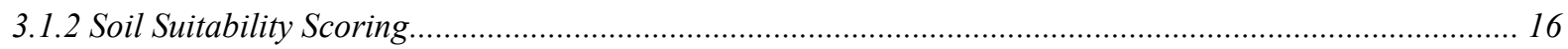

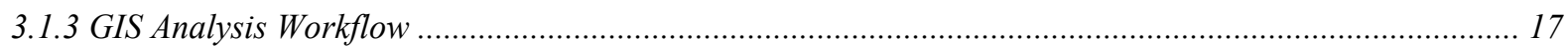

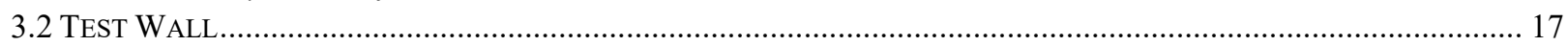

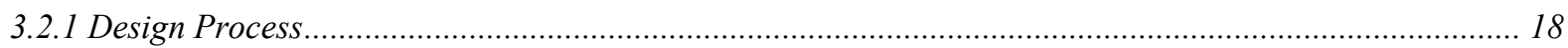

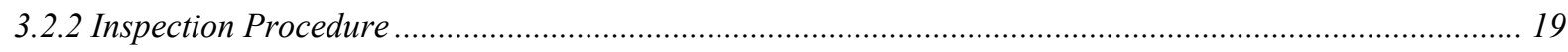

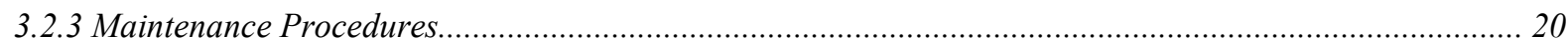

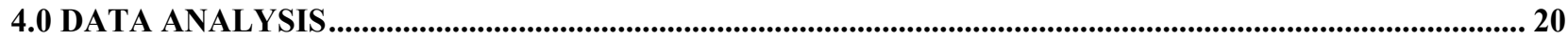

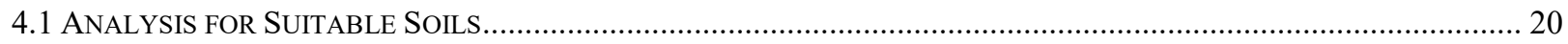

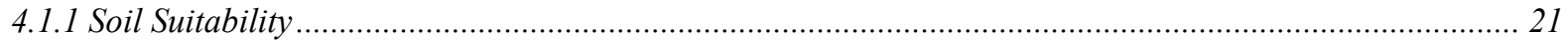

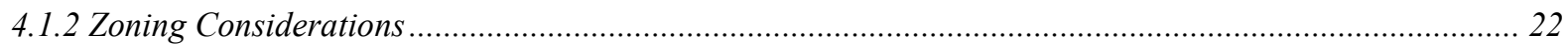

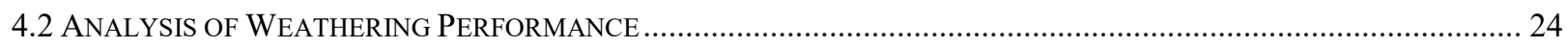

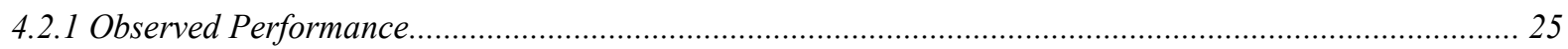

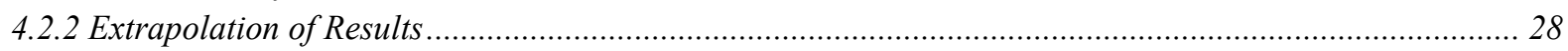

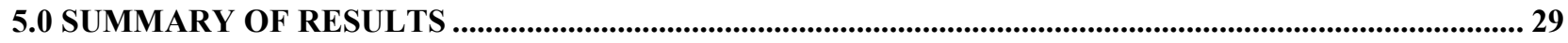

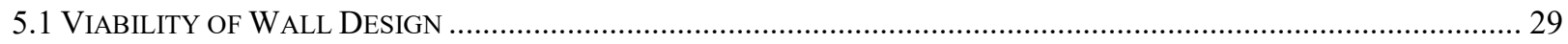

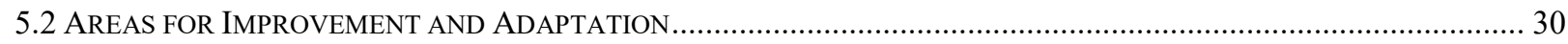

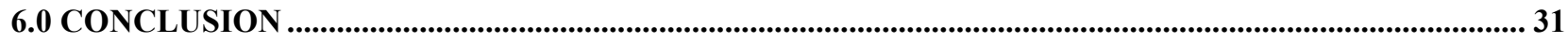

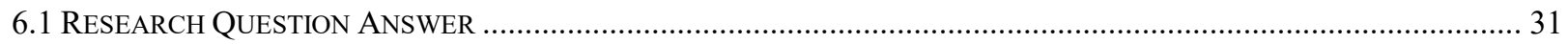

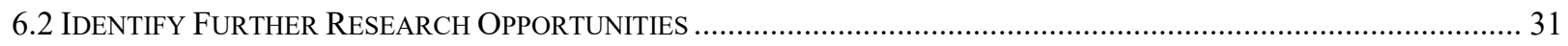

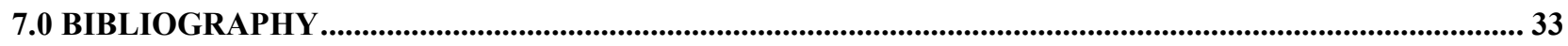

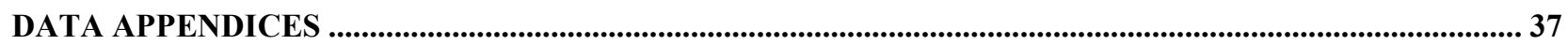




\section{ACKNOWLEDGEMENTS}

This paper was only possible with assistance from the many people who encouraged and supported me. I would first like to thank Evan Kristof. As my advisor, Evan consistently encouraged me and was always supportive of my crazy ideas. He provided critical advice and guidance throughout the entire process.

I also want to thank Rachel Koenig, Eric Jeffery, and Ke Liilah Slingluff for their role in this project. They were my capstone group members and were dedicated to the project and to seeing it to completion. This project could not have happened without their work and support.

A special thanks goes out to Portland State University's Facilities and Property Management (FPM) for their support of this project. I would especially like to thank Megan Schneider who was always pushing the project forward. Additional recognition goes out to Sarah Kenney. I would also like to thank the Civil and Environmental Engineering Department and the University Honors College for their support of this project.

Finally, I would like to also thank those who donated their time to the construction of the wall:

- Sophie Biddle

- $\quad$ Eric Jeffery

- Rachel Koenig

- Evan Kristof

- Kyle Metzger

- Ryan Ngo

- Corina Overman

- Aaron Schmalz

- Ke Liilah Slingluff 


\section{$\underline{\text { ABSTRACT }}$}

This paper evaluates the viability of rammed earth construction in the Portland, Oregon Metro area. The study evaluates local soil conditions and local weather for their impact on the viability of rammed earth. A prototype wall was constructed on the Portland State University campus and left exposed to natural weathering. Weathering on the wall was observed for a period of seven months from August 2017 through February 2018. Numerous shrink/swell cracks were observed throughout the wall, as well as delamination cracks in the upper layer. An analysis of soil composition in Clackamas, Multnomah, and Washington County was conducted using information from the USDA's Web Soil Survey, and GIS Software. Analysis of soil composition indicated $1.7 \%(23,956$ acres $)$ of the total area investigated has soil ideal for rammed earth construction. Of the total area investigated, $0.4 \%$ (5,246 acres) has soil ideal for rammed earth construction and is zoned for low to medium density residential development. This study indicated the potential for rammed earth to be viable in Portland under a limited set of circumstances. 


\section{$\underline{1.0 \text { INTRODUCTION }}$}

With the growing threat of climate change, sustainable alternatives to current building practices are receiving increased attention. Rammed earth is an appealing potential alternative to small scale concrete and masonry construction. Rammed earth often makes use of soil found on-site, with little to no cement added. Though modern rammed earth is typically implemented in arid climates, historic rammed earth can be found in most climatic regions. ${ }^{1}$ Current practices in rammed earth construction suggest that rammed earth is not a feasible construction method in damp climates such as the Pacific Northwest. The purpose of this thesis is to evaluate the viability of rammed earth as a construction technique in the Portland, Oregon Metro area.

\subsection{Research Question}

When considering the feasibility of a particular design, a number of factors need to be considered, such as material cost, material availability, construction time, construction cost, design life, and aesthetics. To evaluate rammed earth in the Portland Metro area for all these factors would be too arduous an undertaking for a study of this size. With that in mind, the focus of this study is on the unique challenges in the location of interest.

In the US, rammed earth is most common in the American Southwest. Earthen construction, such as adobe, is a relatively common practice in this region. The soils in this area are sandy, and the climate is arid. This stands in contrast with the Portland Metro area, where soils are silty, and the climate is damp. To address these two factors and to guide the study of rammed earth, the following research question was developed:

How do native soil conditions and local weather affect the viability of rammed earth construction in the Portland Metro area?

\subsection{Background and Interest}

Rammed earth is a construction technique by which successive layers of soil are compacted to create a single monolithic structure. Small amounts of Portland cement are often added to stabilize the soil layers. Most often, the soil is locally sourced or from on-site. Rammed earth is typically practiced in drier climates with sandy soils. In the American Southwest, archeological records date early rammed earth houses to approximately $700 \mathrm{AD}^{2}$ Some of the oldest structures still standing were constructed using rammed earth. ${ }^{3}$ These historic structures demonstrate the potential longevity and durability of rammed earth.

The technique is an environmentally-friendly alternative to modern construction techniques. Due to the low cement content in rammed earth walls, the embodied carbon of rammed earth is much less than that of Portland Cement Concrete ("concrete"), and similarly sized masonry structures. The use of local materials reduces the emission due to transportation and construction costs. Additionally, the thermal mass of rammed earth makes it a good insulator, increasing thermal comfort, while minimizing energy consumption. However, rammed earth is labor intensive, presenting a significant barrier to implementation.

\footnotetext{
${ }^{1}$ See Houben and Guillaud, 2014 (pg. 6-15) and Easton, 2007 (pg. 5)

${ }^{2}$ See Easton, 2007 (pg. 9)

${ }^{3}$ See Easton, 2007 (pg. 3-9)
} 
Despite the barrier of labor costs, there are many reasons why rammed earth is an appealing construction technique. Rammed earth is a visually appealing construction method. The environmentally-friendly nature of rammed earth is enticing to those wishing to lessen the environmental impact of construction. The use of readily-available materials makes it a cost-effective alternative for those willing to absorb the labor costs or perform the labor themselves. For those willing to perform the construction themselves, rammed earth can provide a comfortable, sustainable, and inexpensive alternative to traditional construction methods.

My interest in rammed earth is from a structural engineering perspective. One of the core tenants promoted by the American Society of Civil Engineers is to develop sustainable engineering designs. ${ }^{4}$ Cement manufacturing is a large contributor to climate change. For every ton of cement commercially made, 1.25 tons of carbon dioxide are produced. ${ }^{5}$ Concrete and Concrete Masonry Units (CMUs) also require the use of sand and gravel, which are often extracted from large quarry sites. These operations often have large carbon dioxide emissions and energy uses associated with them. Transportation of materials only add to the carbon dioxide output and embodied energy levels of these materials.

In order to combat climate change, environmentally-focused improvements and alternatives to the production of concrete and masonry are needed. In recent years, there has been an increased interest in natural building as an alternative to modern construction techniques. Natural building is the principal of using locally available and minimally-processed materials to perform construction in the most sustainable manner. Rammed earth is one natural building technique which has been implemented successfully, particularly in the American Southwest. One measure of successful implementation is the New Mexico structural design code which details design requirements of rammed earth structures, NMAC 14.7.4. The existence of an adopted design code demonstrates a willingness to accept rammed earth as a viable construction technique.

For all its promise, there are significant barriers to implementation of rammed earth specific to the Portland Metro area. ${ }^{6}$ The dominant soil in Portland is low plasticity silt. ${ }^{7}$ Silt is notorious for having poor engineering properties. Portland also experiences more rainfall than the American Southwest. Current design of rammed earth calls for great care to be taken to reduce exposure to rain and wind. There is little to no documented history of rammed earth in Portland. There are also no adopted codes for the structural design of rammed earth in the City of Portland, nor any of the neighboring counties. Yet, the long successful history of rammed earth is an indicator that rammed earth holds positive prospect as an alternative for small scale structures.

The aim of this thesis is to further analyze the barriers to implementing rammed earth in Portland. To analyze weathering performance of rammed earth, a prototype wall was constructed and left exposed to local weather. To study the soil conditions in Portland, an analysis of soil composition overlaid with zoning regulations was conducted using Geographic Information System (GIS) software. A field study of rammed earth's performance under weathering conditions will give valuable metrics for performance in Portland's humid

\footnotetext{
${ }^{4}$ See www.asce.org/issues and advocacy

${ }^{5}$ See Contributions of Working Group 2 to the Second Assessment Report of the Intergovernmental Panel on Climate Change published by Intergovernmental Panel on Climate Change (1995), pg. 661

${ }^{6}$ For the purposes of this study, the Portland Metro area is assumed to include Clackamas, Multnomah and Washington County. It will also be abbreviated as Portland in this paper. Due to differences in soil and zoning data, Clark County was excluded from the Portland Metro area.

${ }^{7}$ Calculated from the USDA's Web Soil Survey, 51\% of the Portland Metro Area had USCS Classification of ML
} 
climate. Analyzing local soil conditions will provide a metric for how much modification local soil would likely need to be used in rammed earth construction. This thesis is being approached from an engineering perspective. An engineer understands barriers to project development and works to design efficient solutions. Approaching this topic from an engineering perspective, this study aims to determine whether rammed earth is a viable construction technique for the Portland Metro area, considering local conditions.

\subsection{Definition of Success}

The scope of this study is to evaluate two location-specific factors and how they relate to rammed earth construction. The first is whether the Portland Metro area has soil conditions suitable for rammed earth construction. The second factor is whether rammed earth is durable enough to withstand the weather patterns of the area. As with any design, modifications can be made to rammed earth to address location-specific criteria. For example, if conditions suggest that local soil does not have a high enough sand content, additional sand can be added to the soil mixture. Similarly, stabilization can be added to increase the durability of rammed earth.

However, the more significant the modifications, the less viable an alternative rammed earth becomes. The addition of more stabilization greatly increases the embodied carbon of the structure. If significant amounts of soil from off-site or stabilization are needed, both material and transportation costs increase. By reducing or removing the environmental and cost benefits of rammed earth, the viability of rammed earth is significantly decreased. Another important consideration when considering rammed earth's viability is the design life and design use of the structure. Durability requirements will change dramatically depending on the design use of the structure, and must be considered in the design. In order to be a viable construction method, local soil without significant modification should provide the necessary composition to construct a rammed earth structure able to withstand local weathering conditions for the proposed design life.

\subsection{LITERATURE REVIEW}

The body of knowledge on rammed earth is extensive, though relatively few published works provide detail for the engineering design of rammed earth. Much of the existing literature is aimed for a non-technical audience, specifically pertaining to the construction of rammed earth. Few countries have fully adopted standards relating to rammed earth construction, though several de facto standards exist, aiding the engineering design of rammed earth. Academic work on rammed earth has primarily focused on the performance of the material, and the potential environmental benefits of using rammed earth. In the past decade, several papers have been published aimed at better understanding the material properties and behavior of rammed earth.

While rammed earth may be an ancient technology, the academic and engineering understanding of rammed earth is still relatively new. There are limited resources targeted toward a practicing engineer designing a rammed earth building. This is likely the result of several factors. Currently, there is not a significant demand for rammed earth construction in industrialized nations. This means less demand for engineers to design rammed earth structures. Additionally, rammed earth construction practiced in industrialized nations has typically been performed by rammed earth subcontractors or owner-builders. For a niche construction 
technique such as rammed earth, owner-builders typically do not seek engineering services, instead relying on historic knowledge and construction best-practices. Likewise, rammed earth subcontractors have specialty knowledge of rammed earth, and can leverage their experience with the material, instead of relying on engineering services. Despite the lack of literature targeted towards practicing engineers, the field of study on rammed earth provides a wealth of information on the material.

\subsection{Popular Literature}

Much of the existing literature on rammed earth is directed towards natural builders and the DIY community. One of the pivotal works in this area is The Rammed Earth House by David Easton, originally published in 1996, and revised in 2007. Easton's work brought the aesthetic quality and environmental benefits of rammed earth construction to focus for a general audience. The Rammed Earth House also discusses the building process to articulate a repeatable procedure. Easton's book targets environmentally focused consumers interested in building their own house in a more sustainable manner.

A wealth of information on rammed earth construction is currently available online. Much of the online work on rammed earth showcases the aesthetic quality of the material as well as potential environmental benefits. Rammed earth demonstrates exciting potential for reducing the carbon footprint of the residential construction industry. Many of the online articles are directed at owner-builders. How to Build a Rammed Earth House (1973) by John McMeekin is a typical example of this pattern. Recently reprinted online to Mother Earth News, McMeekin outlines how he constructed his rammed earth house and discusses benefits of living in a rammed earth house.

Rammed earth has typically been a "low-tech" building method. Typical material tests performed before construction included dropping a ball of the soil mixture to see how it crumbles ${ }^{8}$ and letting soil sit in a jar. ${ }^{9}$ As one of the oldest known construction methods, rammed earth has long been practiced with little to no help from modern technology. Rammed earth has a reputation as a niche building material often associated with the natural building counterculture. As such, there is little demand for understanding the material mechanics of rammed earth.

The connection of rammed earth to the natural building counterculture generally meant rammed earth structures were being built by non-technical owner-builders. Thus, early literature in the United States was geared to act as construction guides. Books such as David Easton's The Rammed Earth Experience (1982) further popularized rammed earth construction. Increased popularity of rammed earth gave the practice more attention. Works such as Adobe and Rammed Earth Buildings by McHenry (1984) began exploring nonindustrial construction techniques, including rammed earth, in a more academic setting.

\subsection{Academic Literature}

The same qualities that make rammed earth appealing to a general audience also make rammed earth appealing to the academic community. The use of rammed earth presents a promising opportunity to greatly

\footnotetext{
${ }^{8}$ The "ball-test" is common-place, and often recommended for rammed earth construction. See Easton, 2007 (pg. 147), ${ }^{9}$ The "jar-test" is also common-place, and typically practiced during preliminary design. See Easton, 2007 (pg. 102), and Houben and Guillaud, 2014 (pg. 49).
} 
reduce greenhouse gas emissions associated with conventional construction. Several studies have been published studying the environmental benefits of rammed earth. Particular attention has been focused on the use of cement to strengthen rammed earth and the environmental trade-offs of this stabilization. The work by Treloar, et al. (2001) demonstrated that rammed earth poses significant benefits in embodied energy compared to a cavity brick system, but an insignificant savings compared to brick-veneer systems. Venkatarama Reddy and Prasanna Kumar (2010) suggest that cement-stabilized rammed earth has 15-25\% of the embodied energy of similar burnt clay brick masonry.

Despite the potential environmental benefits, one of the major concerns with rammed earth is its relatively low strength and durability especially when compared to concrete. For example, the minimum compressive strength of rammed earth is specified as $300 \mathrm{psi}$ in the New Mexico rammed earth code, ${ }^{10}$ whereas typical compressive strengths of concrete are around 4,000 psi. Because of the relatively low compressive strength of rammed earth, there is a fair amount of skepticism on whether it could meet structural requirements. There is also much skepticism on rammed earth's ability to resist weathering.

Several studies have been published assessing the compressive strength of rammed earth. ${ }^{11}$ As highlighted by Bui et al (2009), typical compressive strength tests have ranged from approximately 100 psi to more than 500 psi. The compressive strength of rammed earth varies significantly based on the soil composition used. ${ }^{12}$ To increase the compressive strength of rammed earth, cement content can be increased. Additionally, rammed earth walls are generally constructed much thicker than typical structures to meet the loading requirements of the structure.

Studies on the durability of rammed earth are a major component of the field. One of the first studies on the durability of earthen construction was done by Heathcote (1995). Based on a preliminary observation, Heathcote noted that silt may have a detrimental effect on the durability of earth construction. He also noted that unstabilized earth does not meet standard under simulated erosion testing, such as the Bulletin 5 Accelerated Erosion Test. However, Heathcote's work argues that existing earth structures demonstrate adequate performance. The study by Bui, Morel, Venkatarama and Ghayad (2009) also suggested that modern testing procedures are "too severe and unrealistic" for unstabilized rammed earth. Bui et al studied several test walls which had been exposed to natural weathering for 20 years. Their analysis suggested a design life of approximately 60 years for unstabilized rammed earth.

Academic works on rammed earth have also focused on other material properties. Bui and Morel (2015) examined the effects of ageing on rammed earth. This allowed them to determine a creep coefficient for rammed earth. The determination of a creep coefficient could improve the design of rammed earth, particularly when looking at an extended design life. Bui et al (2011) studied the dynamic characteristics of rammed earth. By determination of the dynamic properties of rammed earth, seismic design of rammed earth can be approached using conventional practices. Gomes et al (2011) explored the seismic resistance of rammed earth structures. This study found that basic steel reinforcing, as is typical with masonry construction, greatly improves the seismic resistance of rammed earth structures.

\footnotetext{
${ }^{10}$ NMAC 14.7.4

${ }^{11}$ Maniatidis and Walker, 2008; Bui et al, 2009; Venkatarama Reddy and Prasanna Kumar, 2011; as well as others.

12 See Bryan, 1988
} 
Other areas of interest in rammed earth include retrofit and repair work, and alternate material design. Works by Gomes and Faria (2011), Gomes et al (2016), and Garcia-Soriano et al (2015) examined methods of repairing both historic and modern rammed earth structures. Works by Gomes et al (2016) and Jawad et al (2014) examined the use of lime to stabilize rammed earth. Houben and Guillaud (2014) also examined the use of lime as a stabilizer for rammed earth. Additional works examined the use of fly-ash ${ }^{13}$ and rice-husk ash as alternative stabilizers in rammed earth. ${ }^{14}$

Another key area of focus on rammed earth is the role of soil in the material properties. This was one of the early undertakings in the academic literature on rammed earth. Bryan (1988) found that a range of soil mixtures provided adequate results for rammed earth. However, the properties for these soil mixtures varied greatly. Houben and Guillaud also explored soil suitability in Earth Construction: A Comprehensive Guide (2014). Houben and Guillaud showed soil suitability by providing a particle size distribution chart overlaid with a recommended zone for the particle size distribution. Building on the work of Bryan and Houben and Guillaud, Hall and Djerbib (2004) tested a series of soil mixtures falling within the recommended particle size distributions. Hall and Djerbib demonstrated there was noticeable variability across soil mixtures. In addition, they also identified several mixtures not meeting suggested minimum criteria outlined in NZS 4298: Materials and Workmanship for Earth Buildings.

Recently, several works furthering the study of rammed earth were presented at the first International Conference on Rammed Earth Construction (ICREC 2015). The conference was designed to bring academics, engineers, architects, and practitioners together to present ideas across disciplinary boundaries. A notable paper that came out of the conference was Earthen Construction: A Geotechnical Engineering Perspective, by Charles Augarde. Augarde summarized the existing work on rammed earth from a geotechnical engineering perspective. By doing so, he was able to identify the current understanding of the material mechanics that provide rammed earth its strength. Augarde also identified gaps in the literature and areas for further study. This was an incredibly useful synthesis on prominent works in the field, and provided an explanation of the mechanics of rammed earth. By examining the mechanics of rammed earth, the process of construction and design can be greatly improved.

An emerging field in the academic literature on rammed earth is the study of rammed earth using engineering analysis techniques. One such study was the work of Ciancio and Robinson (2011) exploring the use of a strut-and-tie model in analysis of rammed earth lintels. This work examined reinforced cement stabilized rammed earth lintels. Ciancio and Robinson found that the strut-and-tie method was appropriate for tensile controlled lentils, but was not adequate for compression controlled lentils. Another study which furthered the engineering analysis of rammed earth was the work presented at ICREC 2015 by Bui, et al. on using discrete element analysis to analyze rammed earth. ${ }^{15}$ With computer modeling becoming more commonplace in structural engineering, a better understanding of how to model rammed earth will allow for more efficient designs, and make rammed earth more appealing to design engineers.

\footnotetext{
${ }^{13}$ See Ma et al, 2016

${ }^{14}$ See Milani et al, 2012

${ }^{15}$ Discrete Element Modeling of Rammed Earth Walls by Bui et al, 2015
} 


\subsection{Current Standards}

Many regions have not formally adopted any rammed earth standards, and existing standards offer only limited resources for the engineering design of rammed earth. Though many codes have been published, the City of Portland has not adopted a code applicable to the engineering design of rammed earth. In order to complete an engineering design without a formally adopted code, an engineer must rely on best practices of the field. With a niche material such as rammed earth, best practices can be hard to identify for a particular region. The engineer must then consult other design standards, academic works, and historic use of the material to design rammed earth structures

The American Society of Testing and Materials (ASTM) produced a standard applicable to the construction of rammed earth, ASTM E2392, however it is not directed toward the engineering design of rammed earth structures. ASTM E2392 contains no design calculations, instead it offers specifications for the empirical design of rammed earth. In Appendix X1, ASTM E2392 states "multiple examples can be found of extant structures with many centuries of useful service life, none of which have been designed by engineers." This gives credence to the use of earthen construction particularly where it has been a historically proven technique. ASTM offers a specification leveraging the historic use of rammed earth, rather than applying modern engineering principles to the practice.

The most comprehensive design code for the engineering design of rammed earth is the New Zealand Standard. There are three standards applicable to rammed earth, NZS 4297: Engineering Design of Earthen Buildings, NZS 4298: Materials and Workmanship for Earthen Buildings, and NZS 4299: Earthen Buildings Not Requiring Specific Design. This set of standards pertains to the structural design of rammed earth as well as requirements for the materials used. In combination with other New Zealand Standards for loading conditions, a complete structural design is possible using only these standards.

In addition to New Zealand, other local governments adopted standards for rammed earth. New Mexico has a standard in their residential building code pertaining to the design and construction of rammed earth and adobe structures. ${ }^{16}$ This standard is much less descriptive than the New Zealand Standard, though it does provide provisions relating to material properties. Zimbabwe also has an adopted code pertaining to the design of rammed earth buildings. ${ }^{17}$ Unlike the New Zealand Standard, the Zimbabwe standard has no structural design calculations. However, it is fairly extensive in its description of the materials and testing required for rammed earth construction. It also provides guidance for the size and shape of the structural components of rammed earth.

In addition to adopted standards, many regions make use of de facto standards for the design of rammed earth. This refers to documents which are used as design standards, but have not been officially adopted by local governments. These represent best-practices of a region. One example is the work by Middleton and Schneider, Bulletin 5: Earth Wall Construction (1987). Originally an adopted standard for Australia, Bulletin 5 has since lost its legal status, and now serves as a de facto standard. Another Australian de facto standard is The Australian Earth Building Handbook, published by Standards Australia. Rammed earth is fairly common in Australia, and this is reflected in the de facto standards. Both Bulletin 5, and the Australian Earth

\footnotetext{
${ }^{16}$ NMAC 14.7.4

${ }^{17}$ SADC ZW HS 983:2014: Rammed earth structures - Code of practice
} 
Building Handbook are fairly comprehensive. The United Kingdom also has a commonly used de facto standard, Rammed Earth: Design and Construction Guidelines. ${ }^{18}$

For regions with de facto standards, adoption of these standards could potentially relieve a significant burden associated with permitting an atypical construction material such as rammed earth. Challenges presented by permitting rammed earth construction in Canada were highlighted by Dick and Krahn at ICREC 2015. ${ }^{19} \mathrm{~A}$ recognized design standard could ease some challenges associated with permitting rammed earth construction. Adoption could also shift tort liability from the engineer to the regional authority. As such, lack of adopted standards presents a challenge to widespread adoption of design codes for rammed earth.

\subsection{Design Guidelines}

The engineering design of rammed earth is generally based on the principles of either masonry design or concrete design. Cement-stabilized rammed earth is similar in principle to concrete: aggregates combined with water and a binding agent placed in forms. There are obvious differences, but the use of concrete design principles is not unwarranted. However, use of masonry design principles is more common, and rammed earth is generally more similar to masonry than to concrete. For example, the compressive strength of rammed earth is much closer to that of masonry. Masonry is constructed in layers and can be constructed without reinforcing, similar to rammed earth.

For the structural design of rammed earth, the New Zealand Standards provide the most comprehensive guide. They serve as a standalone document, and provide structural design equations, material specifications, detailing requirements, and testing procedures. The New Zealand Standards are often referenced in the design of rammed earth, throughout the world. ASTM E2392 suggests that structural engineering of rammed earth should make use of the New Zealand Standards. Another great resource for the design of rammed earth is Earth Construction: A Comprehensive Guide by Houben and Guillaud. ${ }^{20}$ Houben and Guillaud cover material selection, material properties, construction, and testing of rammed earth, as well as many other styles of earthen construction. Included in the book are a number of charts for determining ideal soil composition, stabilization, and other properties.

One of the most useful resources for the design of rammed earth is the work by Maniatidis and Walker, $A$ Review of Rammed Earth Construction. ${ }^{21}$ This work summarizes prominent works relating to rammed earth, and compiles existing code provisions in practice. The intent of the work was to be a precursor to an official British Standard on rammed earth. While an official standard was not created, this work provides an invaluable summary of existing knowledge on the design of rammed earth. Maniatidis and Walker cover soil suitability, structural design, and material properties typical of rammed earth. This work also highlights some significant variations in specifications between existing publications.

For determination of soil suitability and use, Adobe and Rammed Earth Buildings by McHenry (1984) provides information on soil mixture for earth construction. McHenry presents an "ideal" soil mixture for

\footnotetext{
${ }^{18}$ Keable, et al, 2005

${ }^{19}$ See Dick and Krahn, 2015

${ }^{20}$ Houben and Guillaud, 2014

${ }^{21}$ Maniatidis and Walker, 2003
} 
adobe construction, and offers an adjustment on that mixture for rammed earth. This was a useful reference in determining what an ideal soil mixture would look like. Houben and Guillaud (2014) also provided a reference for determining a soil's suitability in earth construction, including a chart of recommended particle size distribution ranges for rammed earth construction. In determining anticipated properties from a soil mixture, the studies performed by Bryan (1988), and Hall and Djerbib (2004) provide useful guidance.

\section{$\underline{\text { 3.0 METHODS }}$}

To evaluate the viability of rammed earth in Portland, both the local soil conditions and the local weathering patterns were evaluated for their impact on rammed earth construction. To assess the local soil conditions, local soil was analyzed for composition using data from the USDA's Web Soil Survey (WSS). ${ }^{22}$ The analysis evaluated soil for sand, silt, clay and organic content, as well as zoning regulations using GIS. To evaluate the weathering patterns of Portland, a prototype rammed earth wall was left exposed to natural weathering. The exposure to Portland weathering conditions allows for evaluation of rammed earth based on conditions closely resembling expected exposure.

\subsection{Soil Conditions}

To quantify the suitability of Portland soils for rammed earth, an analysis of soil composition was conducted using GIS software. The soil composition (percent sand, silt, clay and organic material) for Washington, Multnomah and Clackamas county were compared to recommended soil composition for rammed earth. Soil data was imported into GIS from the WSS and overlaid with zoning regulations for the three counties. By evaluating the suitability of the soil relative to published recommendations, a quantitative analysis of soil suitability is possible. Comparing suitable soils to zoning regulations will indicate locations where implementation of rammed earth is most likely.

\subsubsection{Recommended Soil Composition}

Local soil conditions were evaluated for suitability by comparing their composition to that of typical soil mixtures used in rammed earth construction. Recommended particle size distribution for rammed earth varies significantly, as highlighted by Maniatidis and Walker (2003), ${ }^{23}$ shown in Figures 1 and 2. This suggests a large range of suitable soils for rammed earth. In general, recommendations suggest a sandy soil with approximately $10 \%$ clay content. Organic content in rammed earth should be kept to a minimum. The New Zealand code stipulates that no organic material should be present in rammed earth construction. ${ }^{24}$

\footnotetext{
${ }^{22}$ See https://websoilsurvey.sc.egov.usda.gov/App/HomePage.htm

${ }^{23}$ Maniatidis and Walker (2003), pg. 8-9

${ }^{24}$ NZS 4298 Section 2.1.1.2 (a)
} 


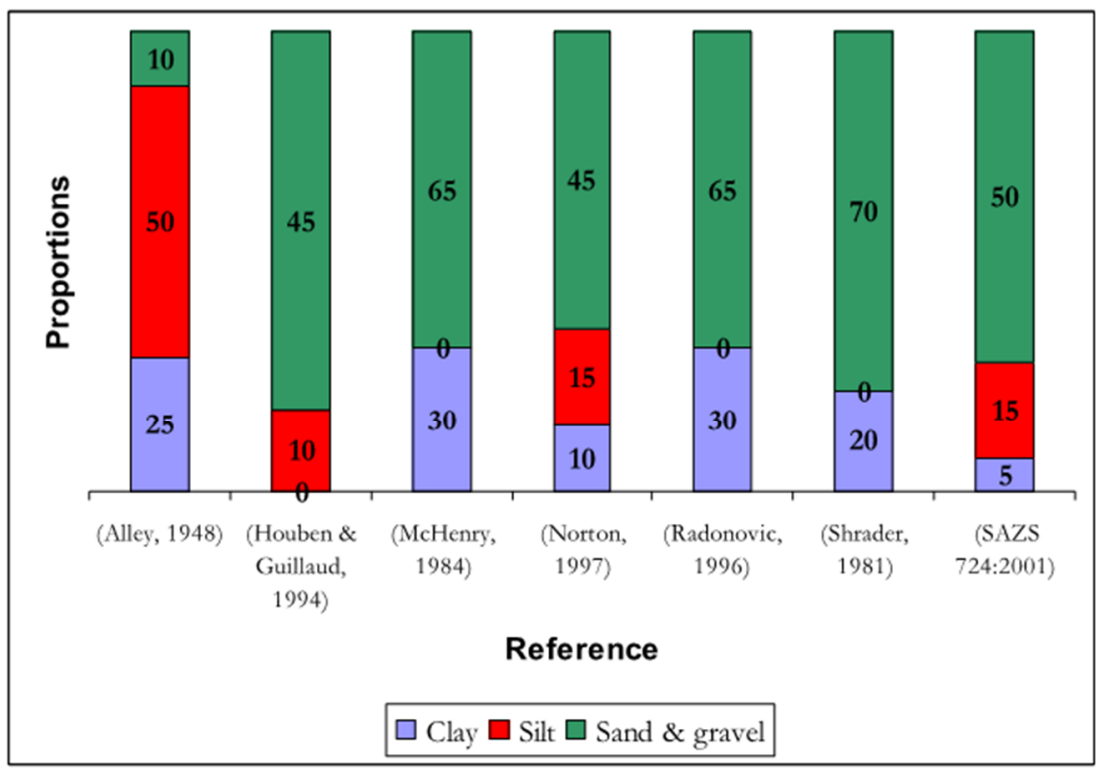

Figure 3.2: Lower range limits for particle size distribution for natural rammed earth.

Figure 1: Lower Limits of Soil Composition Published in Maniatidis and Walker (2003)

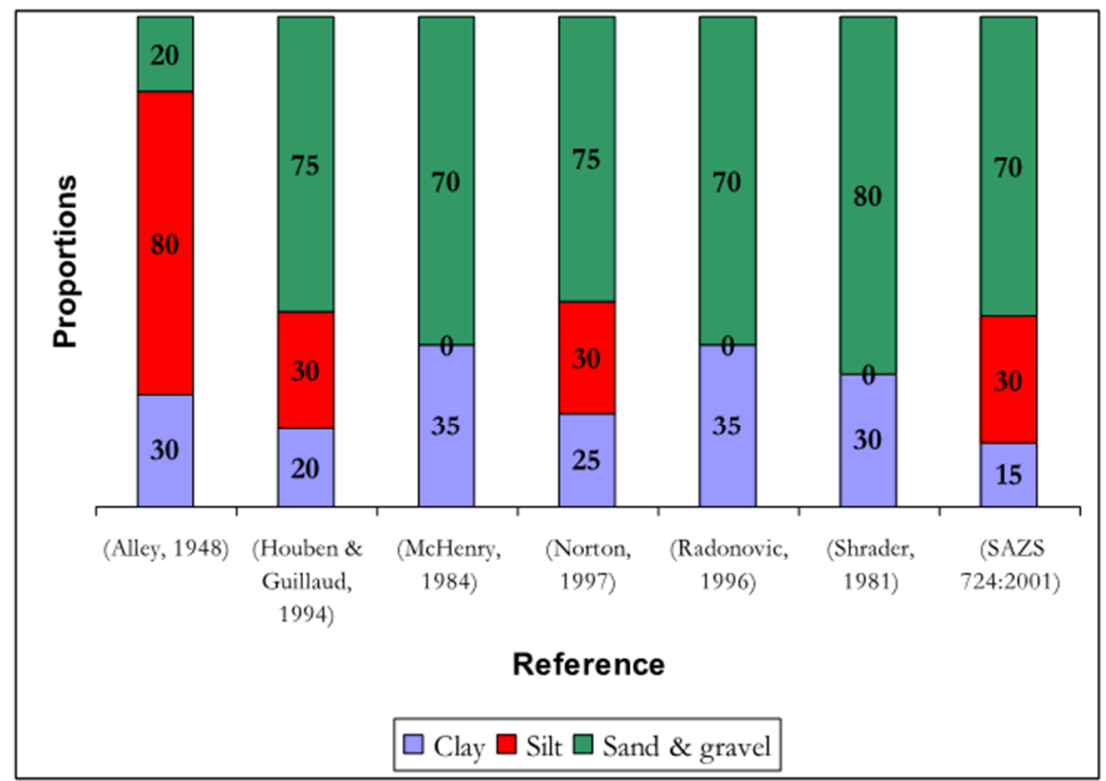

Figure 3.3: Upper range limits for particle size distribution for natural rammed earth

Figure 2: Upper Limits of Soil Composition Published in Maniatidis and Walker (2003)

To determine an "ideal" soil composition, a comparison of the recommendations presented by Maniatidis and Walker (2003) was conducted. Each guideline presented offered upper and lower bounds for sand, silt, and clay contents. The average of each of these values was used to determine a suitable range for each component. Three of the guidelines did not publish recommended silt content, and it was assumed that the recommended clay content included silt content. The comparison suggested a suitable range of 56.7-73.3\% sand, $12.5-30 \%$ silt, and 5-20\% clay. In addition, the average between the upper and lower bound for each 
component was calculated. This resulted in an average recommended sand content of $65 \%$, silt content of $22 \%$, and clay content of $13 \%$. A summary of the calculations is presented in Tables 1, 2 and 3 .

\begin{tabular}{|c|c|c|c|c|c|}
\hline \multirow{11}{*}{$\begin{array}{c}\text { LOWER } \\
\text { LIMITS } \\
\text { (Values } \\
\text { shown are } \\
\text { percentages) }\end{array}$} & STUDY & SAND & CLAY & SILT & $\begin{array}{c}\text { Comb. Silt } \\
\text { and Clay }\end{array}$ \\
\hline & $\begin{array}{c}\text { Houben \& } \\
\text { Guillaud }\end{array}$ & 45 & 0 & 10 & -- \\
\hline & McHenry & 65 & -- & -- & 30 \\
\hline & Norton & 45 & 10 & 15 & -- \\
\hline & Radonovic & 65 & -- & -- & 30 \\
\hline & Shrader & 70 & -- & -- & 20 \\
\hline & SAZS 724:2001 & 50 & 5 & 15 & -- \\
\hline & \multicolumn{5}{|c|}{ Calculated Values } \\
\hline & High & 70.0 & 10.0 & 15.0 & 30.0 \\
\hline & Average & 56.7 & 5.0 & 13.3 & 26.7 \\
\hline & Low & 45.0 & 0.0 & 10.0 & 20.0 \\
\hline
\end{tabular}

Table 1: Average of Lower Limits for Soil Composition ${ }^{25}$

\begin{tabular}{|c|c|c|c|c|c|}
\hline \multirow{11}{*}{$\begin{array}{c}\text { UPPER } \\
\text { LIMITS } \\
\text { (Values } \\
\text { shown are } \\
\text { percentages) }\end{array}$} & STUDY & SAND & CLAY & SILT & $\begin{array}{l}\text { Comb. Silt } \\
\text { and Clay* }\end{array}$ \\
\hline & $\begin{array}{c}\text { Houben \& } \\
\text { Guillaud }\end{array}$ & 75 & 20 & 30 & -- \\
\hline & McHenry & 70 & -- & -- & 35 \\
\hline & Norton & 75 & 25 & 30 & -- \\
\hline & Radonovic & 70 & -- & -- & 35 \\
\hline & Shrader & 80 & -- & -- & 30 \\
\hline & SAZS 724:2001 & 70 & 15 & 30 & -- \\
\hline & \multicolumn{5}{|c|}{ Calculated Values } \\
\hline & High & 80.0 & 25.0 & 30.0 & 35.0 \\
\hline & Average & 73.3 & 20.0 & 30.0 & 33.3 \\
\hline & Low & 70.0 & 15.0 & 30.0 & 30.0 \\
\hline
\end{tabular}

Table 2: Average of Upper Limits for Soil Composition ${ }^{26}$

\begin{tabular}{|c|c|c|c|}
\hline & SAND & CLAY & SILT \\
\hline Extreme Range & $45-80$ & $0-25$ & $10-30$ \\
\hline Range of Averages & $56.7-73.3$ & $5-20$ & $13.3-30$ \\
\hline Average & 65.0 & 12.5 & 21.7 \\
\hline
\end{tabular}

Table 3: Summary of Soil Composition Recommendations

\footnotetext{
${ }^{25} \mathrm{McHenry}$, Radonovic and Shrader do not present values for silt content. It was assumed that the provided clay content included silt content.

${ }^{26} \mathrm{McHenry}$, Radonovic and Shrader do not present values for silt content. It was assumed that the provided clay content included silt content.
} 


\subsubsection{Soil Suitability Scoring}

To quantify suitability of each soil type identified in the WSS, a suitability score was developed to score soil on a scale of $0-100$. A score of 100 indicating a soil as ideal for rammed earth construction. The scoring equation was developed to account for soil composition relative to the recommended proportions. The methodology compared each component to the recommended proportion and calculated an average between the components. The following equations demonstrate the methodology.

$$
\begin{gathered}
\text { TotalScore }=\frac{(\text { SandScore }+ \text { SiltScore }+ \text { ClayScore })}{3}-\text { OrganicScore } \\
\text { SandErr }=\left\{\begin{array}{cc}
\text { sand }<\text { lowerbound, } & \text { lowerbound }- \text { sand } \\
\text { sand }>\text { upperbound, } & \text { sand }- \text { upperbound } \\
\text { lowerbound } \leq \text { sand } \leq \text { upperbound, } & 0
\end{array}\right\}
\end{gathered}
$$

Indicates deviance of sand content from the average recommended content

$$
\text { SandScore }=\operatorname{Max}\left(1-\frac{\text { SandErr }}{\text { AvgSand }}, 0\right)
$$

Indicates suitability of sand content, normalized to the average recommended content

$$
\text { SiltErr }=\left\{\begin{array}{cc}
\text { silt }<\text { lowerbound, } & \begin{array}{c}
\text { lowerbound }- \text { silt } \\
\text { silt }- \text { upperbound }
\end{array} \\
\text { silt }>\text { upperbound, } & \frac{2}{\text { lowerbound } \leq \text { silt } \leq \text { upperbound, }}
\end{array}\right\}
$$

Indicates deviance of silt content from the average recommended content

$$
\text { SiltScore }=\operatorname{Max}\left(1-\frac{\text { SiltErr }}{\text { AvgSilt }}, 0\right)
$$

Indicates suitability of silt content, normalized to the average recommended content

$$
\text { ClayErr }=\left\{\begin{array}{cc}
\text { clay }<\text { lowerbound, } & \begin{array}{c}
\text { lowerbound }- \text { clay } \\
\text { clay }- \text { upperbound }
\end{array} \\
\text { clay }>\text { upperbound, } & \frac{2}{\text { lowerbound } \leq \text { clay } \leq \text { upperbound, }}
\end{array}\right\}
$$

Indicates deviance of clay content from the average recommended content

$$
\text { ClayScore }=\operatorname{Max}\left(1-\frac{\text { ClayErr }}{\text { AvgClay }}, 0\right)
$$

Indicates suitability of clay content, normalized to the average recommended content

$$
\text { OrganicScore }=\frac{\text { Max }(\text { Organic }-1.0 \%, 0)}{20}
$$

Penalizes soil score for presence of organic matter 
The methodology was developed to evaluate the presence of each primary soil component relative to the recommended proportion of each component. If a component of the soil is within the recommended range for that component, the component is deemed "suitable," and tallied as $100 \%$ for that component. The percentage points outside the recommended range is normalized to the average proportion of that component and subtracted from one. This gives an equivalent percentage of the recommended proportioning. To determine a final score for the soil, a value quantifying the organic content of the soil is subtracted from the average score of the three primary components.

The scoring methodology allows trace amounts of organic material in the soil without a significant impact to the score. Higher organic contents have increasingly detrimental impacts to the suitability score of the soil. Additionally, the scoring methodology was adjusted to account for the relatively low percentages of clay and silt in rammed earth construction. The soils with higher clay and silt contents were normalized to half of the upper bound. This prevented small changes in silt and clay content from dramatically changing the score, when it would have a marginal impact on the suitability of a soil.

There are a few limitations to this scoring methodology. It relies on the correlation between the grain size distribution and a soil's suitability for rammed earth construction. There has been work ${ }^{27}$ which suggests that minerology may play a critical role in determining a soil's suitability for rammed earth construction. Most published works rely on the correlation between grain size distribution and material properties of earth construction. Grain size distribution was considered adequate for this study, and a determination of the minerology of Portland soils was not performed.

\subsubsection{GIS Analysis Workflow}

Soil data obtained from WSS was in the form of a shapefile, containing polygons with unique soil identification numbers for Clackamas, Multnomah, and Washington counties. Soil composition for each unique soil ID was available from the WSS in a database. Soil composition for each polygon was imported into GIS using the data from the WSS database. The soil polygons were overlaid with zoning data for the three counties, using a spatial join. This created polygons with soil composition and zoning regulations.

The area of each unique polygon was calculated using GIS. It should be noted that some areas had two applicable zoning regulations. Areas with overlapping zoning regulations were $0.056 \%$ of the total area and were not considered to significantly influence results. Each unique polygon was scored for soil suitability using the technique outlined in section 3.1.2. The data was exported to Excel and queried for area and percentage of suitable soil in Portland.

\subsection{Test Wall}

In order to determine the performance of rammed earth subjected to local weathering patterns, a test wall was constructed on the Portland State University campus. The design of the wall was undertaken as part of a

\footnotetext{
${ }^{27}$ See Bryan 1988 (pg. 319)
} 
senior capstone project for the Civil and Environmental Engineering Department (CEE). The capstone team was composed of Eric Jeffery, Rachel Koenig, Ke Liilah Slingluff, and myself. The scope of the capstone project was to produce plans, specifications, and estimates (PS\&E) for the rammed earth wall. The project scope also included site selection, and structural design of the wall. Construction of the wall was completed by members of the capstone group, Evan Kristof, and volunteers on July 8, 2017.

\subsubsection{Design Process}

The design of the wall was conducted according to New Zealand standards, supplemented by the New Mexico Administrative Code. The New Zealand code was chosen as the primary resource based on the level of detail provided in the code. This allowed for a comprehensive design using a single source. The New Mexico Administrative Code was used as a supplement for the minimum allowable cement content and mix design compressive strength.

The New Zealand code was supplemented by the New Mexico Administrative code based on the provisions governing the compressive strength of the soil mixture. According to NZS 4297, the design compressive strength should be taken as $0.5 \mathrm{MPa}(72.5 \mathrm{psi}) .{ }^{28}$ The minimum design strength in the New Mexico Administrative code is specified as $300 \mathrm{psi}$ at full strength, and $200 \mathrm{psi}$ at seven-day strength. ${ }^{29}$ Since rammed earth remains an unproven material in the Pacific Northwest, the more conservative New Mexico specification was applied.

In order to ensure compliance with the standards, and to confirm the design assumptions, a small trial mixture was made using available soil according to the design proportions. This was done well in advance of receiving soil used for construction. By ensuring the soil mix design meet the specifications early in the design process, any flaws in the design could be corrected with ample lead time. The trial mixture was tested at seven-day strength, to ensure that the minimum 200 psi was achieved. Four samples were tested, and the average compressive strength was $260 \mathrm{psi}$, with a minimum trial of $205 \mathrm{psi}^{30}$

Both the New Mexico and New Zealand codes require testing of the exact soil mixture to be used in construction. In the preliminary stages of design, the construction soil was not available, and thus a sample mixture was tested as a means to confirm the design assumptions. The seven-day test was chosen to confirm the design assumptions sooner rather than later. As the New Mexico code specifically calls out the sevenday strength, this was seen as a relatively quick way to determine if the mix design would be adequate.

The compressive strength of the wall was assumed to be 300 psi, as specified by the New Mexico code. Since the wall was a free-standing structure carrying no load, the design loads were relatively small. To ensure structural stability, the wall was designed as a handrail. This would ensure the wall would be strong enough to support typical human interactions. The loadings and load factors were taken from AS/NZS 1170. The wall was checked in compression, in flexure, and for overturning. Calculations are shown in Appendix C.

\footnotetext{
${ }^{28}$ NZS 4297 Table 4.1

${ }^{29}$ NMAC 14.7.4

${ }^{30}$ See Appendix C, pg. 12
} 
Once the construction soil was available, a second batch of trial samples were made. The exact mix proportions (by weight) were recorded to ensure consistency during construction. Two soils were used for construction, a sand and a silty top soil. Both were obtained from a local aggregate supplier and arrived in dry condition. Water was added to reach the optimum water content as determined from a standard proctor compaction test. Mix proportions are shown in Figure 3. The second batch was tested at 14-day strength, due to scheduling constraints. Five samples were tested, and the average compressive strength was 427 psi with a minimum trial of 410 psi. The performance of the trial batch was better than expected and exceeded minimum design values.

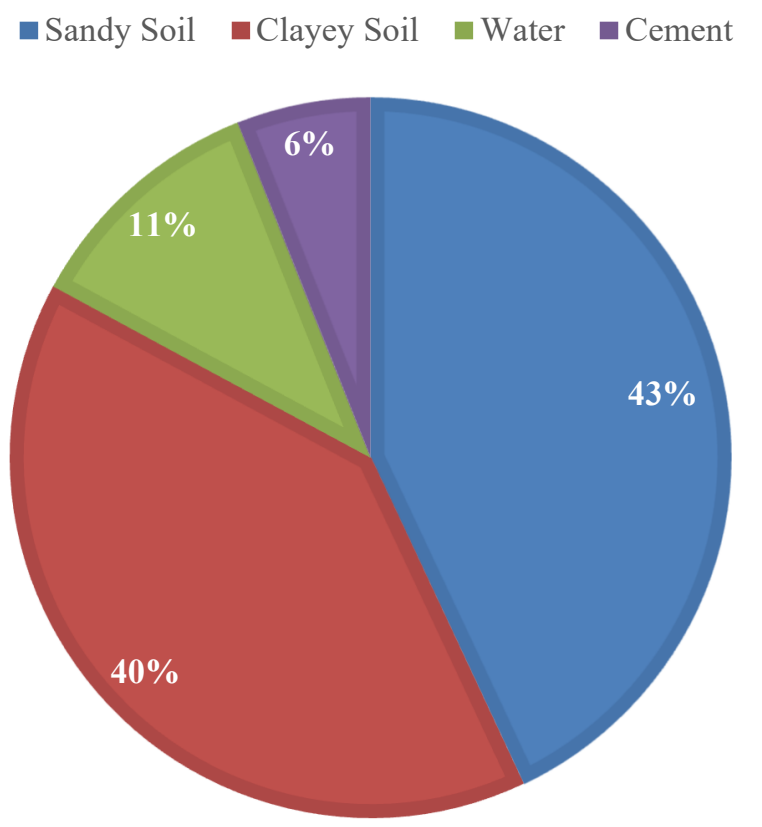

Figure 3: Rammed Earth Wall Soil Mix Composition by Weight

\subsubsection{Inspection Procedure}

To identify and quantify the weathering of the wall, inspection procedures were developed. The inspection procedures were developed to identify new weathering patterns or damage to the wall, as well as to track previously identified weathering or damage. The inspection procedure developed includes visual inspection, acoustic sounding tests, and infrared thermography. For the prototype wall, inspection was to be conducted once a month. Due to scheduling constraints, only visual inspection was conducted on a regular basis over the course of this study. Starting in April 2018, the wall will be inspected monthly.

Visual inspection of the wall is to identify new cracks, crumbling or other weathering and monitor previously identified cracks. Photos of the wall should be taken, and cracks identified on the photos. Crack widths should be measured using a crack gauge and recorded on photographs of the wall. Crack widths should be taken in the same location each time. Crumbling should be measured likewise. The largest dimension of the deteriorated section should be recorded on a photograph. 
Acoustic sounding should also be considered if a delamination crack is suspected. Care should be taken when performing acoustic sounding, due to likely damage to the rammed earth. Acoustic sounding should only be performed using a rubber mallet. Additional testing to inspect the wall will include infrared thermography to detect delamination cracks.

\subsubsection{Maintenance Procedures}

Since the purpose of the test wall was to evaluate the performance of rammed earth, the wall was not to be maintained for erosion. However, procedures were identified for any maintenance required on the wall. Of particular concern to Portland State University Facilities and Property Management (FPM) was graffiti. FPM requested permission to remove graffiti from the wall, rather than relying on students or the Civil Engineering Department at PSU. This allows them to ensure immediate removal of graffiti. Typically, FPM removes graffiti using a power washer. There is no literature on the subject, use of a power washer was deemed unacceptable. Power washing was expected to significantly damage or completely destroy the wall, likely compromising results of the experiment.

As a compromise, it was agreed that in the event the wall is subjected to graffiti, FPM retained the right to paint the wall to cover the graffiti. CEE would retain the right to remove the paint from the wall, on their schedule. This would allow FPM to remove the graffiti immediately, without concern of significant damage to the wall. It would also allow for eventual removal of paint from the wall, in a controlled manner. In the event paint removal is necessary, this also provides an opportunity to research best practices for paint removal from rammed earth. This would inform future rammed earth projects and inform effective graffiti removal techniques which would not compromise the structure.

\subsection{DATA ANALYSIS}

By evaluating the soil conditions in Portland relative to ideal soil for rammed earth construction, a more extensive analysis of the viability of rammed earth was possible. The relative suitability of soil was overlaid with zoning regulations to better indicate likelihood of rammed earth being implemented in Portland. Exposure of rammed earth to local weathering conditions demonstrated the durability of rammed earth in Portland's humid climate. Due to time constraints of the study, a robust analysis of weathering performance was not possible. However, results from the observed performance were extrapolated to determine likely performance over a longer period.

\subsection{Analysis for Suitable Soils}

The majority of soil in Portland was determined to be "Not Suitable" for rammed earth. Typical rammed earth has a higher sand content than the dominant soil condition in Portland. The dominant soil condition in Portland is silty and clayey soils. Despite the generally low sand content relative to typical rammed earth construction, a small percentage of the soils in Portland (4.7\%) were deemed at least "Suitable" for rammed earth. When considering typical use cases of rammed earth and areas zoned for those use cases, the amount of suitable soils increased to $9.5 \%$. 5,246 acres consisted of "Ideal" soils in areas zoned for typical use cases of rammed earth, which was $0.4 \%$ of the total area investigated. 


\subsubsection{Soil Suitability}

Four categories of soil suitability were considered to quantify the suitability of Portland's native soil, "Ideal," "Suitable," "Somewhat Suitable," and "Not Suitable." The suitability levels are summarized in Table 4.

\begin{tabular}{|l|l|l|}
\hline Suitability & Suitability Score Range & Description \\
\hline Ideal & $>95 \%$ & $\begin{array}{l}\text { No soil modification necessary to use in rammed } \\
\text { earth construction }\end{array}$ \\
\hline Suitable & $85 \%-95 \%$ & $\begin{array}{l}\text { Minor soil modification necessary to use in rammed } \\
\text { earth construction }\end{array}$ \\
\hline Somewhat Suitable & $70 \%-85 \%$ & $\begin{array}{l}\text { Major soil modification necessary to use in rammed } \\
\text { earth construction }\end{array}$ \\
\hline Not Suitable & $<70 \%$ & $\begin{array}{l}\text { Soil modification necessary to use in rammed earth } \\
\text { construction would be prohibitive. }\end{array}$ \\
\hline
\end{tabular}

Table 4: Soil Suitability Categories

To establish these levels, soil profiles across Portland were inspected and categorized based on the amount of modification required to meet the typical soil profile for rammed earth. Breaks in suitability were observed at the $95 \%, 85 \%$, and $70 \%$ levels. Below a score of $70 \%$, soil profiles were typically too high in organic content or too high in one component (sand, silt or clay) to be useable for rammed earth. These soils would require more modification than would be practical.

Minor modifications for "Suitable" soils would typically be the addition of 5-10\% sand or the addition of slightly more cement. Major modifications for "Somewhat Suitable" soils may include the addition of 5-15\% sand with additional cement or could be the addition of both sand and clay. One of the primary benefits of rammed earth over other construction methods is the ability to use soils from on-site. If the soil from on-site requires onerous modification, the viability of rammed earth compared to other methods is significantly diminished.

The majority of soil (91.7\%) in Portland was deemed to be "Not Suitable" (i.e. soil score less than 70\%). $3.6 \%$ was determined to be "Somewhat Suitable," 3.0\% was determined to be "Suitable," and 1.7\% was determined to be "Ideal" for rammed earth construction. The total area of "Ideal" and "Suitable" soils was determined to be 66,004 acres. A summary of the soil suitability in Portland is shown in Table 5. Figure 4 shows soil suitability across Portland. By county, Multnomah and Clackamas County each had a higher percentage of suitable soils than Washington County. A summary of the county level soil suitability is shown in Table 6. Maps of soil suitability for each county are shown in Appendix A.

\begin{tabular}{|c|c|c|c|c|c|}
\hline & Total & Ideal & Suitable & $\begin{array}{c}\text { Somewhat } \\
\text { Suitable }\end{array}$ & Not Suitable \\
\hline Area (acres) & $1,391,957$ & 23,956 & 42,048 & 49,521 & $1,276,403$ \\
\hline Percentage & $100 \%$ & $1.7 \%$ & $3.0 \%$ & $3.6 \%$ & $91.7 \%$ \\
\hline
\end{tabular}

Table 5: Soil Suitability across Portland 


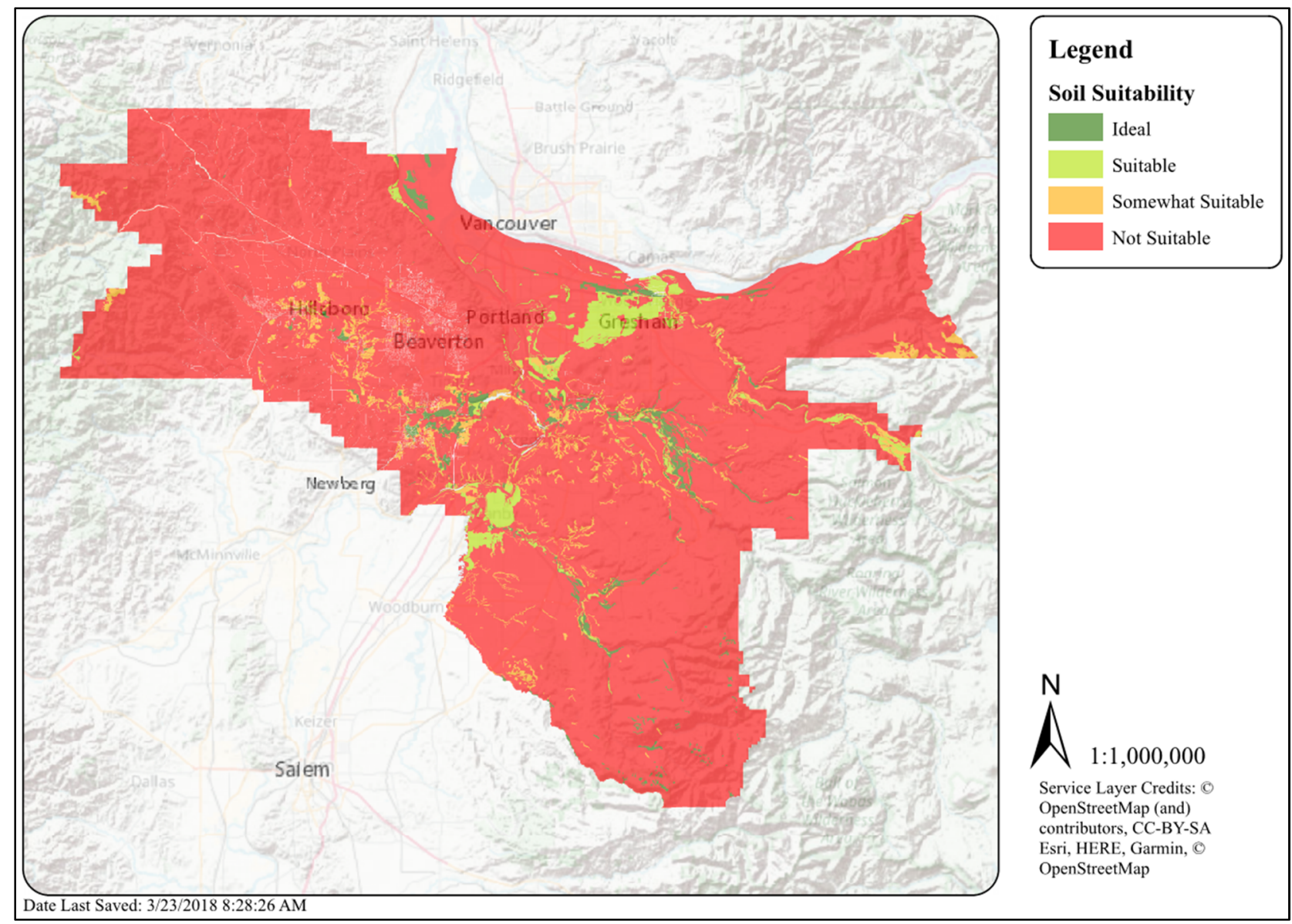

Figure 4: Soil Suitability in Portland

\begin{tabular}{|c|c|c|c|c|c|}
\hline \multirow{2}{*}{ County } & \multirow{2}{*}{ Total Acres } & \multicolumn{4}{|c|}{ Soil Percentage of Total Area } \\
\cline { 3 - 6 } & & Ideal & Suitable & Somewhat Suitable & Not Suitable \\
\hline Clackamas & 642,221 & $2.4 \%$ & $3.1 \%$ & $4.2 \%$ & $90.3 \%$ \\
\hline Multnomah & 296,663 & $1.6 \%$ & $7.4 \%$ & $1.7 \%$ & $89.3 \%$ \\
\hline Washington & 452,298 & $0.9 \%$ & $0.0 \%$ & $3.9 \%$ & $95.2 \%$ \\
\hline
\end{tabular}

Table 6: Soil Suitability by County

\subsubsection{Zoning Considerations}

Examining the total area of suitable soils can only provide limited information regarding the viability of rammed earth. Rammed earth is typically used in residential construction and is more likely to be used in owner occupied dwellings. Due to the low strength of the material, rammed earth is also limited by height. Due to these limitations, rammed earth is most likely to be implemented in medium to low density residential areas. An examination of soil suitability for low and medium density residential areas was performed in addition to the general suitability.

Oregon zoning data for the three counties investigated included 45 distinct zoning categories. To better distill the information for this study, three general categories were considered based on likelihood of rammed earth 
being implemented in each zoning category. The three categories were "High," "Moderate," and "Low" regarding relative likelihood of rammed earth being implemented in that zoning category. The individual zoning categories put into each general category is summarized in Table 7.

\begin{tabular}{|c|l|l|}
\hline $\begin{array}{c}\text { Likelihood of } \\
\text { Implementing } \\
\text { Rammed Earth }\end{array}$ & \multicolumn{2}{|c|}{ Zoning Categories Included } \\
\hline \multirow{5}{*}{ High } & Low-density Res., & Rural Residential 1 acre, \\
& Medium-density Res., & Rural Residential 10 acres, \\
& Medium Low-density Res., & Rural Residential 2-4 acres, \\
& Mixed-Use Com. \& Res. Low, & Rural Residential 5 acres, \\
& Mixed-Use Com. \& Res. Medium, & Very Low-density Res. \\
\hline \multirow{5}{*}{ Moderate } & Commercial - Central, & Mixed-Use Com. \& Res. Med-high, \\
& Commercial - General, & No Data, \\
& Commercial - Neighborhood, & Other, \\
& Commercial - Office, & Public \& semi-public Uses, \\
& Future Urban Development, & Rural Commercial, \\
& Industrial Office, & Rural Industrial, \\
& Medium High-density Res., & UC Rural Industrial \\
& Mixed-Use Com. \& Res. High, & \\
\hline \multirow{5}{*}{ Low } & Coastal Shorelands, & Industrial - Heavy, \\
& Exclusive Farm Use 20+, & Industrial - Light, \\
& Exclusive Farm Use 40+, & Mineral and Aggregate, \\
& Exclusive Farm Use 80, & Mixed-Use Com. \& Res. Extremely High, \\
& Mixed Farm-Forest 20, & Mixed-Use Com. \& Res. V. High, \\
& Mixed Farm-Forest 40, & Open Space/Conservation, \\
& Mixed Farm-Forest 80, & Prime Forest 80, \\
& Federal Forest, & Parks \& Open Space, \\
& High-density Res., & Forest, \\
& Industrial Campus, & Very High-density Res. \\
\hline
\end{tabular}

Table 7: Zoning Categories Organized by Likelihood to implement Rammed Earth

The percentage of suitable soils in locations where rammed earth is likely to be implemented is higher than the percentage of suitable soils across all zoning categories. In places with a high likelihood of rammed earth being implemented, only $84.4 \%$ of soils were deemed "Not Suitable." $2.2 \%$ were determined to be "Ideal," $7.3 \%$ were determined to be "Suitable," and $6.1 \%$ were determined to be "Somewhat Suitable." A similar trend was observed for areas where rammed earth had a moderate likelihood of being implemented.

It should be noted that most of the area investigated in this study was in zones where rammed earth is unlikely to be implemented. While percentages are higher, overall acreage decreases when including zoning regulations. The soil suitability by zoning category is summarized in Table 8 . Soil Suitability for zoning areas with a high likelihood to implement rammed earth is shown in Figure 5. 


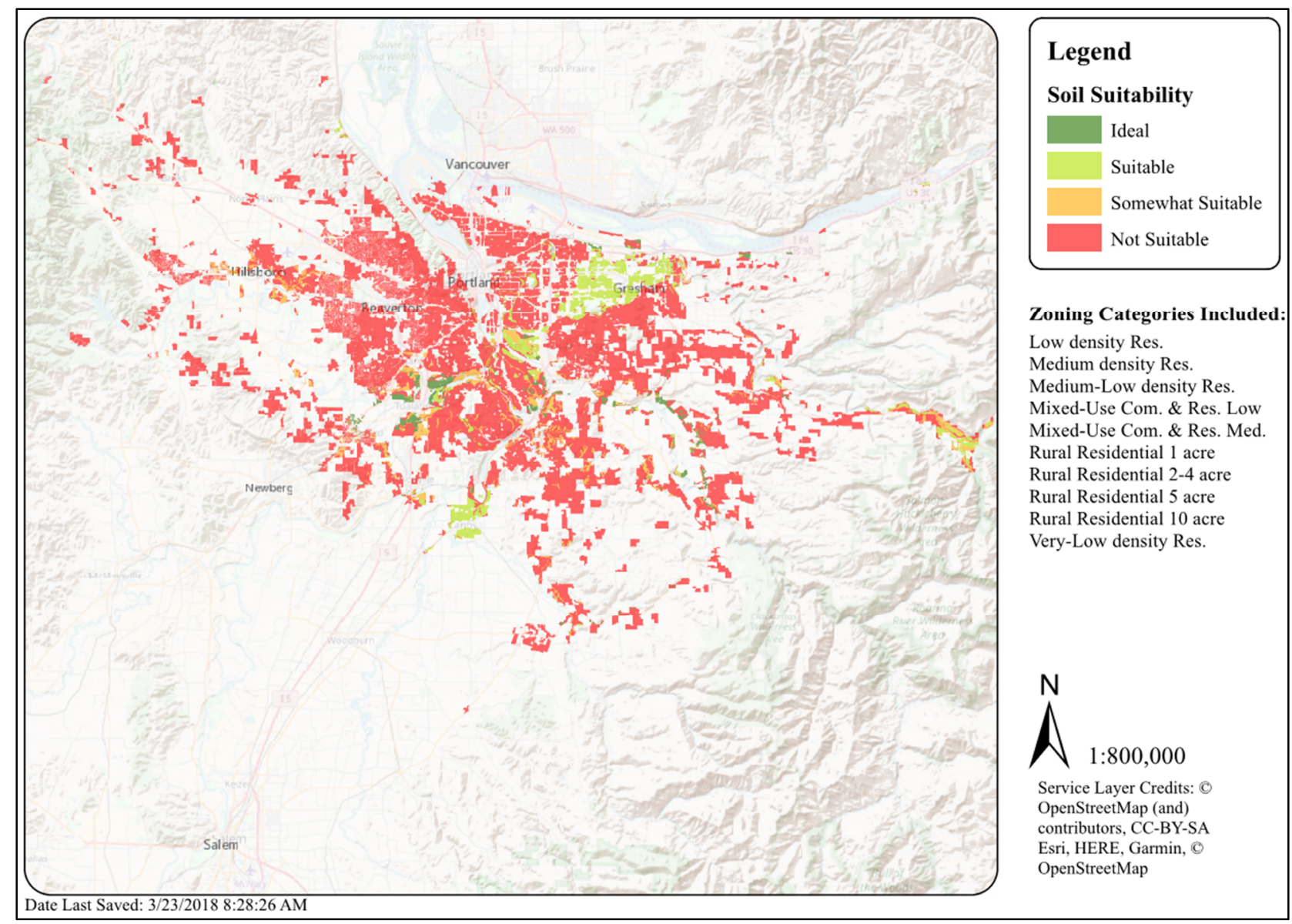

Figure 5: Soil Suitability in Portland for Areas with High Likelihood of Implementing Rammed Earth

\begin{tabular}{|c|c|c|c|c|c|c|c|c|c|}
\hline \multirow{2}{*}{$\begin{array}{c}\text { Likelihood of } \\
\text { Implementing } \\
\text { Rammed } \\
\text { Earth }\end{array}$} & \multirow{2}{*}{$\begin{array}{c}\text { Total } \\
\text { Area } \\
\text { (acres) }\end{array}$} & \multicolumn{2}{|c|}{ Ideal } & \multicolumn{2}{|c|}{ Suitable } & \multicolumn{2}{c|}{$\begin{array}{c}\text { Somewhat } \\
\text { Suitable }\end{array}$} & \multicolumn{2}{c|}{ Not Suitable } \\
\cline { 4 - 10 } & & Area & $\%$ & Area & $\%$ & Area & $\%$ & Area & $\%$ \\
\hline High & 233,220 & 5,246 & $2.2 \%$ & 16,987 & $7.3 \%$ & 14,118 & $6.1 \%$ & 196,869 & $84.4 \%$ \\
\hline Moderate & 35,012 & 1,173 & $3.4 \%$ & 2,257 & $6.4 \%$ & 2,459 & $7.0 \%$ & 29,123 & $83.2 \%$ \\
\hline Low & $1,123,726$ & 17,567 & $1.6 \%$ & 22,804 & $2.0 \%$ & 32,944 & $2.9 \%$ & $1,050,411$ & $93.5 \%$ \\
\hline
\end{tabular}

Table 8: Soil Suitability by Zoning Category

\subsection{Analysis of Weathering Performance}

Natural weathering of the test wall was observed for seven months, from August 2017 to February 2018. The observed weathering of the wall was extrapolated over the design life of the wall and suggested that the weathering of the wall may exceed acceptable weathering levels from a serviceability standpoint. There was a significant amount of shrink/swell cracking in the wall, particularly the upper layer. The wall also developed a substantial moss layer on both the north and south facing sides. 


\subsubsection{Observed Performance}

Preliminary results of weathering performance of the wall indicate significant shrink/swell cracking in the top layer. Figure 6 shows the south side of the wall taken after the construction forms were removed, and Figure 7 shows the same side after seven months of weathering.

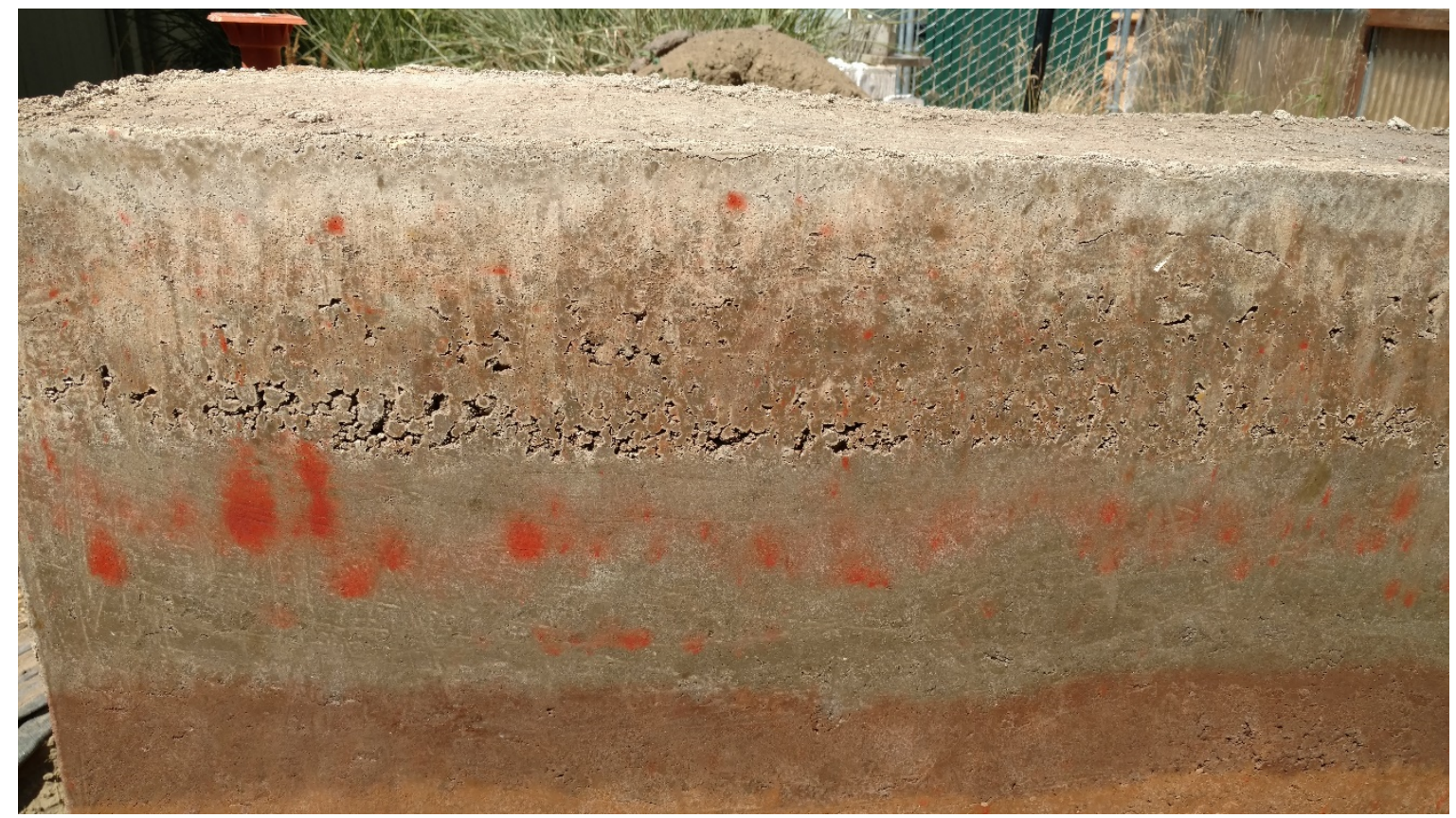

Figure 6: Upper Layers on South Side of Test Wall (Photo Taken July 21, 2017)

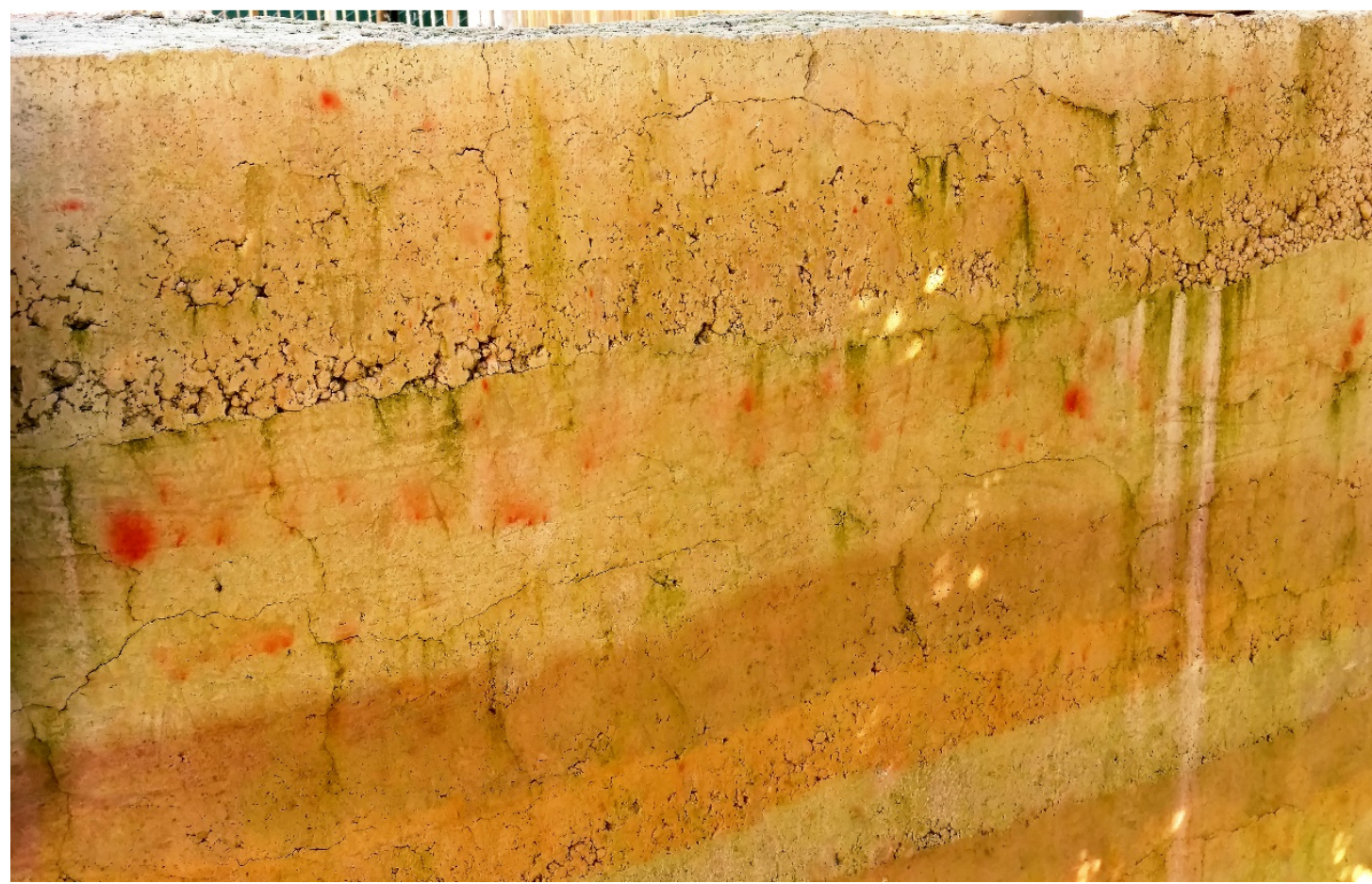

Figure 7: Upper Layers on South Side of Test Wall (Photo Taken February 13, 2018) 
Lower layers on the wall had less obvious cracking. The cracks in the lower layers were typically between 0.007 inches and 0.025 inches wide. Cracks in the upper layers were typically between 0.010 inches and 0.050 inches wide. It should be noted that lower layers on the wall experienced additional compaction energy as subsequent layers were compacted on top. Upper layers were visually less well-compacted than lower layers. Additional compaction increases density, likely decreasing void space and reducing susceptibility to shrink/swell cracking.

More cracks were observed than expected. Minor cracking was expected and was anticipated to be consistent throughout the wall. Shrink/swell effects were expected to contribute to the deterioration of the wall, but not to play a dominant role. Deterioration due to rain and wind was expected to be the dominant weathering process. At the end of the study period, cracking was greater than expected, with the majority occurring in the top layer.

In addition to minor cracks, possible delamination cracks were observed between the upper layer and the adjacent layer below. The cracks appear to continue through the full width of the wall on both the west and east end of the wall. Pictures of the suspected delamination cracks are shown in Figures 8 and 9. An acoustic rebound test was conducted to investigate the possible delamination. Hitting the suspected delamination crack with a rubber mallet produced a flatter sound compared to solid sound produced when hitting the lower sections of the wall.

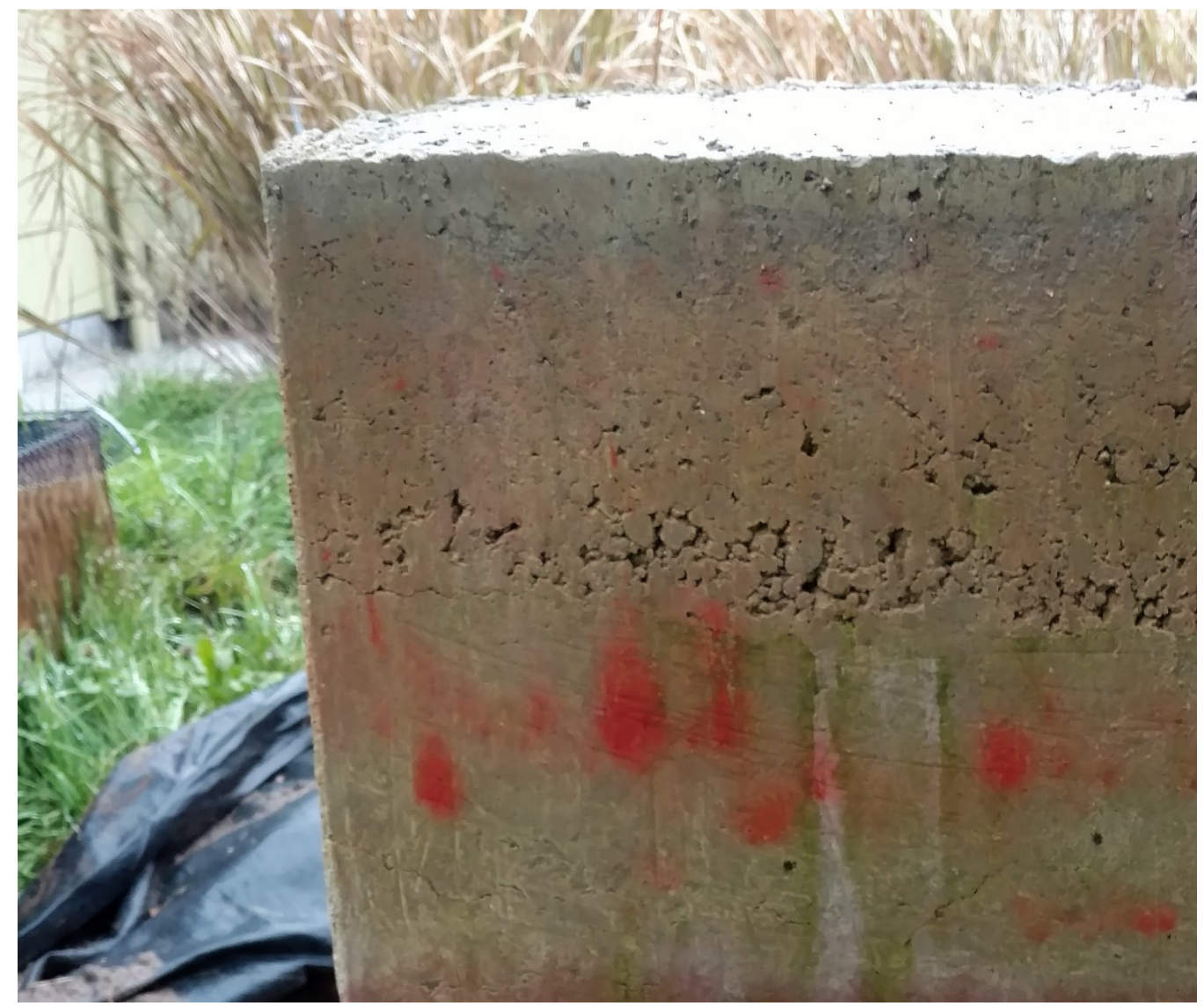

Figure 8: Suspected Delamination Crack along West Side of Test Wall (Photo Taken February 28, 2018) 


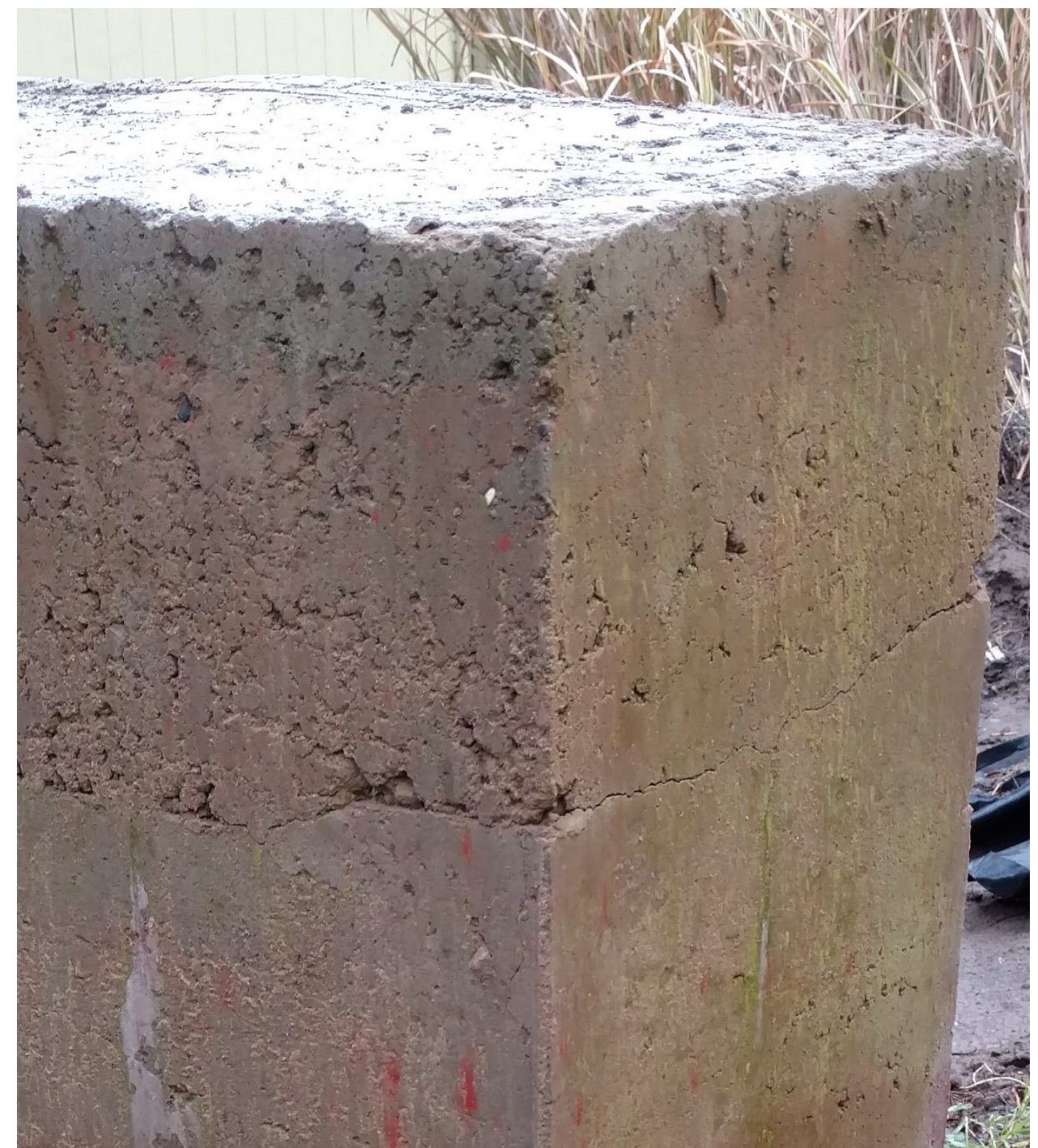

Figure 9: Suspected Delamination Crack along East Side of Test Wall (Photo Taken February 28, 2018)

In addition to minor cracking, localized crumbling was expected along the wall surface and at the corners of the wall. There were a few spots localized crumbling, most occurring at the corners of the wall. Some crumbling was observed at the base of the wall due to separation between the construction forms and the footing. The crumbled sections did not appear to worsen over the course of the study. In addition to the cracking and crumbling, a layer of moss and a few plants were observed growing on the wall, as seen in Figure 10. Organic growth was not expected on the wall. 


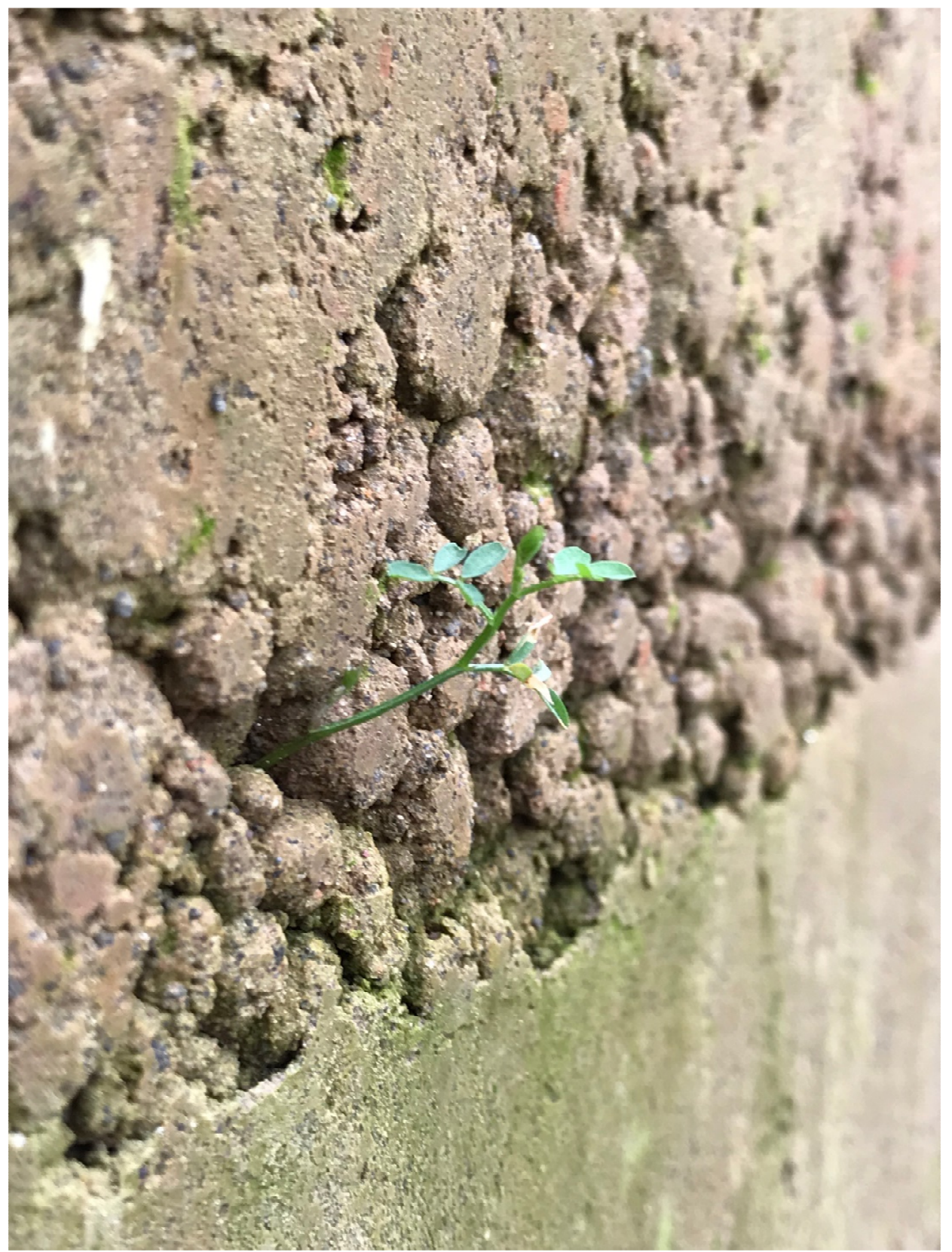

Figure 10: A Small Plant Growing From Voids on the North Side of the Wall (Photo Taken February 7, 2018)

\subsubsection{Extrapolation of Results}

The amount of cracking may or may not be acceptable from a serviceability standpoint. One of the appealing aspects of rammed earth is the aesthetics of the material. The cracking observed on the prototype wall diminished the appearance of the wall. From a strength standpoint, the amount observed cracking was suspected to decrease the flexural, tensile, and shear strength of the wall. The cracking was not expected to

${ }^{31}$ Photo Credit: Evan Kristof 
impact the compression strength of the wall. Structures which carry a moment may require reinforcement to compensate for the lost flexural strength due to cracking.

Due to time constraints, the effect of only one season of weathering was observed. This limits the extent of the conclusion from this study. The most significant weathering was observed over the rainy season, as was expected. Weathering appeared to progress in a linear fashion, with the most significant weathering observed after periods of cold and wet weather. Monthly observations over a longer period will provide a better indication of trends in the weathering data.

It should be noted that the wall was constructed by unskilled laborers. A rammed earth wall constructed by skilled laborers would likely have less initial voids than the test wall constructed for this study. The initial voids in the wall likely contributed to the amount of weathering observed. With more voids, more water can be absorbed by the wall. More water absorbed by the wall contributes to increase shrink/swell cracking. This was also observed by comparing upper layers to lower layers. The upper layers had more voids than lower layers and experienced more cracking. Increased compaction and decreasing the voids in rammed earth would likely help to reduce cracking in rammed earth.

\subsection{SUMMARY OF RESULTS}

Local soil conditions and weathering patterns indicate that rammed earth could be a feasible alternative to traditional construction practices in Portland in a limited set of circumstances. There is a small percentage of area across Portland that has soil suitable for rammed earth construction. Looking at areas zoned for residential development, approximately $2.2 \%$ had soils "Ideal" for rammed earth construction, and 7.3\% had soils "Suitable" for rammed earth construction. This results in a total of approximately 22,233 acres of land with soils suitable for rammed earth construction, in areas where rammed earth construction would be most likely (i.e. residentially zoned).

Separate from the local soil conditions, local weathering patterns also impact the viability of rammed earth. The cracking of the test wall was extensive. Depending on architectural considerations, the amount of cracking may be unacceptable. The cracking was also expected to decrease the flexural, tensile and shear strength of the wall. For lateral loading, rammed earth may need reinforcement to account for lost strength due to cracking. Structural design of rammed earth would need to consider cracking of the rammed earth and its impacts on structural integrity of the structure.

\subsection{Viability of Wall Design}

For the conditions observed, the expected design considerations and design life of five years, rammed earth was determined to be a viable alternative to typical construction techniques for non-critical structures. The amount of cracking was significantly more than expected and was expected to decrease the flexural and shear strength of the wall. As well as the cracking, the wall developed a layer of moss. For non-critical structures with a short design life, these factors should not prevent rammed earth from being utilized. 
For any reduction in flexural strength, reinforcement could be used to provide flexural strength and stability, just as is the case with masonry structures. It should be noted that the majority of the cracking, and therefore the reduction in strength, was observed in the upper layers. For cantilever structures, the maximum loading would occur at the base, where cracking was not as severe. It may also be appropriate to design the top layer as sacrificial. One way to implement this would be to cut the top layer after removing the forms. Alternatively, it could be neglected during design.

Based on the soil data, a typical rammed earth mix design is unlikely to be viable in most areas of Portland. Using a typical mix design would generally require use of purchased soil, as opposed to soil from on-site. Purchase and transport of soil would greatly increase material cost of rammed earth, decreasing its competitive advantage over alternative materials. This would make rammed earth a less viable alternative. To determine whether soil from on-site could be used, testing would likely be necessary. Testing is generally expensive, which could further decrease the viability of rammed earth.

\subsection{Areas for Improvement and Adaptation}

Despite the obstacles to implementing rammed earth in Portland, there is opportunity for adaptation. The most significant opportunity for implementation is non-critical structures. Due to the relatively low strength and high variability of rammed earth, critical and occupied structures will likely not adopt rammed earth anytime soon. With additional testing and increased reliability, rammed earth may be adopted in Portland in limited circumstances. For widespread adoption, standardization of rammed earth design and construction would be necessary. Standardization would require a substantial research basis, and development of a design code for rammed earth.

Non-critical structures could provide proof of concept for rammed earth and form the basis of research required for a design code. One area where rammed earth could be implemented is in low retaining walls and planter box walls. Rammed earth could also be used in temporary sound walls for construction. Deconstruction of the wall could also provide construction fill. Another possible use of rammed earth could be in wildlife channelization. In remote areas, aesthetics would be less important than in areas regularly seen by people, and cracking would not limit serviceability of the design.

One area for investigation would be the performance of unstabilized rammed earth. If no stabilization is necessary, material cost of rammed earth is significantly reduced. Unstabilized rammed earth could be beneficial in temporary wall applications such as construction sound walls, as the material would be completely reusable. There is evidence that stabilization provides only limited increase in durability. ${ }^{32}$ In addition to unstabilized rammed earth, investigation on rammed earth constructed from atypical soil composition could increase the likelihood of rammed earth being implemented in Portland. Due to the low sand content of most soil in Portland, typical rammed earth construction generally requires purchase of soil, increasing material cost.

To determine potential decrease in strength due to the observed cracking, a destructive test could be performed on the prototype wall. A pull test at one end would evaluate the shear strength near the

\footnotetext{
${ }^{32}$ See Bui et al., 2009 (pg. 919)
} 
delamination crack. This would help to quantify shear strength lost due to delamination. Another test could involve pulling the wall at mid-section to put the wall in flexure. Measuring the moment required to fail the wall would give valuable information on the flexural strength of an in-situ rammed earth wall.

\section{$\underline{\text { 6.0 CONCLUSION }}$}

This study has demonstrated that rammed earth could likely be utilized in the Portland Metro area with adaptations to account for local conditions. A small percentage of areas zoned for low to medium density residential development have soil suitable or ideal for rammed earth. This indicates moderate possibility for typical rammed earth construction to be used in Portland. In addition to the use of typical rammed earth, soil mixtures with varying composition offer significant potential. To adopt rammed earth with alternative mix composition, additional research would be needed to verify properties and appropriate uses.

\subsection{Research Question Answer}

To further the research on rammed earth and examine rammed earth in the Portland Metro area, the following research question was developed:

How do native soil conditions and local weather affect the viability of rammed earth construction in the Portland Metro area?

This study demonstrates that local soil conditions and local weather hinder adoption of rammed earth in Portland in its current form. The relatively low sand content of most native soil makes rammed earth a less viable alternative to traditional construction techniques for most areas in Portland. Portland is also a significantly more humid climate than locales where rammed earth is typically practiced. The humidity appears to cause significant shrink/swell cracking in rammed earth.

However, despite conditions which limit adoption of rammed earth in its current form, there is significant possibility for rammed earth to be utilized in an alternate form which could be more conducive for conditions in Portland. It may be permissible to have a lower sand content than typical rammed earth in non-critical structures. Non-critical structures may be more resilient to the shrink/swell cracking observed over the course of this study. Additional research would be required to verify performance of rammed earth using alternate mix designs.

\subsection{Identify Further Research Opportunities}

Rammed earth remains an under-studied material relative to more conventional building materials. There are several opportunities to research the performance of rammed earth under various conditions. One area of study which would benefit adoption of rammed earth in Portland is further study of rammed earth with high clay and silt content. Rammed earth soil mixtures typically have a high sand content. Due to low sand content of most soils in Portland, soil from on-site is often impractical for rammed earth in its current form. Additional research could verify the durability of rammed earth using soil mixtures more closely aligned with typical soil composition in Portland. 
Further study of how mix composition affects the strength and durability properties of rammed earth could aid in design where on-site soil differs from typical mix composition. Rammed earth could greatly benefit from a mix design procedure similar to concrete mix design. This could allow the designer to work within local constraints to produce a design which meets project specifications.

There are also significant opportunities to research construction improvements. Rammed earth is a laborintensive construction technique. If the construction process could be improved, the relative cost of rammed earth could be decreased. One way to improve the process would be alternative compaction methods requiring less labor than pneumatic tampers. Research on construction practices may also help to identify ways to quantify compaction of rammed earth layers. This could help standardize and improve quality control of rammed earth construction.

Additional areas for research could include long term performance studies. Long term studies demonstrating the performance of rammed earth under various conditions would help to assuage concerns of owners and the public that rammed earth can be used on a more widespread basis. One such study could be destructive testing of aged rammed earth. Destructive testing could help validate assumed strength of rammed earth. 


\subsection{BIBLIOGRAPHY}

American Society of Testing and Materials. (2010). E2392: Standard Guide for Design of Earthen Wall Building Systems. West Conshohocken, Pennsylvania: American Society of Testing and Materials.

Augarde, C. E. (2015). Earthen Construction: A Geotechnical Engineering Perspective. In D. Ciancio (Ed.), \& C. Beckett (Ed.), Rammed Earth Construction: Cutting Edge Research on Traditional and Modern Rammed Earth (pp. 17-26). Leiden, The Netherlands: CRC Press/Balkema.

Bryan, A. J. (1988). Criteria for the Suitability of Soil for Cement Stabilization. Building and Environment, 23 (4), 309-319.

Bui, Q. B., \& Morel, J.-C. (2015). First Exploratory Study on the Ageing of Rammed Earth Material. Materials, 8, 1-15.

Bui, Q. B., Bui, T. T., Limam, A., \& Morel, J.-C. (2015). Discrete Element Modeling of Rammed Earth Walls. In D. Ciancio (Ed.), \& C. Beckett (Ed.), Rammed Earth Construction: Cutting-Edge Research on Traditional and Modern Rammed Earth (pp. 57-62). Leiden, The Netherlands: CRC Press/Balkema.

Bui, Q. B., Hans, S., Morel, J.-C., \& Do, A.-P. (2011). First exploratory study on dynamic characteristics of rammed earth buildings. Engineering Structures, 33(12), 3690-3695.

Bui, Q. B., Morel, J.-C., Hans, S., \& Munier, N. (2009). Compression Behaviour of Nonindustrial Materials in Civil Engineering by Three Scale Experiments: The Case of Rammed Earth. Materials and Structures, 42(8), 1101-1116.

Bui, Q. B., Morel, J.-C., Hans, S., \& Walker, P. (2014). Effect of Moisture Content on Mechanical Characteristics of Rammed Earth. Construction and Building Materials, 54, 163-169.

Bui, Q.-B., Morel, J.-C., Venkatarama Reddy, B. V., \& Ghayad, W. (2009). Durability of Rammed Earth Walls Exposed for 20 years to Natural Weathering. Building and Environment, 44 (5), 912-919.

Bui, T. T., Bui, Q. B., Limam, A., \& Morel, J.-C. (2016). Modeling Rammed Earth Wall Using Discrete Element Method. Continuum Mechanics and Thermodynamics, 28(1), 523-538.

Calkins, M. (2009). Materials for Sustainable Sites. Hoboken, New Jersey: John WIley and Sons, Inc.

Ciancio, D., \& Robinson, S. (2011). Use of the Strut-and-Tie Model in the Analysis of Reinforced Cement Stabilized Rammed Earth Lintels. Journal of Materials in Civil Engineering, 23(5), 587-596.

Ciancio, D., Beckett, C., Augarde, C. E., \& Jaquin, P. (2016). First International Conference on Rammed Earth Construction: Report. Construction Materials, 169, 271-275.

Ciancio, D., Beckett, C., Buratti, N., \& Mazzotti, C. (2015). Notched Mini Round Determinate Panel Test to Calculate Tensile Strength and Fracture Energy of Fibre Reinforced Cement Stabilised Rammed Earth. In D. Ciancio (Ed.), \& C. Beckett (Ed.), Rammed Earth Construction: Cutting-Edge Research on Traditional and Modern Rammed Earth (pp. 75-78). Leiden, The Netherlands: CRC Press/ Balkema.

Ciancio, D., Jaquin, P., \& Walker, P. (2013). Advances on the Assessment of Soil Suitability for Rammed Earth. Construction and Building Materials, 42, 40-47.

Dahmen, J. (2006). RAMMED EARTH MIT. Retrieved from Joe Dahmen / Rammed Earth MIT, MIT Department of Architecture,: http://web.mit.edu/masonry/rammed/index.html

Dahmen, J., \& Ochsendorf, J. (2005). Mechanics and Form of Rammed Earth Construction. Boston, Massachusetts: Boston Society of Architects.

Dick, K. J., \& Krahn, T. J. (2015). Preparing Regulatory Challenges and Opportunities for Small to Medium Residential Scale Stabilized Rammed Earth Buildings in Canada. In D. Ciancio (Ed.), \& C. Beckett 
(Ed.), Rammed Earth Construction: Cutting-Edge Research on Traditional and Modern Rammed Earth (pp. 93-96). Leiden, The Netherlands: CRC Press/ Balkema.

Dobson, S. (2015). Rammed Earth in the Modern World. In D. Ciancio (Ed.), \& C. Beckett (Ed.), Rammed Earth Construction: Cutting-Edge Research on Traditional and Modern Rammed Earth (pp. 3-10). Leiden, The Netherlands: CRC Press/ Balkema.

Easton, D. (1982). The Rammed Earth Experience. Wilseyville, California: Blue Mountain Press.

Easton, D. (2007). The Rammed Earth House. White River Junction, Vermont: Chelsea Green Publishing.

Easton, D. (2015). The Future and Common Ground. In D. Ciancio (Ed.), \& C. Beckett (Ed.), Rammed Earth Construction: Cutting-Edge Research on Traditional and Modern Rammed Earth (pp. 11-16). Leiden, The Netherlands: CRC Press/ Balkema.

Garcia-Soriano, L., Mileto, C., \& Vegas Lopez-Manzanares, F. (2015). Techniques of Intervention in Monumental Rammed Earth Buildings in Spain in the Last Decade (2004-2013). 1\% Cultural Programme. In D. Ciancio (Ed.), \& C. Beckett (Ed.), Rammed Earth Construction: Cutting-Edge Research on Traditional and Modern Rammed Earth (pp. 97-100). Leiden, The Netherlands: CRC Press/ Balkema.

Gomes, M. I., \& Faria, P. (2011). Repair Mortars for Rammed Earth Constructions. International Conference on Durability of Building Materials and Components, (pp. 1-8). Porto, Portugal.

Gomes, M. I., Goncalves, T. D., \& Faria, P. (2016). Hydric Behaviour of Earth Materials and the Effects of Their Stabilization with Cement or Lime: Study on Repair Mortars for Historical Rammed Earth Structures. Journal of Materials in Civil Engineering, 28(7), 1-11.

Gomes, M. I., Lopes, M., \& Brito, J. d. (2011). Seismic Resistance of Earth Construction in Portugal. Engineering Structures, 33, 932-941.

Gramlich, A. N. (2013). A Concise History of the use of Rammed Earth Building Technique Including Information on Methods of Preservation, Repair and Maintenance. University of Oregon, Interdisciplinary Studies Program: Historic Preservation. Eugene, Oregon: University of Oregon.

Hall, M. (2002). Rammed Earth: Traditional Methods, Modern Techniques, Sustainable Future. Building Engineer, 22-24.

Houben, H., \& Guillaud, H. (2014). Earth Construction: A Comprehensive Guide. Warwickshire, United Kingdom: Practical Action Publishing.

Jaquin, P., Augarde, C. E., Gallipoli, D., \& Toll, D. G. (2009). The Strength of Unstabilised Rammed Earth Materials. Geotechnique, 59(5), 487-490.

Jawad, I. T., Taha, M. R., Majeed, Z. H., \& Khan, T. A. (2014). Soil Stabilization Using Lime: Advantages, Disadvantages and Proposing a Potential Alternative. Research Journal of Applied Sciences: Engineering and Technology, 8(4), 510-520.

Keable, J., \& Keable, R. (2011). Rammed Earth Structures: A Code of Practice. Warwickshire, United Kingdom: Practical Action Publishing.

Krayenhoff, M. (2015). Rammed Earth in a Concrete World. In D. Ciancio (Ed.), \& C. Beckett (Ed.), Rammed Earth Construction: Cutting-Edge Research on Traditional and Modern Rammed Earth (pp. 111-114). Leiden, The Netherlands: CRC Press/ Balkema.

Lombillo, I., Villegas, L., Fodde, E., \& Thomas, C. (2014). In Situ Mechanical Investigation of Rammed Earth: Calibration of Minor Destructive Testing. Construction and Building Materials, 51, 451-460.

Ma, C., Chen, L., \& Chen, a. B. (2016). Experimental Study of Effect of Fly Ash on Self-Compacting Rammed Earth Construction Stabilized with Cement-Based Composites. Journal of Materials in Civil Engineering, 28(7), 1-10. 
Maniatidis, V., \& Walker, P. (2003). A Review of Rammed Earth Construction. Bath, United Kingdom: Natural Building Technology Group, University of Bath.

Maniatidis, V., \& Walker, P. (2008). Structural Capacity of Rammed Earth in Compression. Journal of Materials in Civil Engineering, 20(3), 230-238.

McHenry, P. G., \& May, G. W. (1984). Adobe and Rammed Earth Buildings. Tuscon, Arizona: The University of Arizona Press.

Middleton, G. F., \& Schneider, L. M. (1987). Bulletin 5: Earth Wall Construction. Chatswood, Australia: National Building Technology Center.

Milani, A. P., \& Labaki, L. C. (2012). Physical, Mechanical, and Thermal Performance of Cement-Stabilized Rammed Earth-Rice Husk Ash Walls. Journal of Materials in Civil Engineering, 24(6), 775-782.

Minke, G. (2006). Building with Earth: Design and Technology of a Sustainable Architecture. Basal, Switzerland: Birkhäuser.

Morel, J.-C., Pkla, A., \& Walker, P. (2007). Compressive Strength Testing of Compressed Earth Blocks. Construction and Building Materials, 21, 303-309.

Morsier, Y. d. (n.d.). A Manual for Rammed Earth Building. Bega, Australia: Desert Creek House.

Nanjunda Rao, K. S., Venkatarama Reddy, B. V., \& Anitha, M. (2015). Dynamic Behavior of Scaled Cement Stabilized Rammed Earth Building Models. In D. Ciancio (Ed.), \& C. Beckett (Ed.), Rammed Earth Construction: Cutting-Edge Research on Traditional and Modern Rammed Earth (pp. 123-128). Leiden, The Netherlands: CRC Press/ Balkema.

Natural Resources Conservation Services: United States Department of Agriculture. (2017, May 5). Web Soil Survey Home. Retrieved from Web Soil Survey: https://websoilsurvey.nrcs.usda.gov/app/

New Mexico Administrative Code. (2016). NMAC 14.7.4: New Mexico Earthen Building Materials Code. Santa Fe, New Mexico: New Mexico Commissions of Public Records: Construction Industries Division of the Regulation and Licensing Department.

Padavic, M. (2002). Resurrection: Rammed Earth Construction. Building Technology, 1-9.

Pyatt, R., O'Hara, C., \& Hu, R. (2015). Rammed Earth Construction for the Colorado Front Range. In D. Ciancio (Ed.), \& C. Beckett (Ed.), Rammed Earth Construction: Cutting-Edge Research on Traditional and Modern Rammed Earth (pp. 129-132). Leiden, The Netherlands: CRC Press/ Balkema.

Ruzicka, J., Havlik, F., Richter, J., \& Stanek, K. (2015). Advanced Prefabricated Rammed Earth Structures - Mechanical, Building Physical and Environmental Properties. In D. Ciancio (Ed.), \& C. Beckett (Ed.), Rammed Earth Construction: Cutting-Edge Research on Traditional and Modern Rammed Earth (pp. 139-143). Leiden, The Netherlands: CRC Press/ Balkema.

Smith, J. C., \& Augarde, C. E. (2015). The Role of Clay and Sand in the Mechanics of Soil-Based Construction Materials. In D. Ciancio (Ed.), \& C. Beckett (Ed.), Rammed Earth Construction: Cutting-Edge Research on Traditional and Modern Rammed Earth (pp. 145-149). Leiden, The Netherlands: CRC Press/ Balkema.

Southern African Development Community Cooperation in Standardization. (2014). SADC ZW HS 983:2014: Rammed Earth Structures - Code of Practice. Harare, Zimbabwe: Standards Association of Zimbabwe Technical Committee BC 042: Rammed Earth Structures.

Standards New Zealand. (1998). NZS 4297:1998 Engineering Design of Earth Buildings. Wellington, New Zealand: Standards New Zealand.

Standards New Zealand. (1998). NZS 4298:1998 Materials and Workmanship for Earth Buildings. Wellington, New Zealand: Standards New Zealand. 
Standards New Zealand. (Earthen Buildings not Requiring Specific Design). NZS 4299:1998. Wellington, New Zealand: Standards New Zealand.

Treloar, G. J., Owen, C., \& Fay, R. (2001). Environmental Assessment of Rammed Earth Construction Systems. Structural Survey, 19(2), 99-105.

Tripura, D. D., \& Singh, K. D. (2015). Structural Behavior of Cement-Stabilized Rammed Earth Column Under Compression. In D. Ciancio (Ed.), \& C. Beckett (Ed.), Rammed Earth Construction: CuttingEdge Research on Traditional and Modern Rammed Earth (pp. 157-162). Leiden, The Netherlands: CRC Press/ Balkema.

Venkatarama Reddy, B. V., \& Prasanna Kumar, P. (2010). Embodied Energy in Cement Stabilised Rammed Earth Walls. Energy and Buildings, 42, 380-385.

Venkatarama Reddy, B. V., \& Prasanna Kumar, P. (2011). Cement Stabilised Rammed Earth. Part A: Compaction Characteristics and Physical Properties of Compacted Cement Stabilised Soils. Materials and Structures, 44(3), 681-693.

Venkatarama Reddy, B. V., \& Prasanna Kumar, P. (2011). Cement Stabilised Rammed Earth. Part B: Compressive Strength and Stress-Strain Characteristics. Materials and Structures, 44(3), 695-707.

Venkatarama Reddy, B. V., \& Prasanna Kumar, P. (2011). Structural Behavior of Story-High CementStabilized Rammed-Earth Walls Under Compression. Journal of Materials in Civil Engineering, 23(3), 240-247.

Venkatarama Reddy, B. V., \& Raju, L. (2015). Analytical Model for Predicting the Stress-Strain Behavior of Cement Stabilised Rammed Earth. In D. Ciancio (Ed.), \& C. Beckett (Ed.), Rammed Earth Construction: Cutting-Edge Research on Traditional and Modern Rammed Earth (pp. 133-137). Leiden, The Netherlands: CRC Press/ Balkema.

Venkatarama Reddy, B. V., Suresh, V., \& Nanjunda Rao, K. S. (2015). Specimen Slenderness Effect on Compressive Strength of Cement Stabilized Rammed Earth. In D. Ciancio (Ed.), \& C. Beckett (Ed.), Rammed Earth Construction: Cutting-Edge Research on Traditional and Modern Rammed Earth (pp. 163-166). Leiden, The Netherlands: CRC Press/ Balkema.

Walker, P., Keable, R., Martin, J., \& Maniatidis, V. (2005). Rammed Earth: Design and Construction Guidelines. Bracknell, United Kingdom: BRE Press.

Williamson, J., \& Rutz, F. (2015). Earth Construction: Poured Earth Mix Design. In D. Ciancio (Ed.), \& C. Beckett (Ed.), Rammed Earth Construction: Cutting-Edge Research on Traditional and Modern Rammed Earth (pp. 167-170). Leiden, The Netherlands: CRC Press/ Balkema.

Windstorm, B., \& Schmidt, A. (2013). A Report of Contemporary Rammed Earth Construction and Research in North America. Sustainability, 5(2), 400-416.

Wolf, L. A., Augarde, C. E., \& Jaquin, P. A. (2015). Investigating the Lateral Capacity of Wall Top Fixings in Rammed Earth Materials. In D. Ciancio (Ed.), \& C. Beckett (Ed.), Rammed Earth Construction: Cutting-Edge Research on Traditional and Modern Rammed Earth (pp. 171-174). Leiden, The Netherlands: CRC Press/ Balkema.

Wolfskill, L. A., \& Others. (1981). Handbook for Building Homes of Earth. Appropriate Technologies for Development. Peace Corps, Department of Housing and Urban Development, Office of International Affairs. Washington, District of Columbia: Agency for International Development. 


\section{DATA APPENDICES}

Appendix A) GIS Maps

Appendix B) Plan Set

Appendix C) Design Calculations

Appendix E) Photos 


\section{APPENDIX A) GIS Maps}

\section{Contents:}

Soil Suitability for Portland Metro Area (Clackamas, Multnomah, and Washington County) _................ Pg. 1

Soil Suitability for Portland Metro Area, only High Likelihood Zones _............................................. Pg. 2

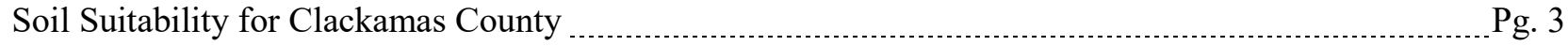

Soil Suitability for Clackamas County, only High Likelihood Zones _ P P. 4

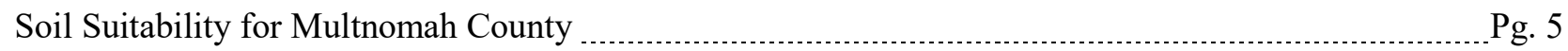

Soil Suitability for Multnomah County, only High Likelihood Zones _.............................................Pg. 6

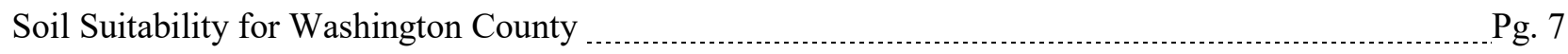

Soil Suitability for Washington County, only High Likelihood Zones _ Pg. 8 


\section{Soil Suitability for Rammed Earth Construction}

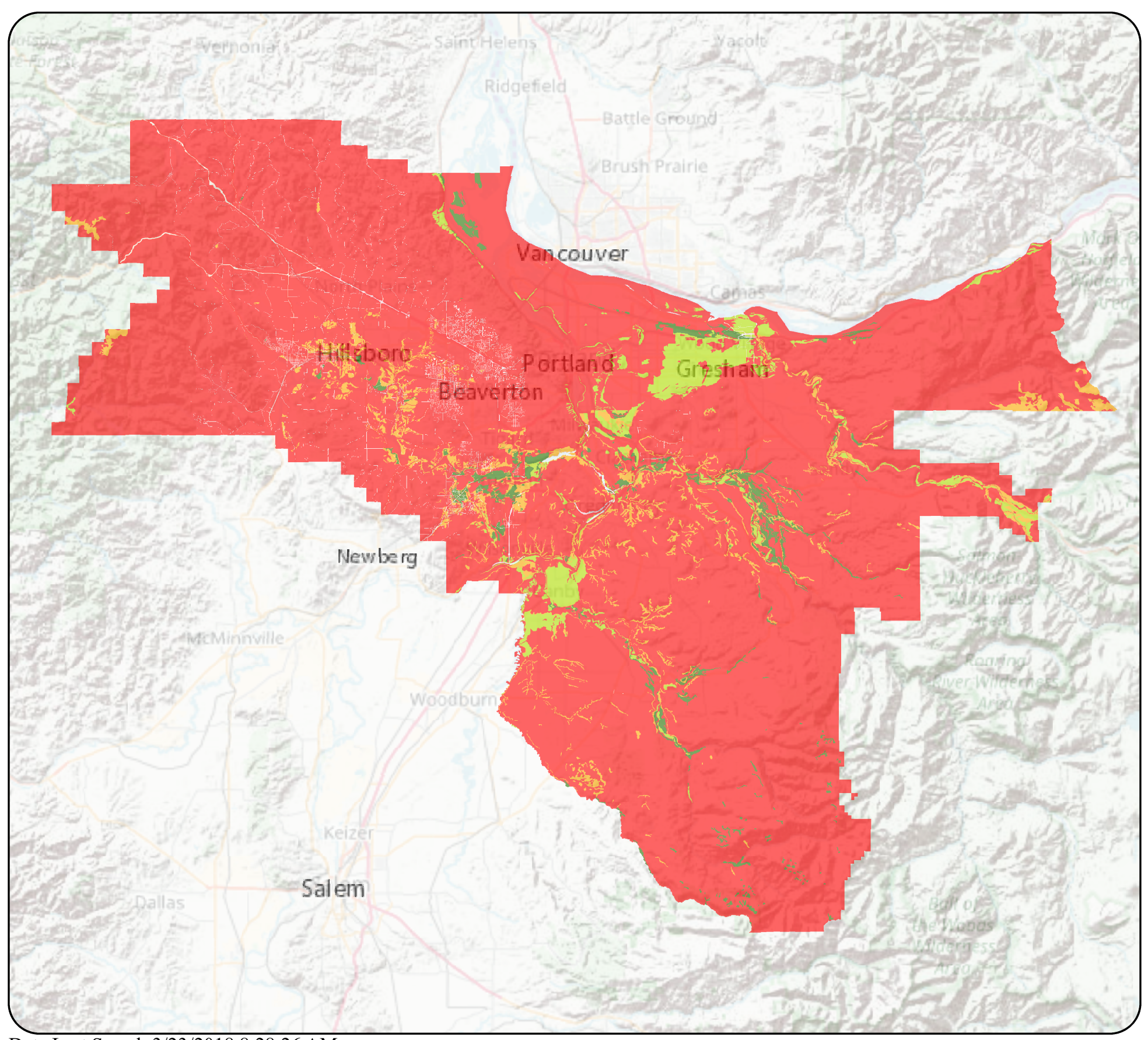

\section{Legend \\ Soil Suitability \\ Ideal \\ Suitable \\ Somewhat Suitable \\ Not Suitable}

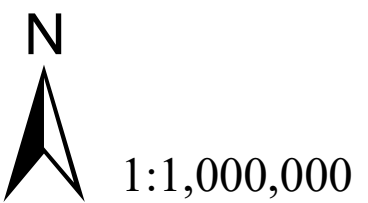

Service Layer Credits: C

OpenStreetMap (and)

contributors, CC-BY-SA

Esri, HERE, Garmin, (C)

OpenStreetMap 


\section{Soil Suitability for Rammed Earth Construction}

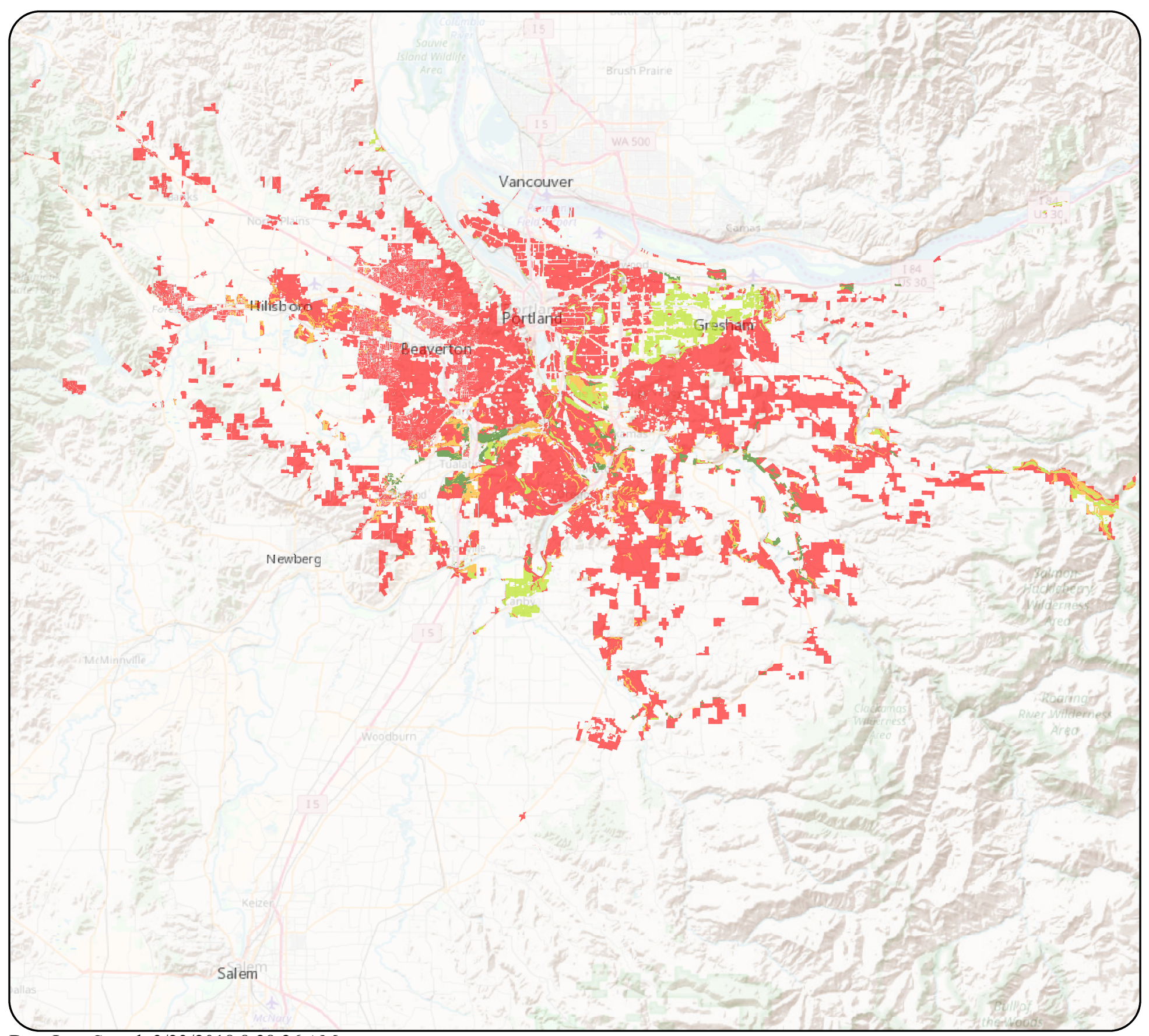

\section{Legend}

\section{Soil Suitability}

Ideal

Suitable

Somewhat Suitable

Not Suitable

Zoning Categories Included:

Low density Res.

Medium density Res.

Medium-Low density Res.

Mixed-Use Com. \& Res. Low

Mixed-Use Com. \& Res. Med.

Rural Residential 1 acre

Rural Residential 2-4 acre

Rural Residential 5 acre

Rural Residential 10 acre

Very-Low density Res.

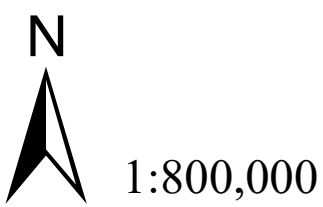

Service Layer Credits: (C) OpenStreetMap (and) contributors, CC-BY-SA Esri, HERE, Garmin, (C) OpenStreetMap 


\section{Soil Suitability for Rammed Earth Construction}

Clackamas County

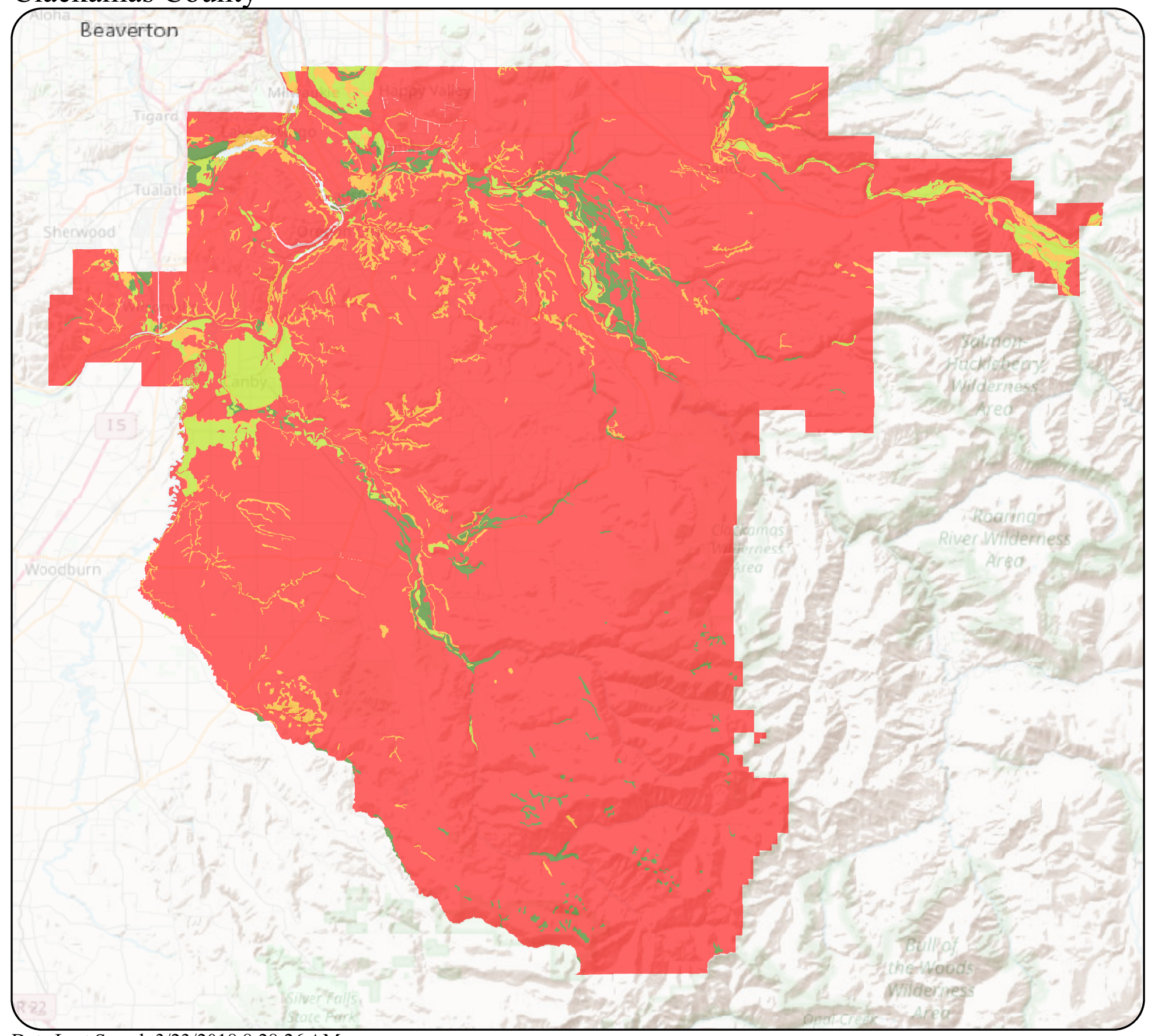

Date Last Saved: 3/23/2018 8:28:26 AM

\section{Legend}

Soil Suitability

Ideal

Suitable

Somewhat Suitable

Not Suitable

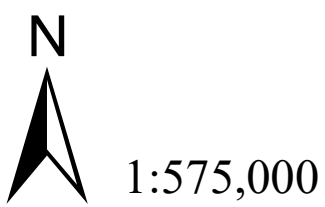

Service Layer Credits: (C)

OpenStreetMap (and)

contributors, CC-BY-SA

Esri, HERE, Garmin, (C)

OpenStreetMap 


\section{Soil Suitability for Rammed Earth Construction}

Clackamas County



\section{Legend}

\section{Soil Suitability}

Ideal

Suitable

Suitable

Somewhat Suitable

Not Suitable

Zoning Categories Included:

Low density Res.

Medium density Res.

Medium-Low density Res.

Mixed-Use Com. \& Res. Low

Mixed-Use Com. \& Res. Med.

Rural Residential 1 acre

Rural Residential 2-4 acre

Rural Residential 5 acre

Rural Residential 10 acre

Very-Low density Res.

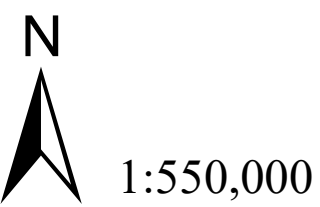

Service Layer Credits: (C) OpenStreetMap (and) contributors, CC-BY-SA Esri, HERE, Garmin, (C) OpenStreetMap 


\section{Soil Suitability for Rammed Earth Construction}

Multnomah County

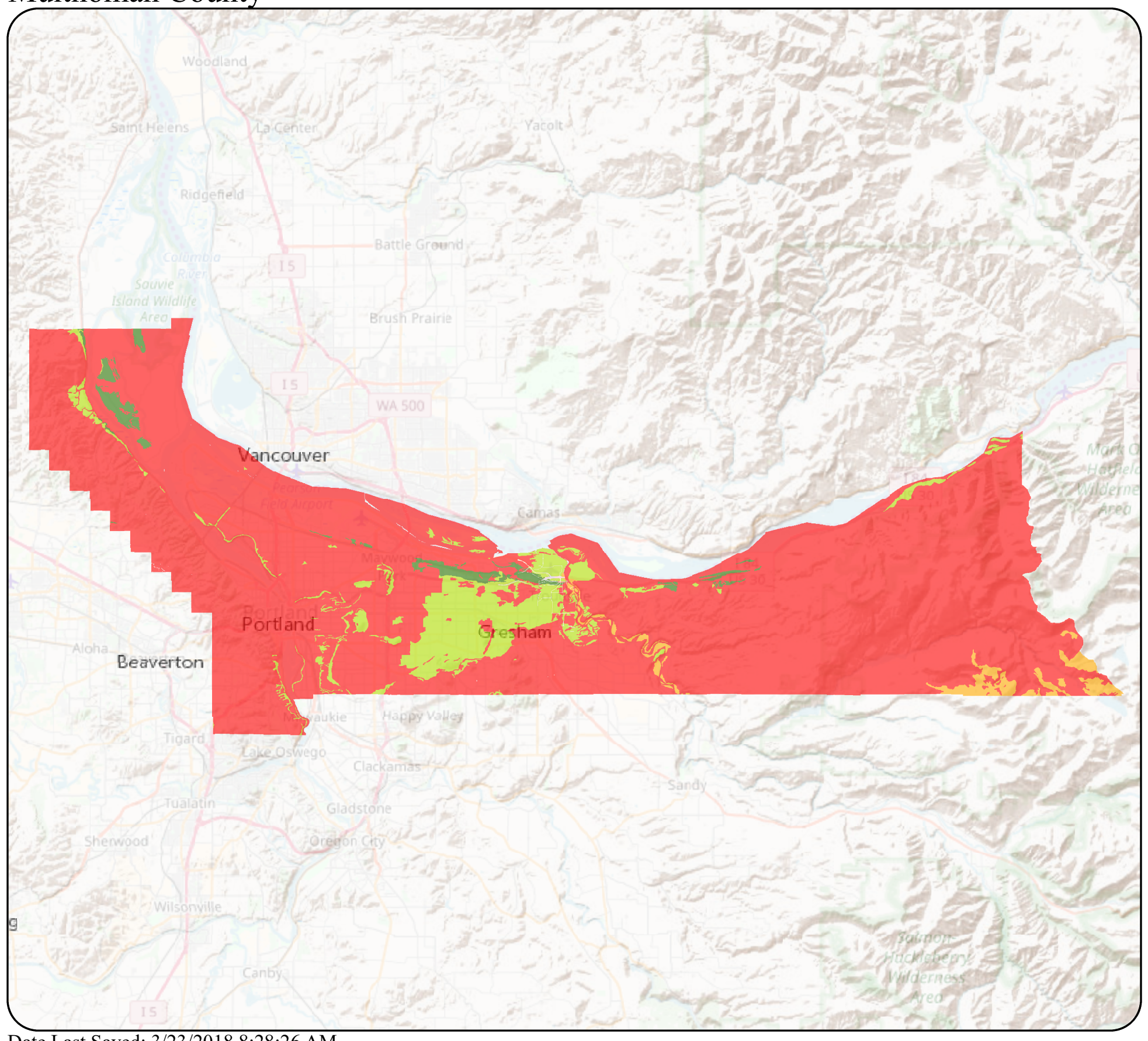

$\mathrm{N}$

$\widehat{N}_{1: 650,000}$

Service Layer Credits: (C)

OpenStreetMap (and)

contributors, CC-BY-SA

Esri, HERE, Garmin, (C)

OpenStreetMap 


\section{Soil Suitability for Rammed Earth Construction}

Multnomah County

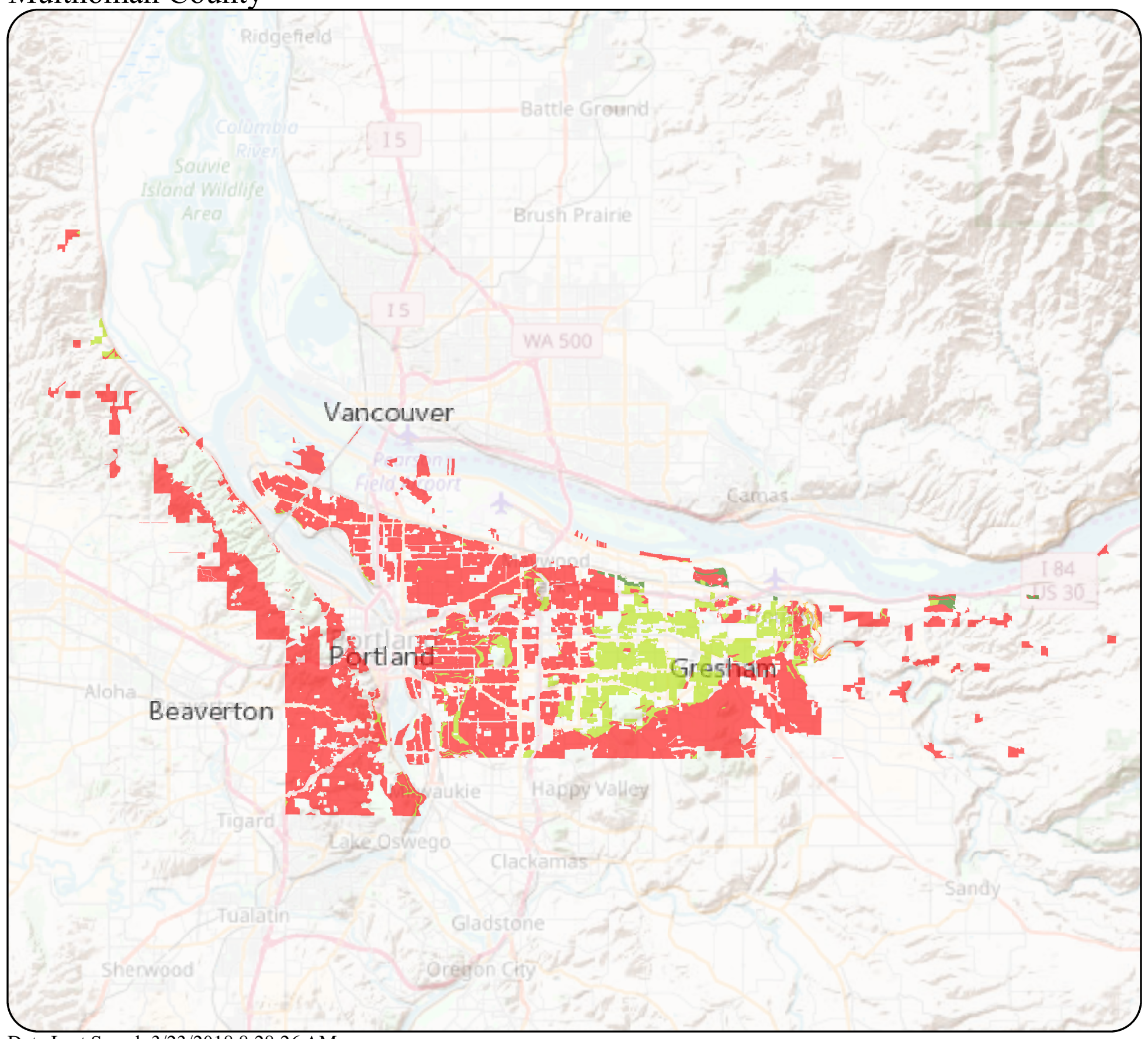

Date Last Saved: 3/23/2018 8:28:26 AM

\section{Legend}

\section{Soil Suitability}

Ideal

Suitable

Somewhat Suitable

Not Suitable

Zoning Categories Included:

Low density Res.

Medium density Res.

Medium-Low density Res.

Mixed-Use Com. \& Res. Low

Mixed-Use Com. \& Res. Med.

Rural Residential 1 acre

Rural Residential 2-4 acre

Rural Residential 5 acre

Rural Residential 10 acre

Very-Low density Res.

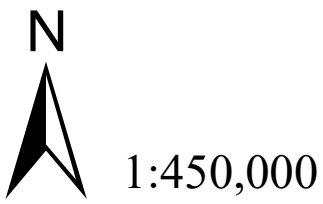

Service Layer Credits: (C) OpenStreetMap (and) contributors, CC-BY-SA Esri, HERE, Garmin, (C) OpenStreetMap 


\section{Soil Suitability for Rammed Earth Construction}

Washington County

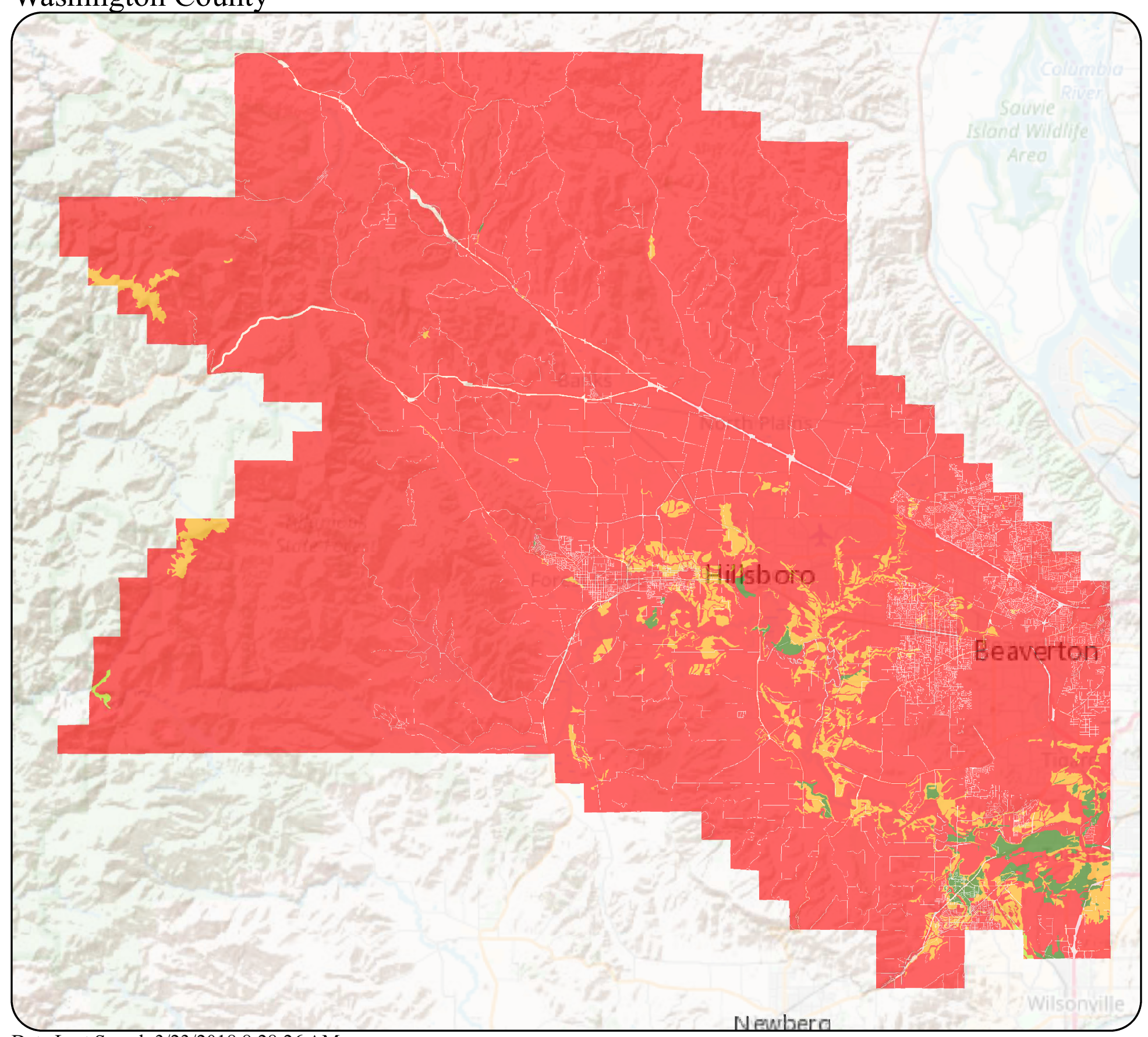

Date Last Saved: 3/23/2018 8:28:26 AM

\section{Legend}

Soil Suitability

Ideal

Suitable

Somewhat Suitable

Not Suitable

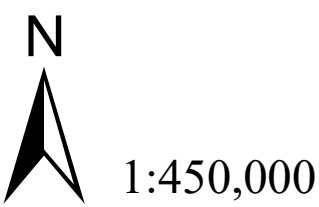

Service Layer Credits: (C)

OpenStreetMap (and)

contributors, CC-BY-SA

Esri, HERE, Garmin, (C)

OpenStreetMap 


\section{Soil Suitability for Rammed Earth Construction}

Washington County

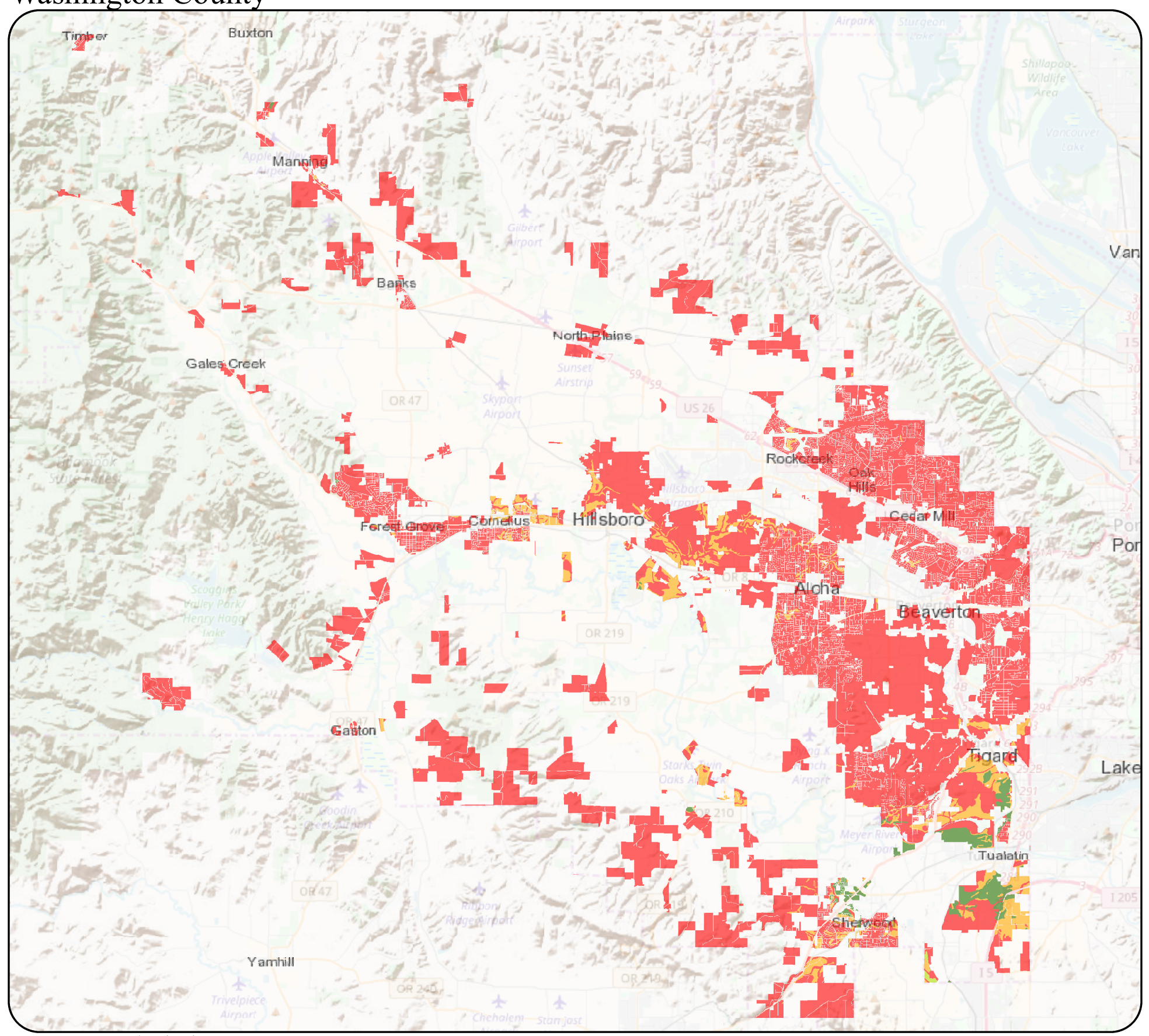

\section{Legend}

\section{Soil Suitability}

Ideal

Suitable

Somewhat Suitable

Not Suitable

Zoning Categories Included:

Low density Res.

Medium density Res.

Medium-Low density Res.

Mixed-Use Com. \& Res. Low

Mixed-Use Com. \& Res. Med.

Rural Residential 1 acre

Rural Residential 2-4 acre

Rural Residential 5 acre

Rural Residential 10 acre

Very-Low density Res.

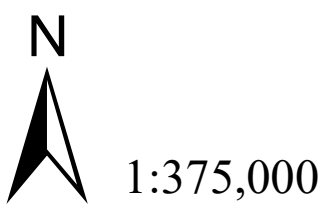

Service Layer Credits: (C) OpenStreetMap (and) contributors, CC-BY-SA Esri, HERE, Garmin, (C) OpenStreetMap 


\section{APPENDIX B) Plan Set}

\section{Contents:}

Title Page

Pg. 1

Construction Notes

Pg. 2

Site Plan

Pg. 3

Foundation

Pg. 4

Wall Design

Pg. 5

Forms Detail

Pg. 6 


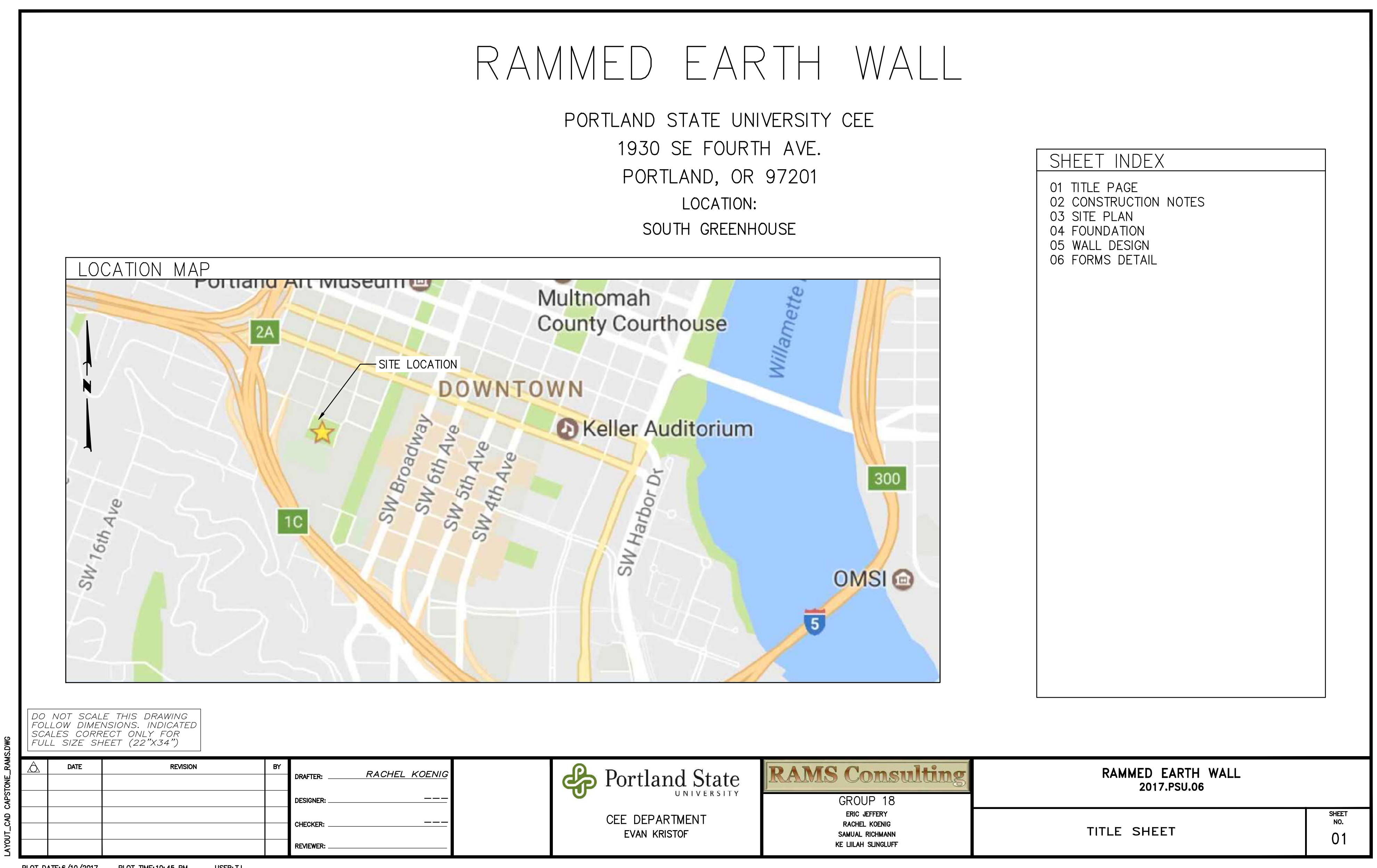

PLOT TIME:10:45 PM USER.TS 


\section{CONSTRUCTION/GENERAL NOTES:}

1. DRAWINGS ARE NOT TO BE SCALED, WRITTEN DIMENSIONS TAKE PRECEDENSE, AND THIS SET OF DOCUMENTS IS INTENDED TO BE USED FOR DIAGRAMMATIC PURPOSE ONLY, UNLESS NOTED OTHERWISE.

2. ALL WORK PERFORMED OF THE PROJECT AND MATERIALS INSTALLED SHALL BE IN STRICT ACCORDANCE WITH ALL APPLICABLE CODES, REGULATIONS, AND ORDINANCES.

3. ALL PERSONS ON THE PROJECT SITE MUST BE AWARE OF AND IMPLEMENT ALL SAFETY PROCEDURES PUT IN PLACE BY THE PORTLAND STATE UNIVERSITY ENVIRONMENTAL HEALTH \& SAFETY PRE-TASK PLAN CHECK LIST.

4. PROJECT SITE LOCATION MUST BE FENCED OFF INCLUDED PROPER SIGNAGE WHEN CONSTRUCTION IS NOT BEING PERFORMED.

5. ALL UTILITY LOCATES MUST BE COMPLETED BEFORE ANY EXCAVATION IS TO START.

6. ANY STOCKPILED CONSTRUCTION MATERIALS SHALL BE PROPERLY STORED IN AN ENCLOSED LOCATION WHEN CONSTRUCTION ACTIVITIES ARE NOT OPERATIONAL.

7. ANY GRADING ON SITE SHALL BE COMPLETED AS TO MAINTAIN EXISITING DRAINAGE FROM ADJACENT PROPERTIES.

8. ALL EXISTING STRUCTURES, TREES, AND LANDSCAPING SHALL BE PROTECTED IN PLACE UNLESS OTHERWISE NOTED.

9. EXCAVATED MATERIAL AND CLEARING OF ANY MATERIAL ON SITE SHALL BE DUMPED IN THE PROPER WASTE BINS LOCATED IN THE PORTLAND STATE UNIVERSITY LANDSCAPING YARD.

10. ALL EXPOSED STRUCTURAL REINFORCEMENT SHALL BE PROPERLY CAPPED.

11. PLACE AND CURE ALL CONCTRETE PER ACI CODES AND STANDARDS.

12. ALL REINFORCING STEEL SHALL BE ASTM A515, GRADE 50 .

13. FABRICATE AND INSTALL REINFORCING STEEL PER PROPER ACI CODES AND STANDARDS.

14. ALL WORK SHALL BE CONSTRUCTED AS TO THE DIMENSIONS OF THE CONSTRUCTION PLANS, UNLESS OTHERWISE NOTED BY THE ENGINEER.

\begin{tabular}{|c|c|c|c|c|c|}
\hline$\Delta$ & DATE & REnSION & BY & DRATER: RACHEL KOENIG & $\mathscr{P}$ Portland State \\
\hline & & & & CHECKER: & $\begin{array}{l}\text { CEE DEPARTMENT } \\
\text { EVAN KRISTOF }\end{array}$ \\
\hline
\end{tabular}

RAMS

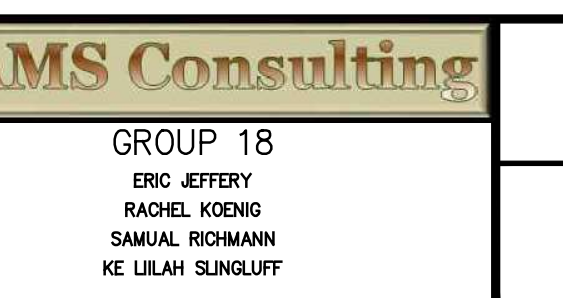

\begin{tabular}{|c} 
RAMMED EARTH WALL \\
2017. PSU.06 \\
\hline CONSTRUCTION NOTES
\end{tabular}

PLOT DATE: $6 / 10 / 2017 \quad$ PLOT TME: $10: 45$ PM $\quad$ USER:TS 


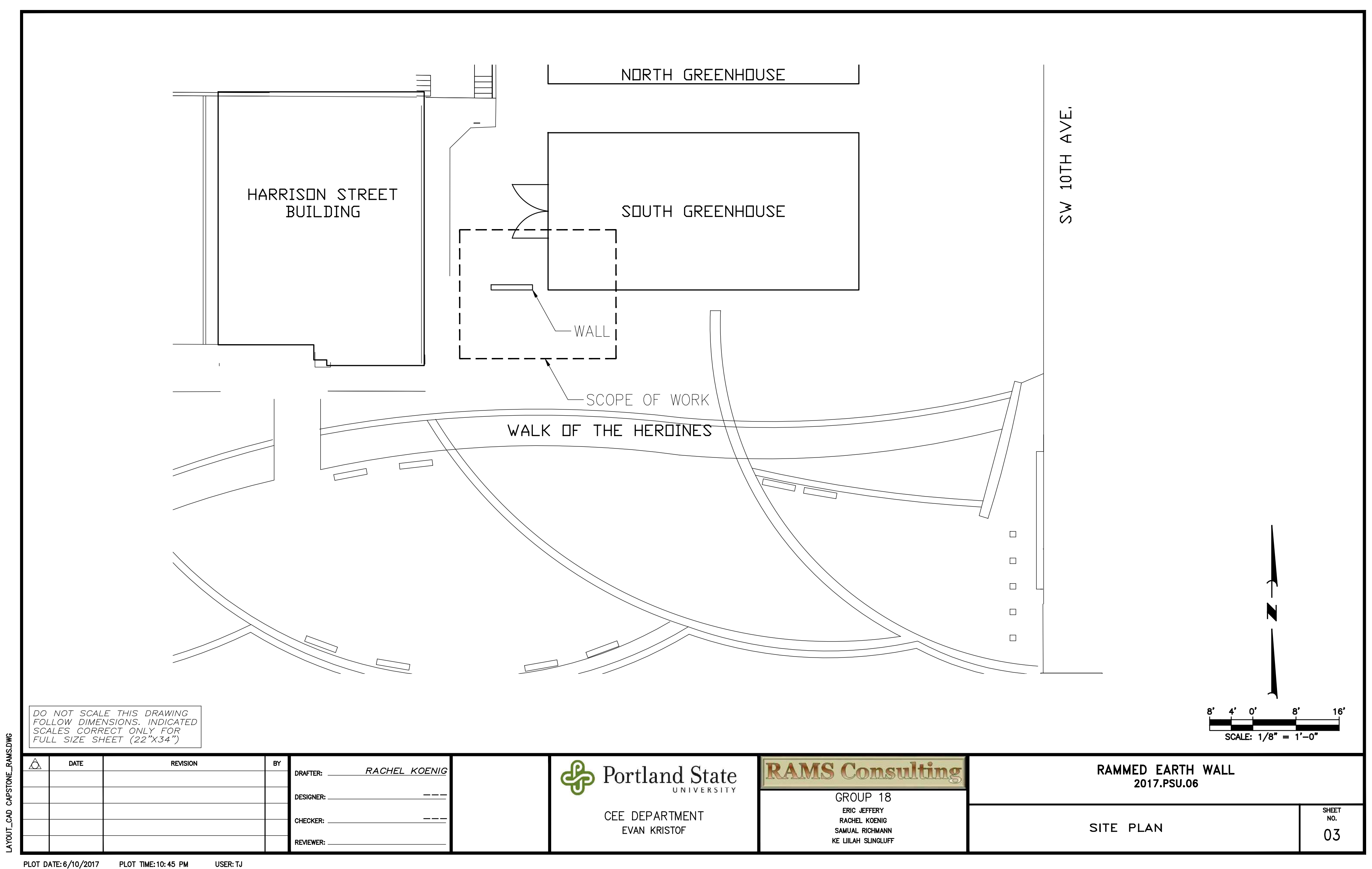




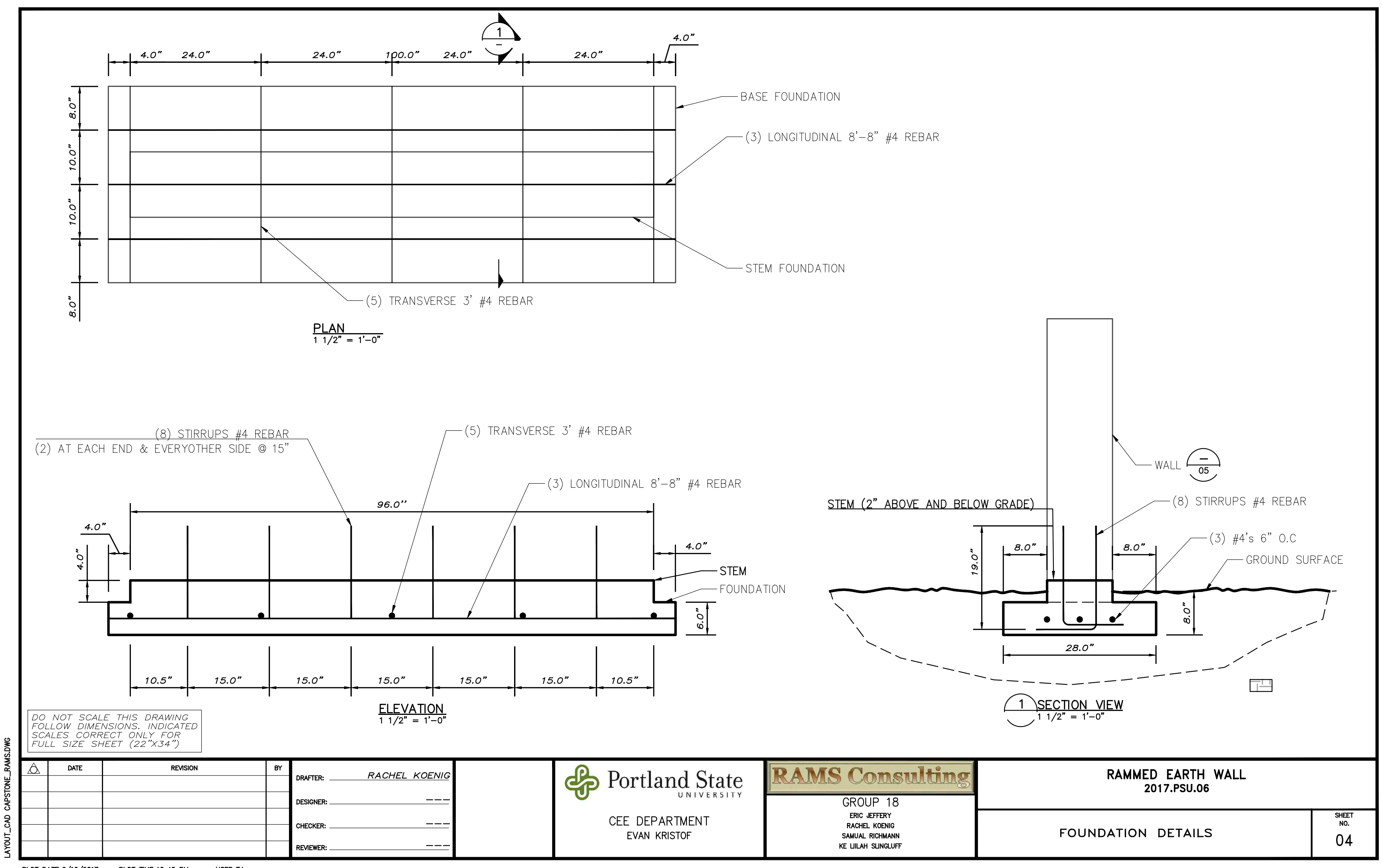

PLOT TME:10:45 PM USER:TJ 


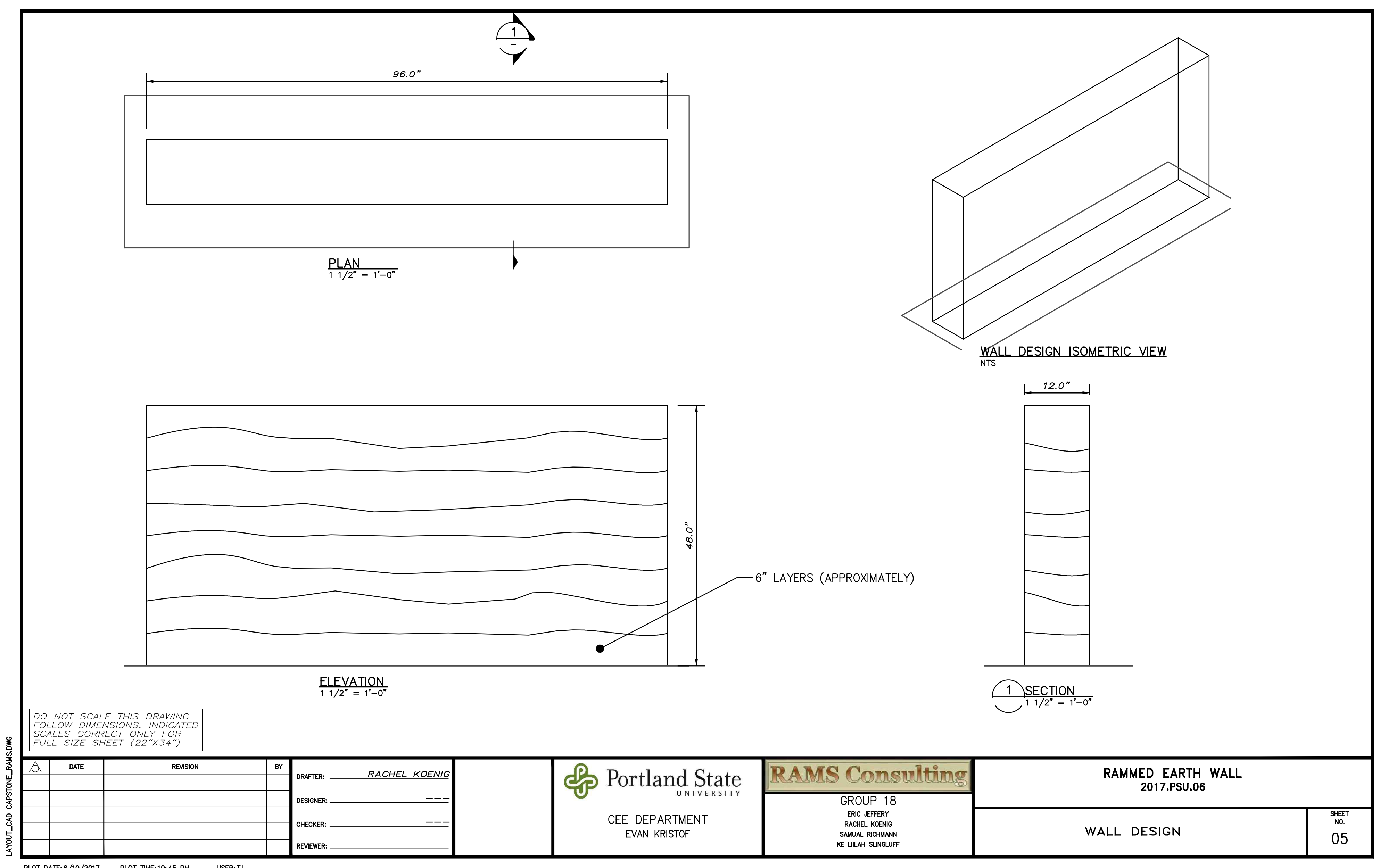




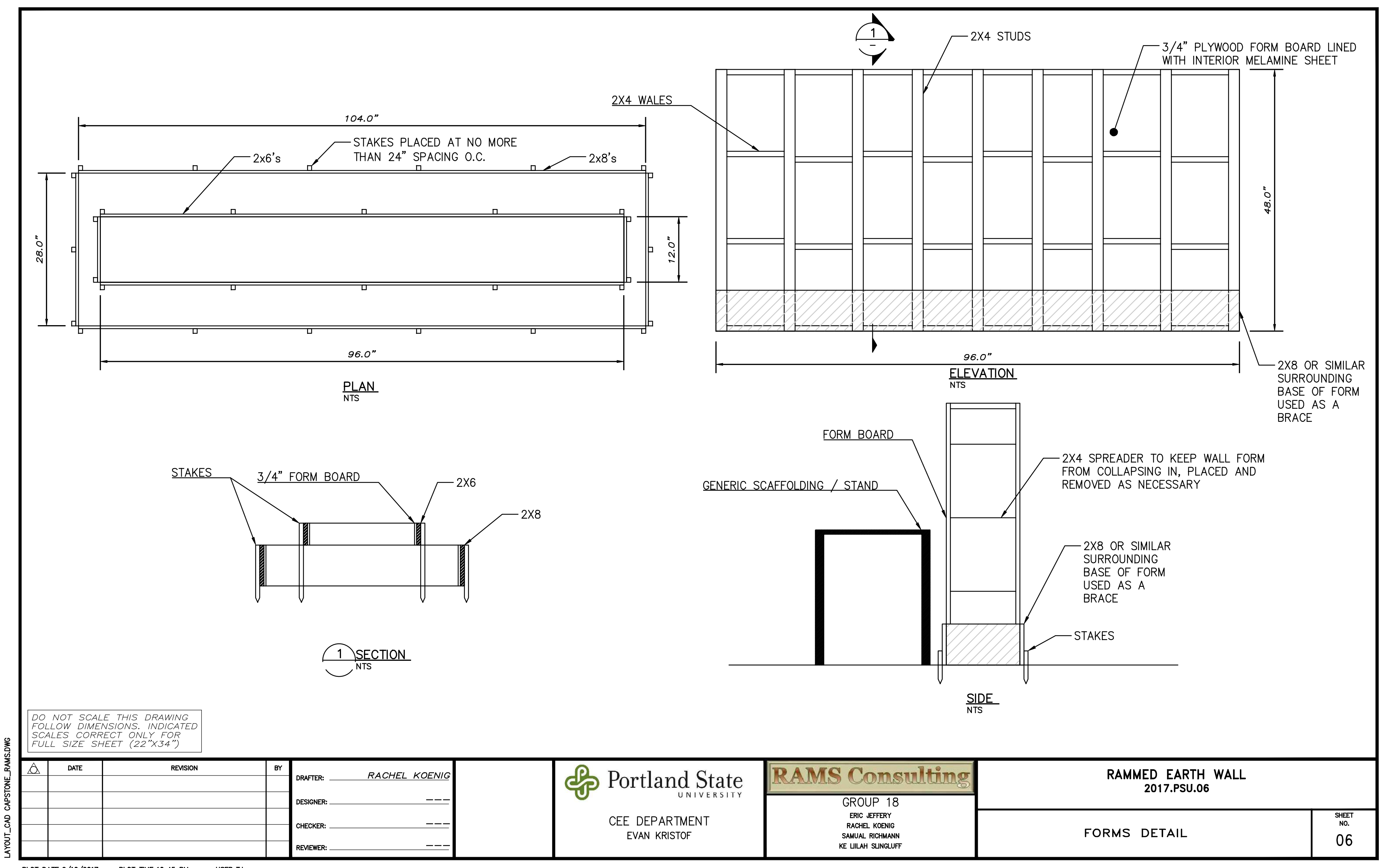

PLOT DAE: 6/10/2017 PLOT TME:10:45 PM USER: TS 


\section{APPENDIX C) Design Calculations}

Contents:

Soil Quantities for Wall Pg. 1

Settlement Calculations

Pg. 3

Soil Quantities for Text Cylinders Pg. 4

Flexural Capacity of Wall

Pg. 6

Standard Proctor Compaction Test

Pg. 9

Compressive Strength from Cylinder Testing Pg. 12 


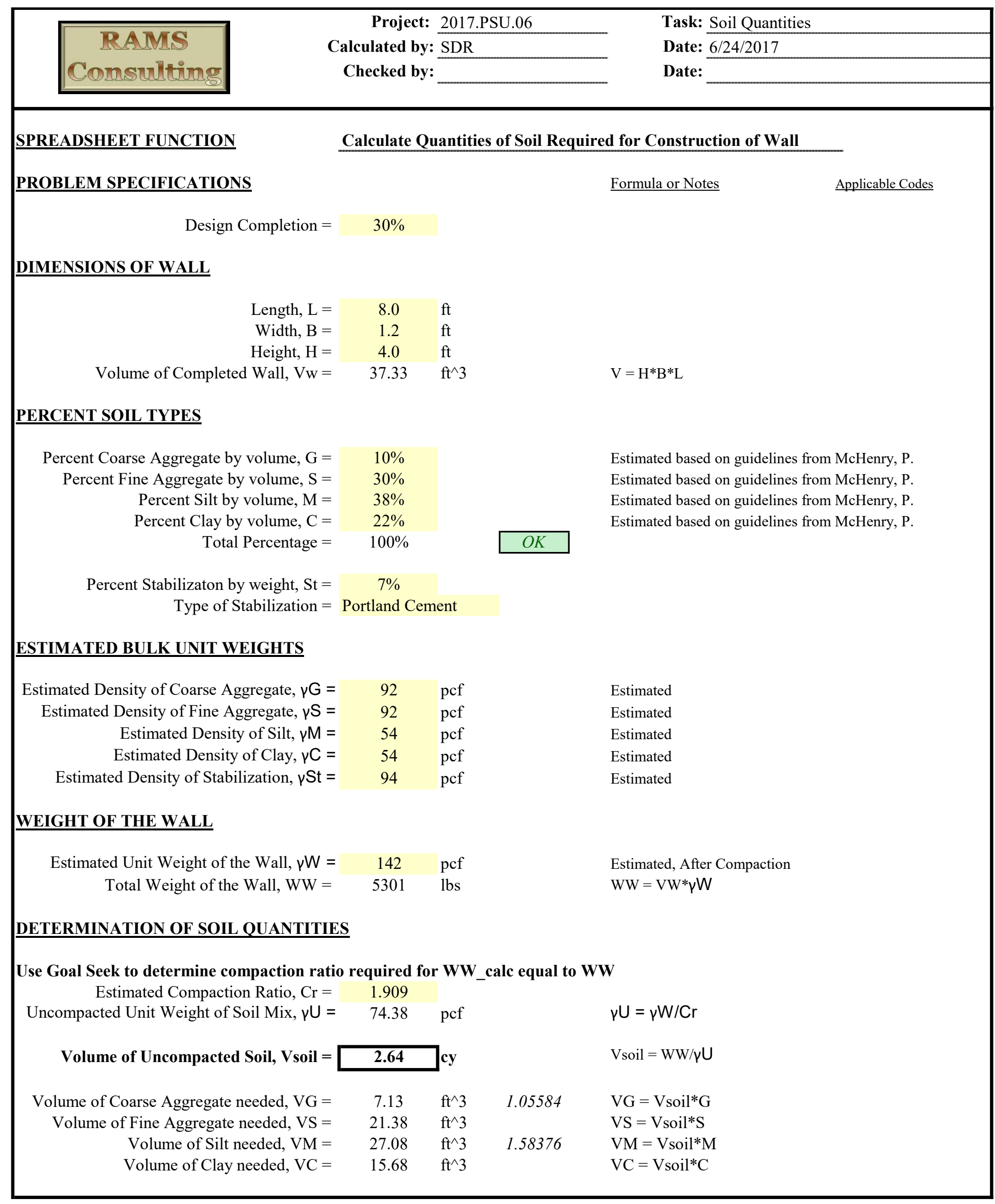




\begin{tabular}{|c|c|c|c|c|}
\hline & \multirow{3}{*}{\multicolumn{3}{|c|}{$\begin{aligned} & \text { Project: } 2017 . \text { PSU.06 } \\
& \text { Calculated by: } \text { SDR } \\
& \text { Checked by: }\end{aligned}$}} & \multirow{3}{*}{$\begin{array}{l}\text { Task: Soil Quantities } \\
\text { Date: } 6 / 24 / 2017 \\
\text { Date: }\end{array}$} \\
\hline RAMMS & & & & \\
\hline Comsutting & & & & \\
\hline \multicolumn{5}{|l|}{ SOIL AND STABILIZATION NEEDED } \\
\hline \multirow{4}{*}{$\begin{array}{r}\text { Weight of Coarse Aggregate needed, WG }= \\
\text { Weight of Fine Aggregate needed, WS }= \\
\text { Weight of Silt needed, WM }= \\
\text { Weight of Clay needed, WC }=\end{array}$} & 655.7 & $\mathrm{lb}$ & 2622.71 & $\mathrm{WG}=\mathrm{VG}^{*} \gamma \mathrm{G}$ \\
\hline & 1967.0 & $\mathrm{lb}$ & $49.5 \%$ & $\mathrm{WS}=\mathrm{VS} * \mathrm{~s}$ \\
\hline & 1462.4 & $\mathrm{lb}$ & 2309.13 & $\mathrm{WM}=\mathrm{VM} * \gamma \mathrm{M}$ \\
\hline & 846.7 & $\mathrm{lb}$ & $43.6 \%$ & $\mathrm{WC}=\mathrm{VC}^{*} \gamma \mathrm{C}$ \\
\hline \multirow{2}{*}{$\begin{array}{r}\text { Weight of Stabilization needed, WSt }= \\
\text { Volume of Stabilization needed, } \mathbf{V S t}=\end{array}$} & 369.39 & \multirow{2}{*}{$\mathbf{f t}^{\wedge} \mathbf{3}$} & \multirow[t]{2}{*}{$6.97 \%$} & $\mathrm{Wst}=(\mathrm{WG}+\mathrm{WS}+\mathrm{WM}+\mathrm{WC}) * \mathrm{St}$ \\
\hline & 3.93 & & & $\mathrm{VSt}=\mathrm{WSt} / \gamma \mathrm{St}$ \\
\hline Calculated Weight of Wall, WW_calc $=$ & 5301 & lbs & \begin{tabular}{|l|}
$O K$ \\
\end{tabular} & $\mathrm{WW} \_$calc $=\mathrm{WG}+\mathrm{WS}+\mathrm{WM}+\mathrm{WC}+\mathrm{WSt}$ \\
\hline \multicolumn{5}{|c|}{ Change Compaction ratio such that the sum of the wight of the individual components is equal to the weight of the whole wall } \\
\hline
\end{tabular}




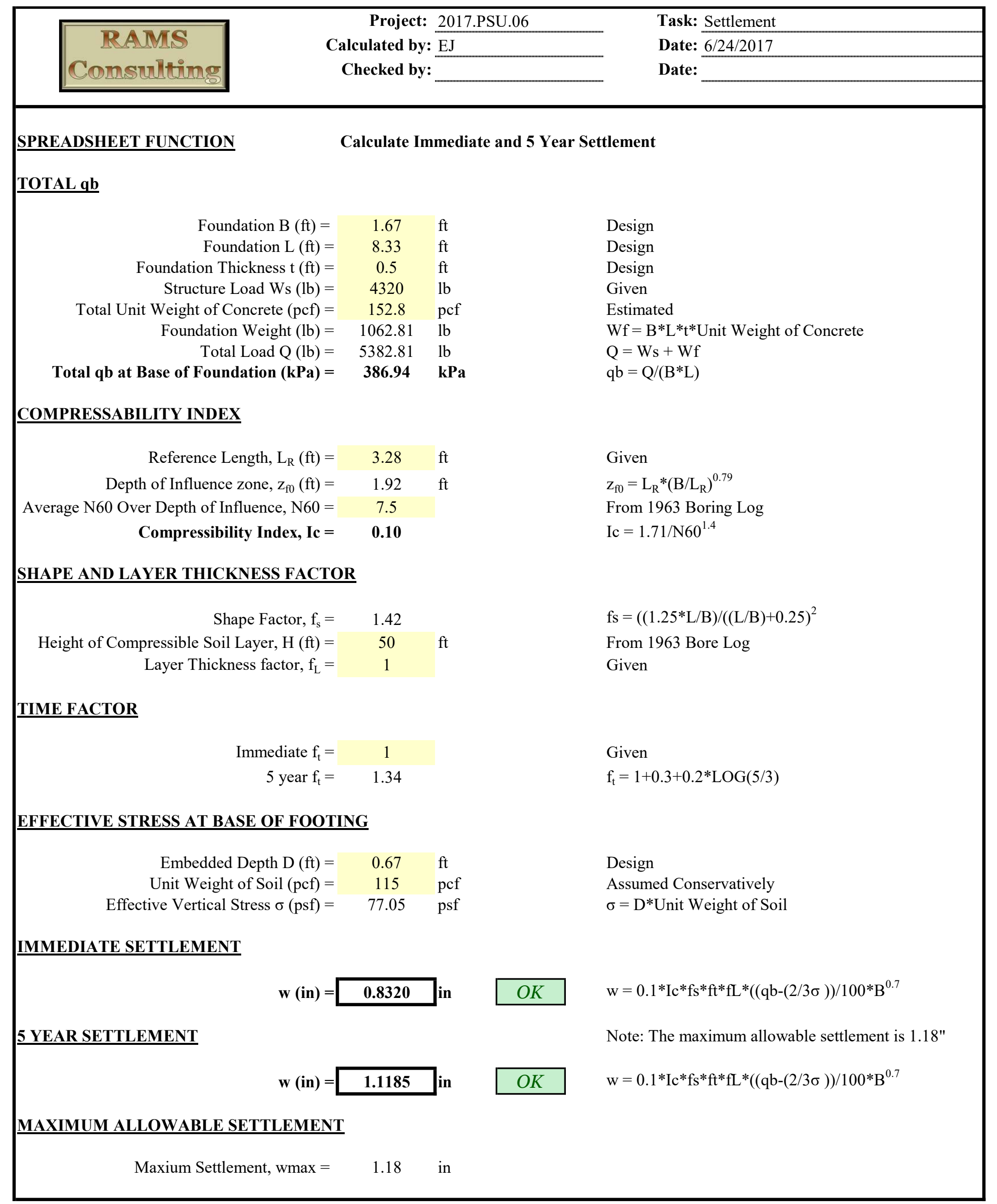




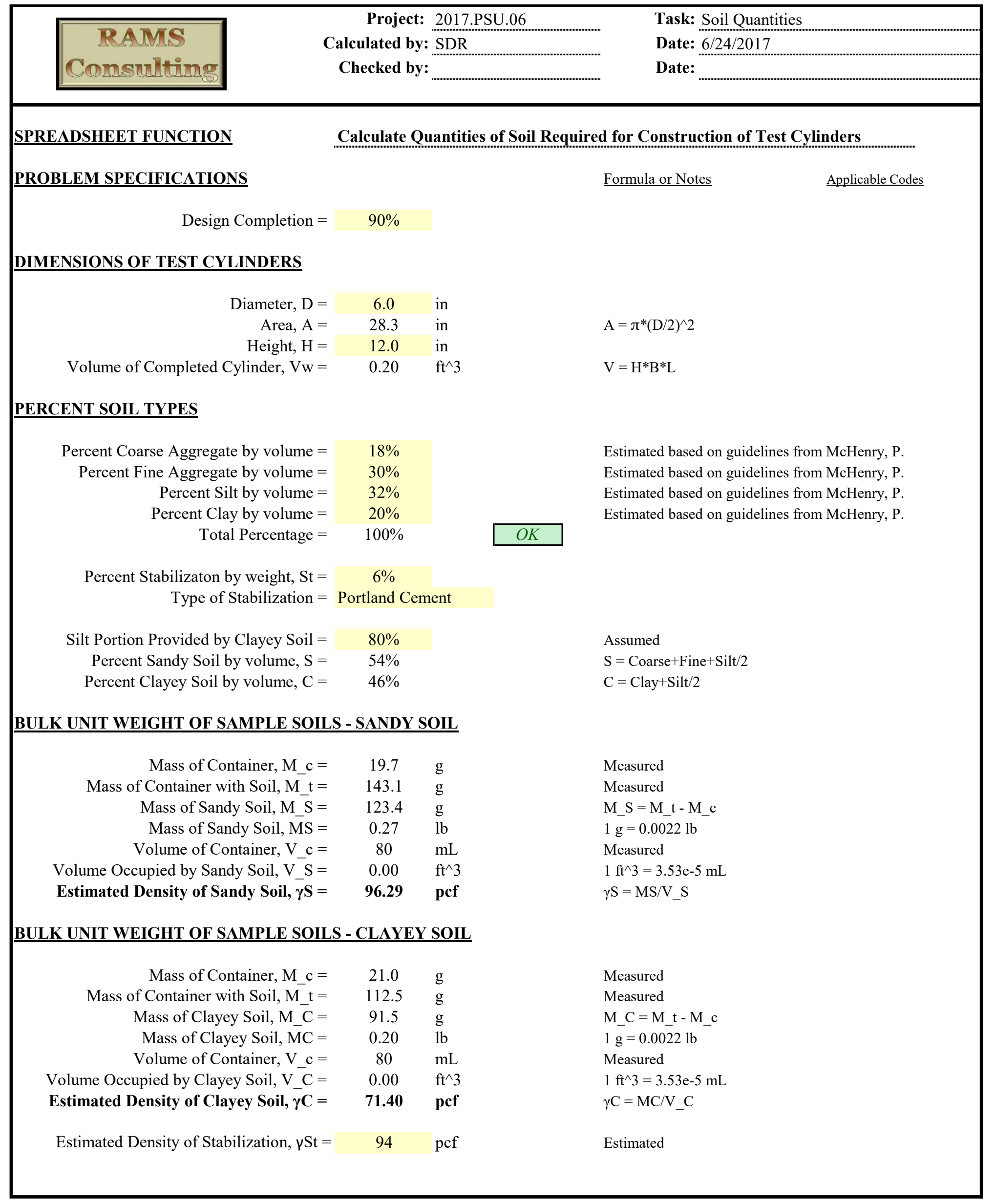




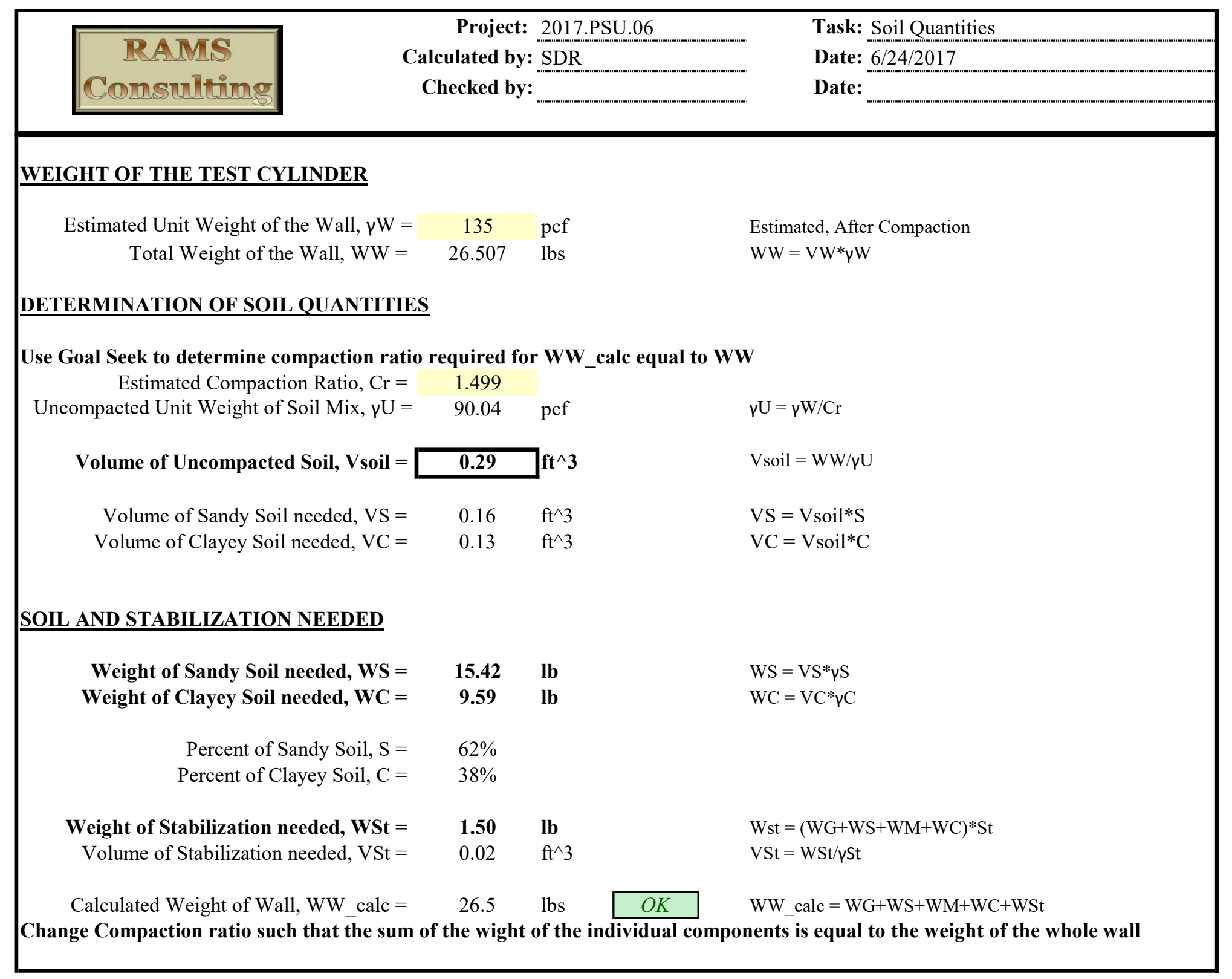




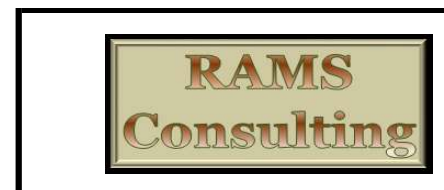

SPREADSHEET FUNCTION

PROBLEM SPECIFICATIONS

Design Completion $=90 \%$
Project: 2017.PSU.06

Calculated by: SDR

Checked by:
Task: Flexural Loading

Date: $6 / 24 / 2017$

Date:

\section{Calculate the Flexural Capacity of Unreinforced Rammed Earth}

Formula or Notes

\section{GEOMETRIC PROPERTIES}

Length, $\mathrm{L}=$ Height, $\mathrm{h}=$

Wall Thickness, $\mathrm{t}=$

Equivalent width being Analyzed, $\mathrm{b}=$

Worst-Case Average Weathering, $\mathrm{w}=$ Adjusted Wall Thickness, tw $=$ Area of Earth Cross Section, $\mathrm{Ab}=$ Lateral Section Modulus of Wall, $\mathrm{Zu}=$

Equivalent Length Factor, av = Slenderness Ratio of Wall, $\mathrm{Sr}=$

$\begin{array}{cc}8.0 & \mathrm{ft} \\ 4.0 & \mathrm{ft} \\ 12.0 & \text { in } \\ 48.0 & \text { in }\end{array}$

0.0 in

12.0 in

576 in^2

1152 in^3

2.00

8.00
In a cantilever, design section is at the base.

Load placed at top of a wall will distribute at 45 deg to base

Worst case load would be at corner, distriuted to 4 ' section

Compare Capacities of Pristine Section to Weathered

$\mathrm{Ab}=\mathrm{b} * \mathrm{t}$

$\mathrm{Zu}=\mathrm{b} * \mathrm{~h}^{2} / 6$

Fixed-Free (Cantilever)

$\mathrm{Sr}=\mathrm{av} * \mathrm{~h} / \mathrm{t}$

NSZ-4297 6.4.3.3 NSZ-4297 Eq 6-3

\section{FOOTING PROPERTIES}

Footing Offset Dimension, toff $=$

Footing Thickness, $\mathrm{tf}=$ Footing Depth, $\mathrm{df}=$ 8.0 in 28.0 in

Unit Weight of Footing $\gamma \mathrm{c}=$

7.5 in

150 pcf

\section{MATERIAL PROPERTIES}

Estimated Unit Weight of the Wall, $\gamma \mathrm{W}=$ 142 pcf

Compressive Strength of Test Sample, fuc $=$

$1.75 \mathrm{MPa}$

$1.75 \mathrm{MPa}$

Compressive Strength of Earth, fe =

Flexural Tension Strength of Earth, fet = Shear Strength of Earth, fes =

Compressive Strength of Earth, fe = Flexural Tension Strength of Earth, fet $=$ Shear Strength of Earth, fes = Modulus of Elasticity of Earth, Ee =

\section{CAPACITY REDUCTION FACTORS}

Reduction Factor for Axial Compression, $\phi \mathrm{c}=$ Reduction Factor for Flexure, $\phi \mathrm{f}=$ Reduction Factor for Shear, $\phi \mathrm{s}=$

\section{$0.175 \quad \mathrm{MPa}$}

$0.123 \mathrm{MPa}$

$253.8 \quad$ psi

$25.4 \quad$ psi

17.8 psi

76145 psi
Specify Test Data, If Available

$\mathrm{fe}=$ f'uc

NSZ-4297 4.5.1

fet $=0.10 * \mathrm{fe}$

NSZ-4297 4.5.5

fes $=0.07 * \mathrm{fe}$

NSZ-4297 Eq 4-1

$1 \mathrm{Mpa}=145 \mathrm{psi}$

$1 \mathrm{Mpa}=145 \mathrm{psi}$

$1 \mathrm{Mpa}=145 \mathrm{psi}$

$\mathrm{Ee}=300 * \mathrm{fe}$

NSZ-4297 4.5.6 


\begin{tabular}{|c|c|c|}
\hline & Project: 2017.PSU............ & Task: Flexural Loading \\
\hline RAMIS & Calculated by: SDR & Date: $6 / 24 / 2017$ \\
\hline Comsulting & Checked by: & Date: \\
\hline
\end{tabular}

\section{LOADING (PER EQUIVALENT WIDTH)}

Axial Loading on Wall, $\mathrm{P}=$ Horizontal Force on Wall, $\mathrm{Fh}=$ Assumed Location of Horizontal Load, $\mathrm{zh}=$

Equivalent Fluid Pressure of Soil, $\gamma$ fill =

Height of Soil Backfill, hfill =

\section{LOAD FACTORS}

Load Factor for Dead Load, D = 1.25

Load Factor for Live Load, $\mathrm{L}=$ Load Factor for Earth Loading, $\mathrm{E}=$ Load Factor for Impact, Im =

1.10

\section{WALL LOADING VALUES}

Horizontal Moment on Wall, $\mathrm{M}^{*} \mathrm{dh}=$ Self Weight of Wall, SW =

Design Axial Loading, $\mathrm{N}^{*}=$ Self Weight of Footing, SWf $=$

Eccentricity of Vertical Loading, $\mathrm{e}=$ Maximum Allowable Eccentricity, $\mathrm{t} / 6=$ Eccentricity to Thickness ratio $=$ Axial Reduction Factor, $\mathrm{k}=$

\section{STRESS CHECKS}

Nominal Compressive Strength of Earth, $\mathrm{N}_{0}=$

Design Compressive Strength of Earth, $\mathrm{N}=$

Design Axial Loading on Wall, $\mathrm{N}^{*}=$

Design Flexural Strength of Wall, Mch =

Design Flexural Load on Wall, $\mathrm{M}^{*} \mathrm{dh}=$

Allowable Moment, Mf_all = owable Load Placed at Top of Wall, F_all = lowable Load Placed at Mid Height, F_all =

\section{OVERTURNING CHECK}

Bearing Force on Soil, Nbear $=$ Moment at Base of Footing, $\mathrm{Mf}=$ Eccentricity of Bearing Force, $\mathrm{xf}=$ Allowable Eccentricity of Bearing Force, ef =

Allowable Moment, Mf_all = owable Load Placed at Top of Wall, F_all = lowable Load Placed at Mid Height, F_all =

$\begin{array}{cl}0.0 & \text { lbs } \\ 135.0 & \text { lbs } \\ 4.0 & \mathrm{ft} \\ & \\ 40.0 & \text { pcf } \\ 4.0 & \mathrm{ft}\end{array}$

From Human Activity

From Human Activity

From Human Activity

Assumed Retaining Wall Backfill

Assumed Retaining Wall Backfill
540.0

2272.0

lb-ft

2272.0

$875.0 \quad$ lbs

$\begin{array}{ll}2.9 & \text { in } \\ 2.0 & \text { in } \\ 0.24 & \\ 0.34 & \end{array}$

$146198 \quad \mathrm{lb}$

$29824 \quad \mathrm{lb}$

$2272 \quad \mathrm{lb}$

$1949.3 \quad$ lb-ft

$540.0 \quad$ lb-ft

$O K$

$1949.3 \quad$ lb-ft

487.3 lbs

974.7 lbs

$3147.0 \quad \mathrm{lbs}$

$624.4 \quad \mathrm{lb}-\mathrm{ft}$

2.38 in

4.67 in

OK

1223.8 lb-ft

264.6 lbs

466.2 Ibs

$$
\begin{aligned}
& \mathrm{M} * \mathrm{dh}=\mathrm{Fh} * \mathrm{zh} \\
& \mathrm{SW}=(\mathrm{b} * \mathrm{~h} * \mathrm{t}) * \mathrm{\gamma W} \\
& \mathrm{N}^{*}=\mathrm{SW}+\mathrm{P} \\
& \mathrm{SWf}=(\mathrm{df} * \mathrm{tf} * \mathrm{~b}) * \gamma \mathrm{c}
\end{aligned}
$$

$\mathrm{e}=\mathrm{M}^{*} \mathrm{dh} / \mathrm{N}^{*}$

$\mathrm{e}<\mathrm{t} / 6 \quad$ OK to use

$\mathrm{e} / \mathrm{t}$

NSZ-4297 6.4.3.1

NSZ-4297 Table 6.1

NSZ-4297 Eq 6-2

NSZ-4297 Eq 6-1

NSZ-4297 Eq 6-7 NSZ-4297 Eq 6-5
F_all $=$ Mf_all $/ \mathrm{h}$

F_all = Mf_all/(h/2)

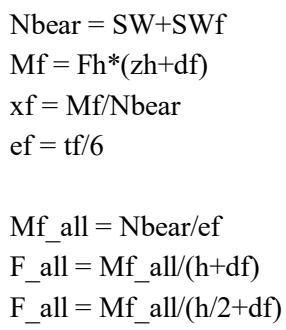




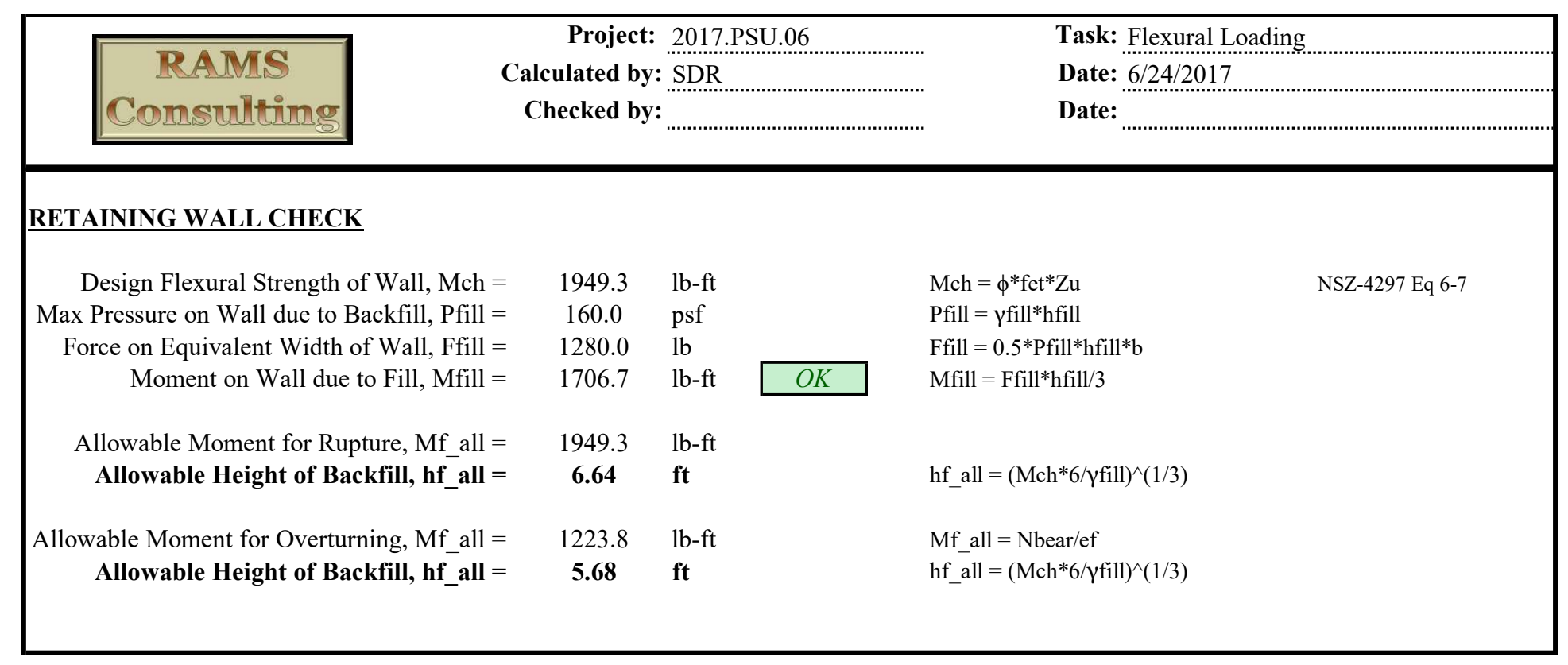




\begin{tabular}{|c|c|c|}
\hline & Project: 2017.PSU.06 & Task: Standard Proctor Compaction \\
\hline RAMS & Calculated by: SDR & Date: $6 / 24 / 2017$ \\
\hline Consutting & Checked by: & Date: \\
\hline
\end{tabular}

\section{SPREADSHEET FUNCTION}

\section{PROBLEM SPECIFICATIONS}

Percent Coarse Aggregate by volume $=$ Percent Fine Aggregate by volume $=$ Percent Silt by volume $=$ Percent Clay by volume $=$ Total Percentage $=$

Percent Stabilizaton by weight, $\mathrm{St}=$ Type of Stabilization $=$ Portland Cement
$18 \%$

$30 \%$

$32 \%$

$20 \%$

$100 \%$

\section{Determine Optimum Water Content by Standard Proctor Compaction}

$\underline{\text { Formula or Notes }}$

$\underline{\text { Applicable Codes }}$

Estimated based on guidelines from McHenry, P. Estimated based on guidelines from McHenry, P. Estimated based on guidelines from McHenry, P. Estimated based on guidelines from McHenry, P.

\section{DEFINE CONSTANTS}

Mass of Proctor Compaction Mold, $\mathrm{M}=$ Volume of Proctor Compaction Mold, $\mathrm{V}=$ Mass of Sample Weighing Container, $\mathrm{W}=$ Gram to Pounds Conversion Factor, $\mathrm{g} \_\mathrm{lb}=$

\section{TRIAL 1}

Weight of Compacted Soil in Mold, Mc = Moist Soil Weight, $\mathrm{Mm}=$ Moist Soil Weight, $\mathrm{Mm}=$ Moist Unit Weight, $\mathrm{pm}=$

Moist Soil Sample Weight in Container, $\mathrm{Sm}=$ Dry Soil Sample Weight in Container, $\mathrm{Sd}=$

Weight of Moisture in Sample, $\mathrm{Sw}=$

Dry Weight of Soil in Sample, Ss =

Moisture Content of Sample, MC = Dry Unit Weight of Compacted Soil, $\gamma d=$

\section{TRIAL 2}

Weight of Compacted Soil in Mold, $\mathrm{Mc}=$ Moist Soil Weight, $\mathrm{Mm}=$ Moist Soil Weight, $\mathrm{Mm}=$ Moist Unit Weight, $\gamma \mathrm{m}=$

Moist Soil Sample Weight in Container, $\mathrm{Sm}=$ Dry Soil Sample Weight in Container, $\mathrm{Sd}=$ Weight of Moisture in Sample, $\mathrm{Sw}=$ Dry Weight of Soil in Sample, Ss =

Moisture Content of Sample, $\mathrm{MC}=$ Dry Unit Weight of Compacted Soil, $\gamma d=$

$\begin{array}{cl}4275 & \mathrm{~g} \\ 0.033 & \mathrm{ft}^{\wedge} 3 \\ 0.4 & \mathrm{~g} \\ 0.0022 & \end{array}$

Measured in Lab $\mathrm{V}=1 / 30 \mathrm{ft} \wedge 3$

Measured in Lab
Measured in Lab
$\mathrm{Mm}=\mathrm{Mc}-\mathrm{M}$
$\mathrm{Mm}=\mathrm{Mm}^{*} \mathrm{~g} \_\mathrm{lb}$
$\gamma \mathrm{m}=\mathrm{Mm} / \mathrm{V}$
Measured in Lab
Measured in Lab
$\mathrm{Sw}=\mathrm{Sm}-\mathrm{Sd}$
$\mathrm{Ss}=\mathrm{Sd}-\mathrm{W}$
$\mathrm{MC}=\mathrm{Sw} / \mathrm{Ss}$
$\gamma \mathrm{d}=\gamma \mathrm{m} /(1+\mathrm{MC})$

Measured in Lab

$\mathrm{Mm}=\mathrm{Mc}-\mathrm{M}$

$\mathrm{Mm}=\mathrm{Mm} * \mathrm{~g} \_\mathrm{lb}$

$\gamma \mathrm{m}=\mathrm{Mm} / \mathrm{V}$

Measured in Lab

Measured in Lab

$\mathrm{Sw}=\mathrm{Sm}-\mathrm{Sd}$

$\mathrm{Ss}=\mathrm{Sd}-\mathrm{W}$

$\mathrm{MC}=\mathrm{Sw} / \mathrm{Ss}$

$\gamma \mathrm{d}=\gamma \mathrm{m} /(1+\mathrm{MC})$ 
Project: 2017.PSU.06

Calculated by: SDR

Checked by:
Task: Standard Proctor Compaction

Date: $6 / 24 / 2017$

Date:

TRIAL 3

Weight of Compacted Soil in Mold, $\mathrm{Mc}=$ Moist Soil Weight, $\mathrm{Mm}=$ Moist Soil Weight, $\mathrm{Mm}=$ Moist Unit Weight, $\gamma \mathrm{m}=$

Moist Soil Sample Weight in Container, $\mathrm{Sm}=$ Dry Soil Sample Weight in Container, $\mathrm{Sd}=$ Weight of Moisture in Sample, $\mathrm{Sw}=$ Dry Weight of Soil in Sample, Ss =

Moisture Content of Sample, MC = Dry Unit Weight of Compacted Soil, yd =

\section{TRIAL 4}

Weight of Compacted Soil in Mold, $\mathrm{Mc}=$ Moist Soil Weight, $\mathrm{Mm}=$ Moist Soil Weight, $\mathrm{Mm}=$ Moist Unit Weight, $\mathrm{\gamma m}=$

Moist Soil Sample Weight in Container, $\mathrm{Sm}=$ Dry Soil Sample Weight in Container, $\mathrm{Sd}=$ Weight of Moisture in Sample, $\mathrm{Sw}=$ Dry Weight of Soil in Sample, Ss =

Moisture Content of Sample, MC = Dry Unit Weight of Compacted Soil, $\gamma d=$

$\begin{array}{cl}6240 & \mathrm{~g} \\ 1965 & \mathrm{~g} \\ 4.32 & \mathrm{lb} \\ 129.7 & \text { pcf }\end{array}$

$8.4 \quad \mathrm{~g}$

$7.4 \quad \mathrm{~g}$

$1.0 \quad \mathrm{~g}$

$7.0 \quad \mathrm{~g}$

$14.3 \%$

113.5 pcf
Measured in Lab

$\mathrm{Mm}=\mathrm{Mc}-\mathrm{M}$

$\mathrm{Mm}=\mathrm{Mm}{ }^{*} \mathrm{~g} \_\mathrm{lb}$

$\gamma \mathrm{m}=\mathrm{Mm} / \mathrm{V}$

Measured in Lab Measured in Lab $\mathrm{Sw}=\mathrm{Sm}-\mathrm{Sd}$ $\mathrm{Ss}=\mathrm{Sd}-\mathrm{W}$

$\mathrm{MC}=\mathrm{Sw} / \mathrm{Ss}$ $\gamma \mathrm{d}=\gamma \mathrm{m} /(1+\mathrm{MC})$
6220

1945

4.28

128.4

$6.4 \mathrm{~g}$

$5.6 \mathrm{~g}$

$0.8 \quad \mathrm{~g}$

$5.2 \quad \mathrm{~g}$

$15.4 \%$

111.3 pef
Measured in Lab $\mathrm{Mm}=\mathrm{Mc}-\mathrm{M}$ $\mathrm{Mm}=\mathrm{Mm}^{*} \mathrm{~g} \_\mathrm{lb}$ $\gamma \mathrm{m}=\mathrm{Mm} / \mathrm{V}$

Measured in Lab Measured in Lab $\mathrm{Sw}=\mathrm{Sm}-\mathrm{Sd}$ $\mathrm{Ss}=\mathrm{Sd}-\mathrm{W}$

$\mathrm{MC}=\mathrm{Sw} / \mathrm{Ss}$ $\gamma \mathrm{d}=\gamma \mathrm{m} /(1+\mathrm{MC})$

\section{TABULATED RESULTS}

Trial

Moisture Content

Dry Unit Weight

\begin{tabular}{|c|c|c|c|}
\hline 1 & 2 & 3 & 4 \\
\hline $9.1 \%$ & $9.8 \%$ & $14.3 \%$ & $15.4 \%$ \\
\hline 99.8 & 109.4 & 113.5 & 111.3 \\
\hline
\end{tabular}

\section{ESTIMATED OPTIMUM WATER CONTENT}

Estimated Optimum Water Content, OWC $=\quad 12.5 \%$

Estimated Dry Unit Weight of Soil $\gamma \mathrm{d}=$

119.0

pcf

Estimated Moist Unit Weight of Soil, $\gamma=133.9$

\section{CALCULATION FOR ZERO AIR VOID (ZAV) LINE}

Assumed Specific Gravity, SG =

pcf

ZAV Line, $\mathrm{SG}=2.65$

Moisture Content

Dry Unit Weight

\begin{tabular}{|c|c|c|c|}
\hline $5.0 \%$ & $10.0 \%$ & $15.0 \%$ & $20.0 \%$ \\
\hline $\mathbf{1 4 6 . 0}$ & $\mathbf{1 3 0 . 7}$ & $\mathbf{1 1 8 . 3}$ & $\mathbf{1 0 8 . 1}$ \\
\hline
\end{tabular}

Estimated

Estimated

$\gamma=\gamma \mathrm{d}^{*}(1+\mathrm{OWC})$

Estimated

$\gamma \mathrm{d}=\gamma \mathrm{w} /(\mathrm{WC}+(1 / \mathrm{SG}))$ 


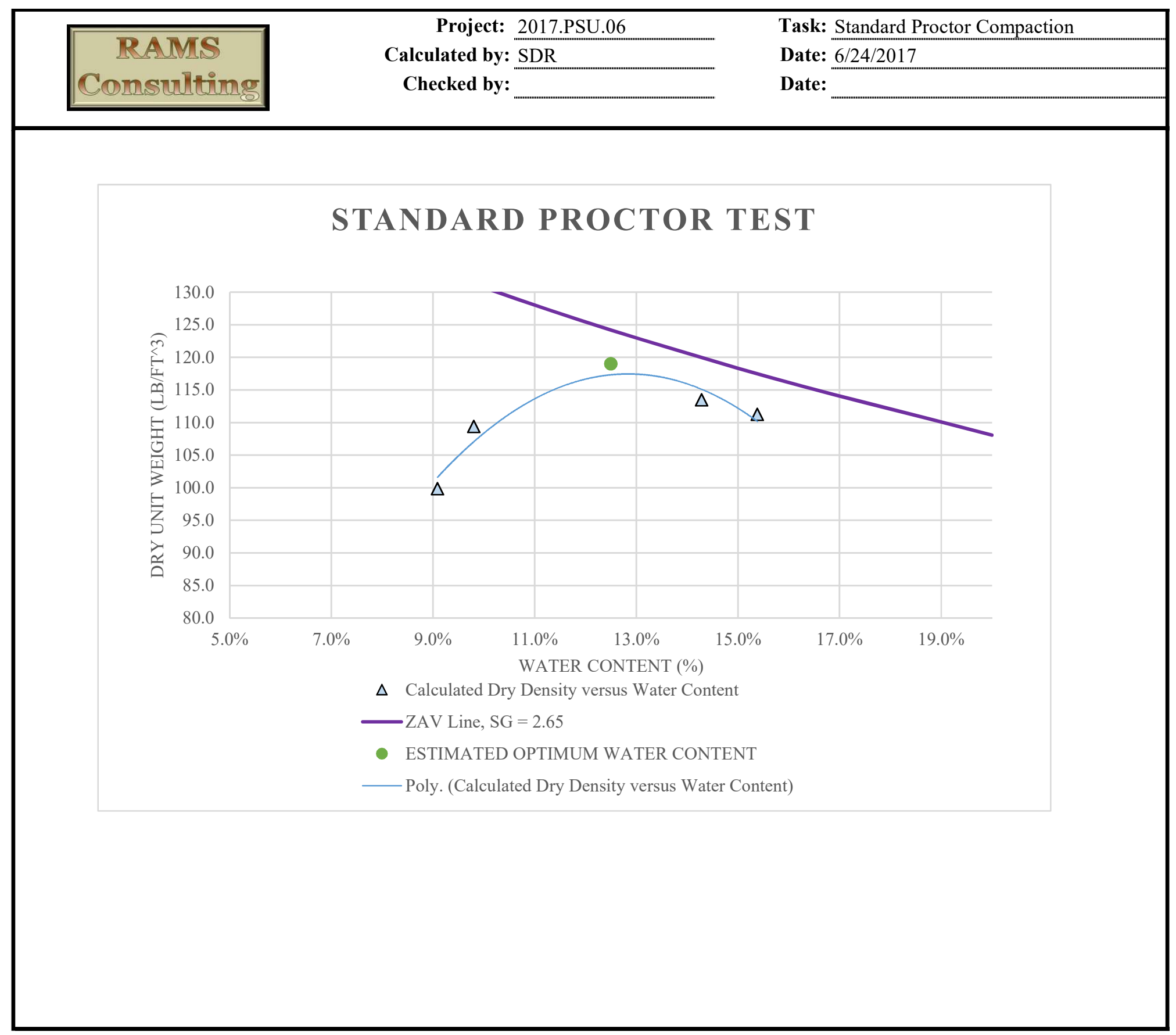




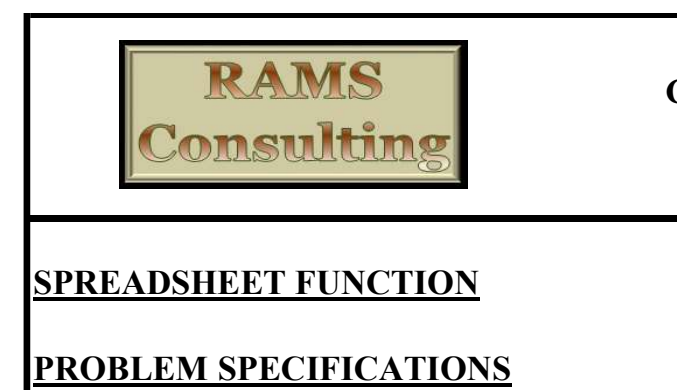

PROBLEM SPECIFICATIONS

Weight of Sandy Soil in Mixture $=$ Weight of Clayey Soil in Mixture = Weight of Stabilization in Mixture =

Cumulative Weight of Mixture $=$

Percent Sandy Soil by weight $=$ Percent Clayey Soil by weight $=$

Percent Stabilizaton by weight $=$

\section{DEFINE CONSTANTS}

Diameter of Test Cylinder, $\mathrm{D}=$ Area of Cylinder, $\mathrm{A}=$ Minimum 7-day Strength, fe_min = Recommended Design Strength $=$
Project: 2017.PSU.06

Calculated by: SDR

Checked by:
Task: Compressive Strength of Earth

Date: $6 / 24 / 2017$

Date:
Determine Compressive Strength of Rammed Earth from Test Cylinders

Formula or Notes

Applicable Codes
$15.4 \quad \mathrm{lb}$

$9.6 \quad \mathrm{lb}$

$1.5 \quad \mathrm{lb}$

$26.5 \quad 1 b$

$58 \%$

$36 \%$

$6 \%$
Measured

Measured

Measured

Weight $=$ Clay + Sand + Stabilization

Sand $\%=$ Sand $/$ Mix

Clay $\%=$ Clay $/ \mathrm{Mix}$

$\mathrm{PC} \%=\mathrm{PC} / \mathrm{Mix}$
3.0 in

7.07 in`2

$200 \quad$ psi

$300 \quad$ psi
$A=\pi^{*}(D / 2)^{\wedge} 2$

NMAC 14.7.4.14-C

NMAC 14.7.4.14-C

\section{TRIAL 1 - LAYERED}

Maximum Load Before Crushing, $\mathrm{P}=$ Compressive Strength of Cylinder, $\mathrm{f}^{\prime} \mathrm{e}=$

\section{TRIAL 2 - NO PIGMENT}

Maximum Load Before Crushing, $\mathrm{P}=$ Compressive Strength of Cylinder, $\mathrm{f}^{\prime} \mathrm{e}=$

\section{TRIAL 3 - BROWN PIGMENT}

Maximum Load Before Crushing, $\mathrm{P}=$ Compressive Strength of Cylinder, $\mathrm{f}^{\mathrm{e}}=$

lb psi

\section{$O K$}

Measured in Lab

$\mathrm{f}^{\prime} \mathrm{e}=\mathrm{P} / \mathrm{A}$

Measured in Lab

$\mathrm{f}^{\prime} \mathrm{e}=\mathrm{P} / \mathrm{A}$

\section{TRIAL 4 - RED PIGMENT}

Maximum Load Before Crushing, $\mathrm{P}=$

2160

$\mathrm{lb}$

Compressive Strength of Cylinder, $\mathrm{f}^{\prime} \mathrm{e}=$

306 psi

$O K$

Measured in Lab

$\mathrm{f}^{\prime} \mathrm{e}=\mathrm{P} / \mathrm{A}$

\section{TABULATED RESULTS}

Trial

f'e (psi)

\begin{tabular}{|c|c|c|c|}
\hline 1 & 2 & 3 & 4 \\
\hline 287 & 205 & 228 & 306 \\
\hline
\end{tabular}

\section{SUMMARY OF RESULTS}

Minimum Compressive Strength, $f^{\prime} \mathbf{e}=$ Average Compressive Strength, $\mathrm{f}^{\prime} \mathrm{e}=$

\begin{tabular}{|l|}
\hline$O K$ \\
\hline$O K$ \\
\hline
\end{tabular}

$\mathrm{f}^{\prime} \mathrm{e}>\mathrm{f}$ 'e_min

f'e $>$ f'e_min 


\section{APPENDIX D) Photos}

\section{Contents:}

Photos from July 21, 2017 Pg. 1

Photos from October 22, 2017 Pg. 12

Photos from January 8, 2018 Pg. 19

Photos from February 28, 2018 Pg. 24 


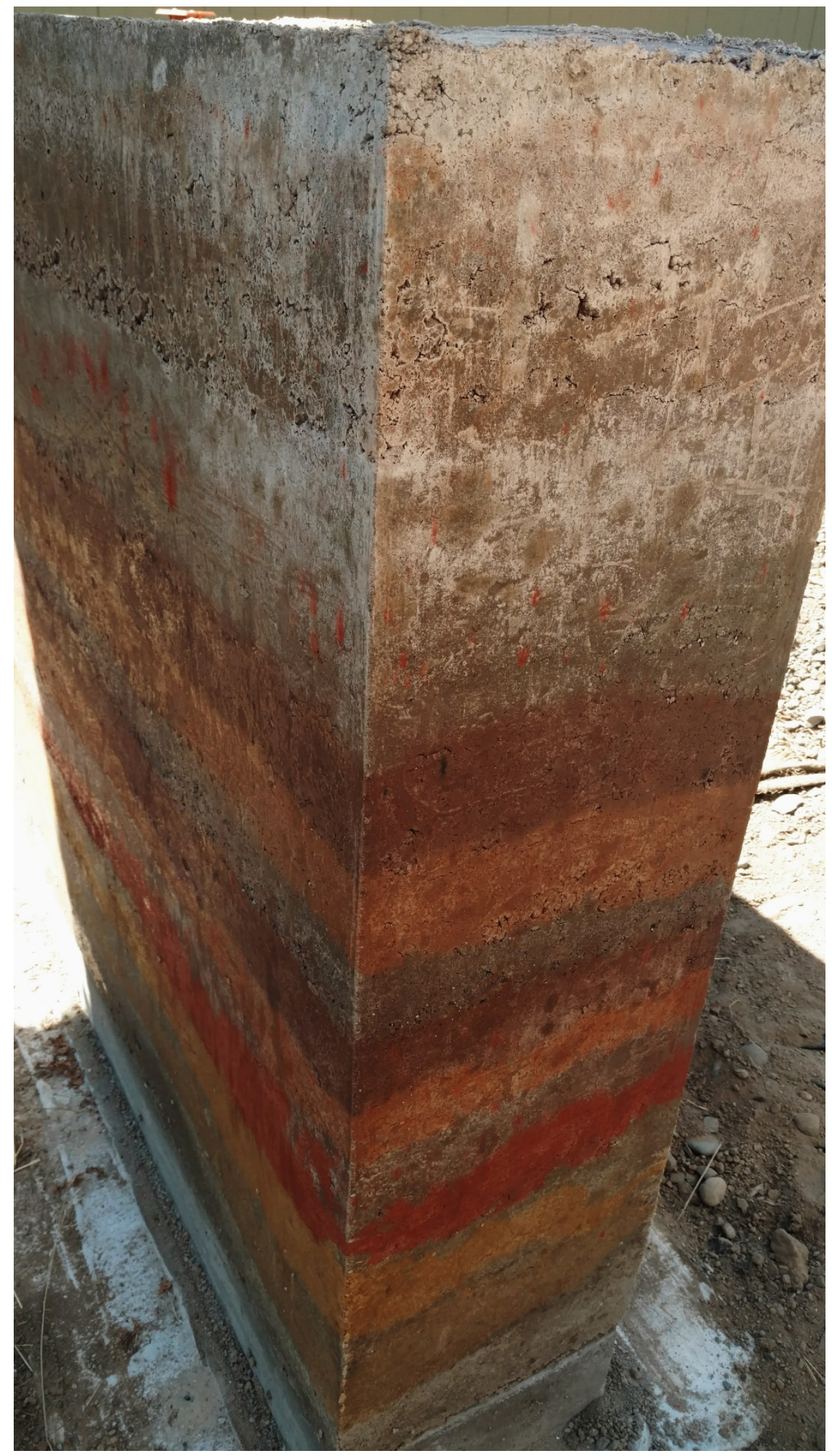

7/21/17 - Looking at Southeast Corner

D - 1 


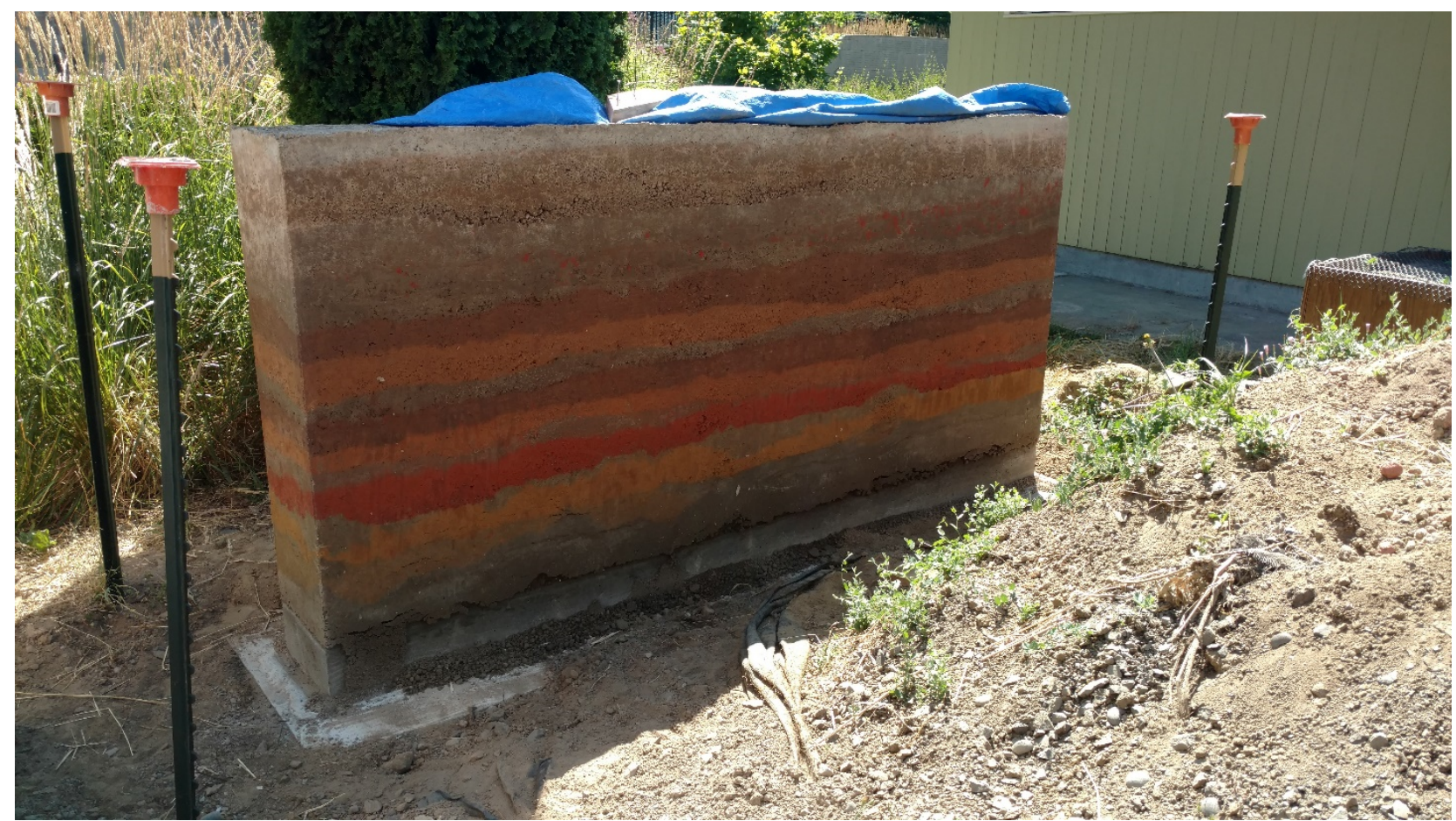

7/21/17 - Looking Southwest

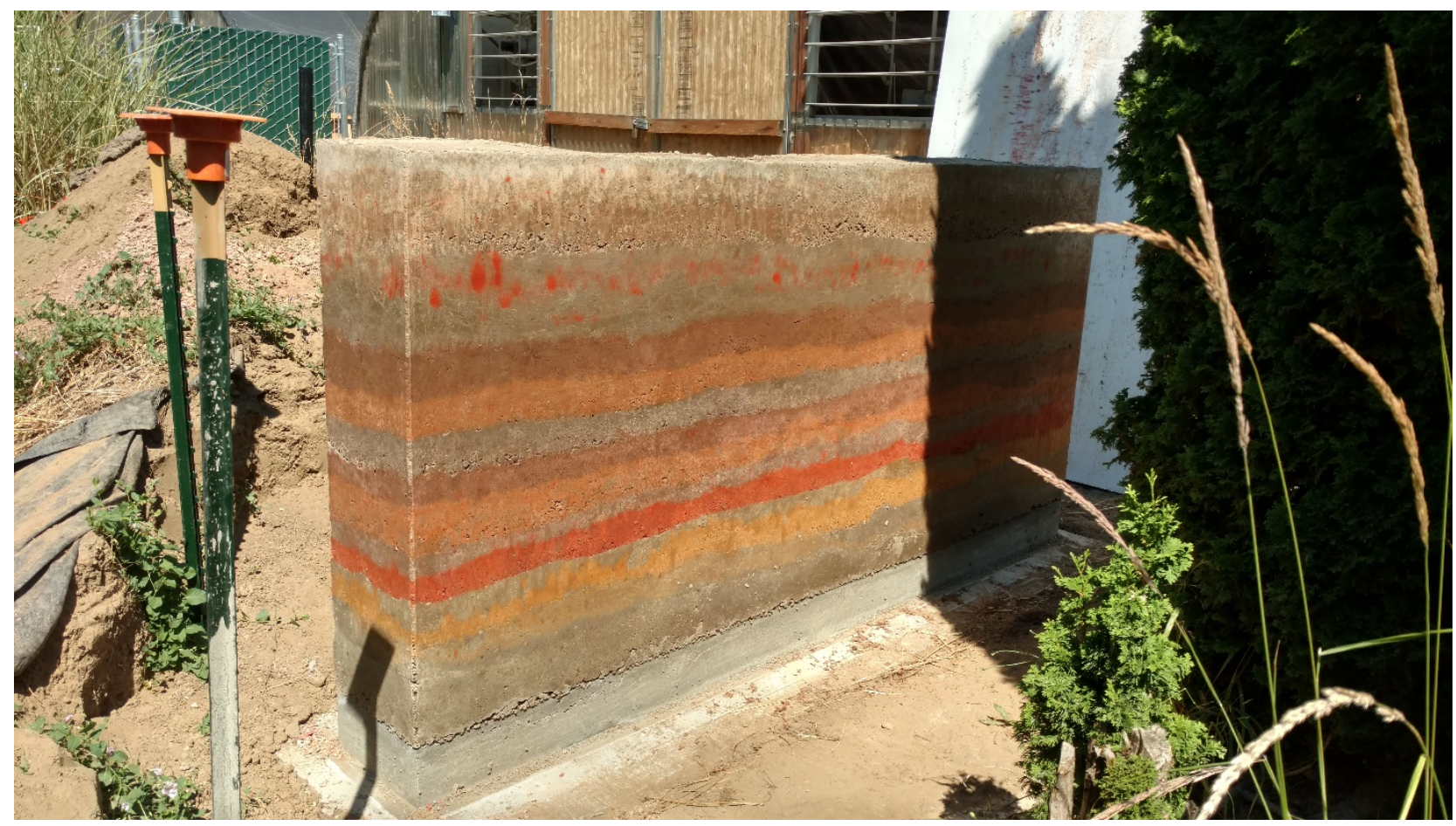

7/21/17 - Looking Northeast 


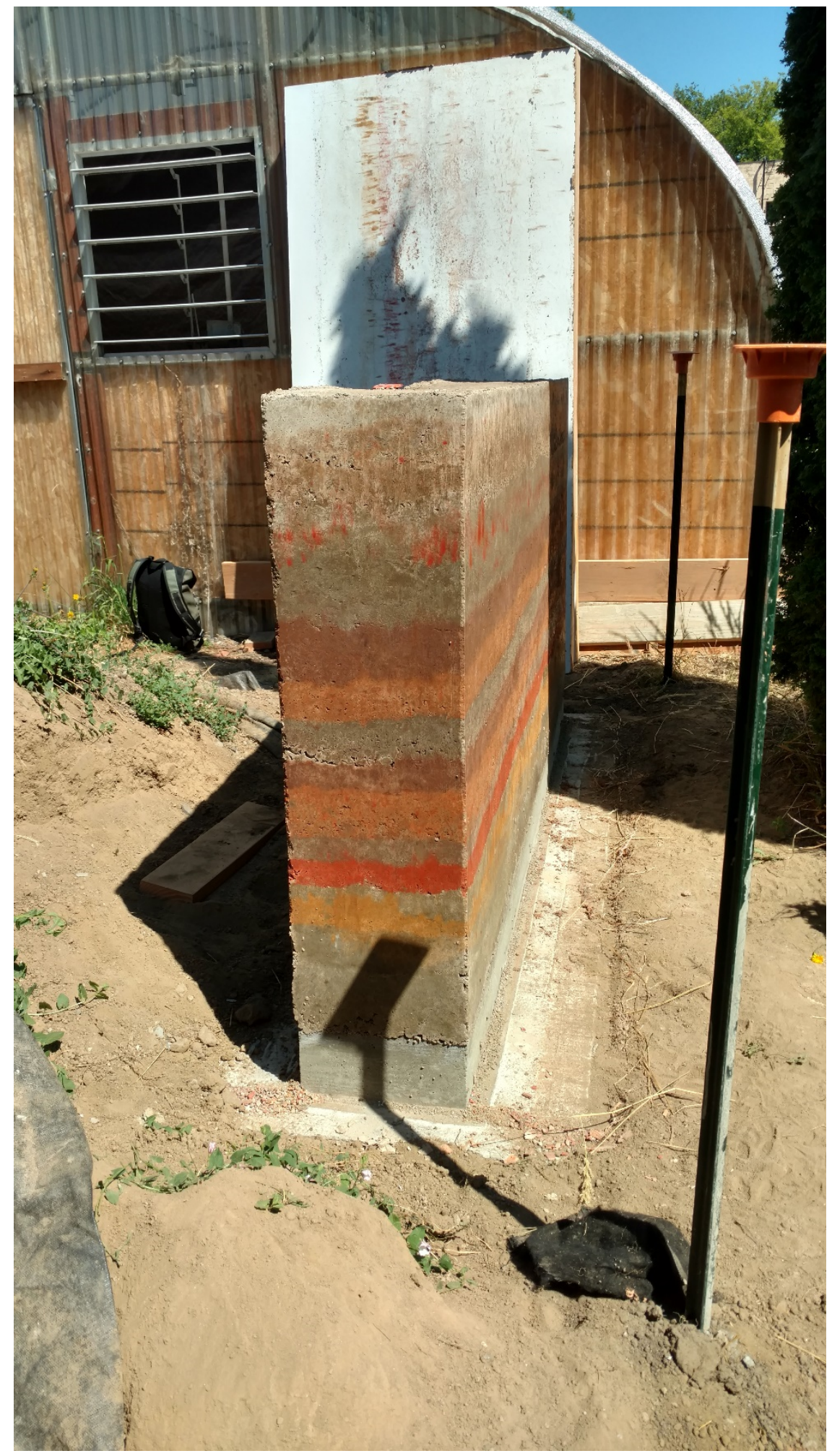

7/21/17 - Looking East 


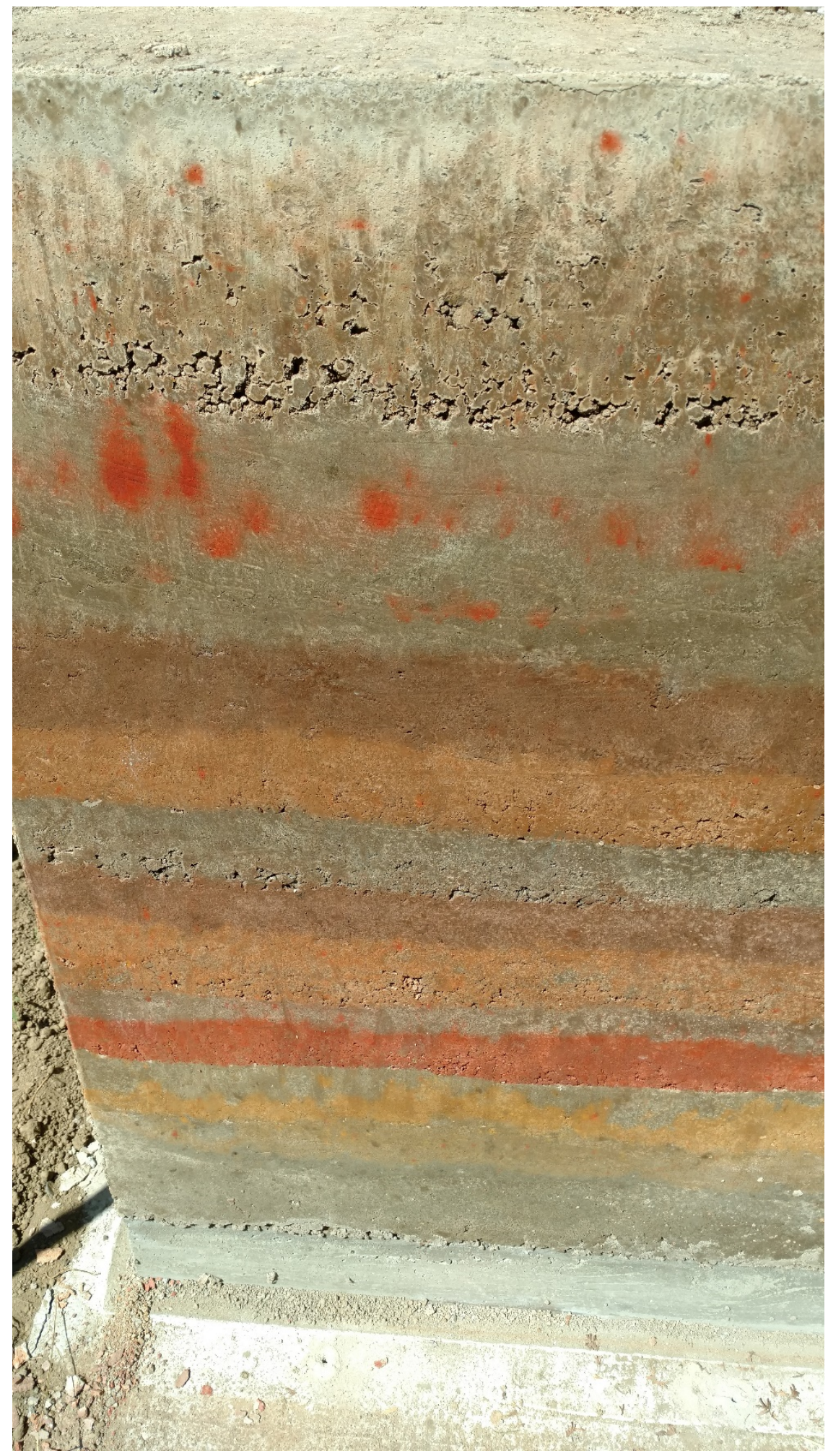

7/21/17 - Looking North at Southwest Side 


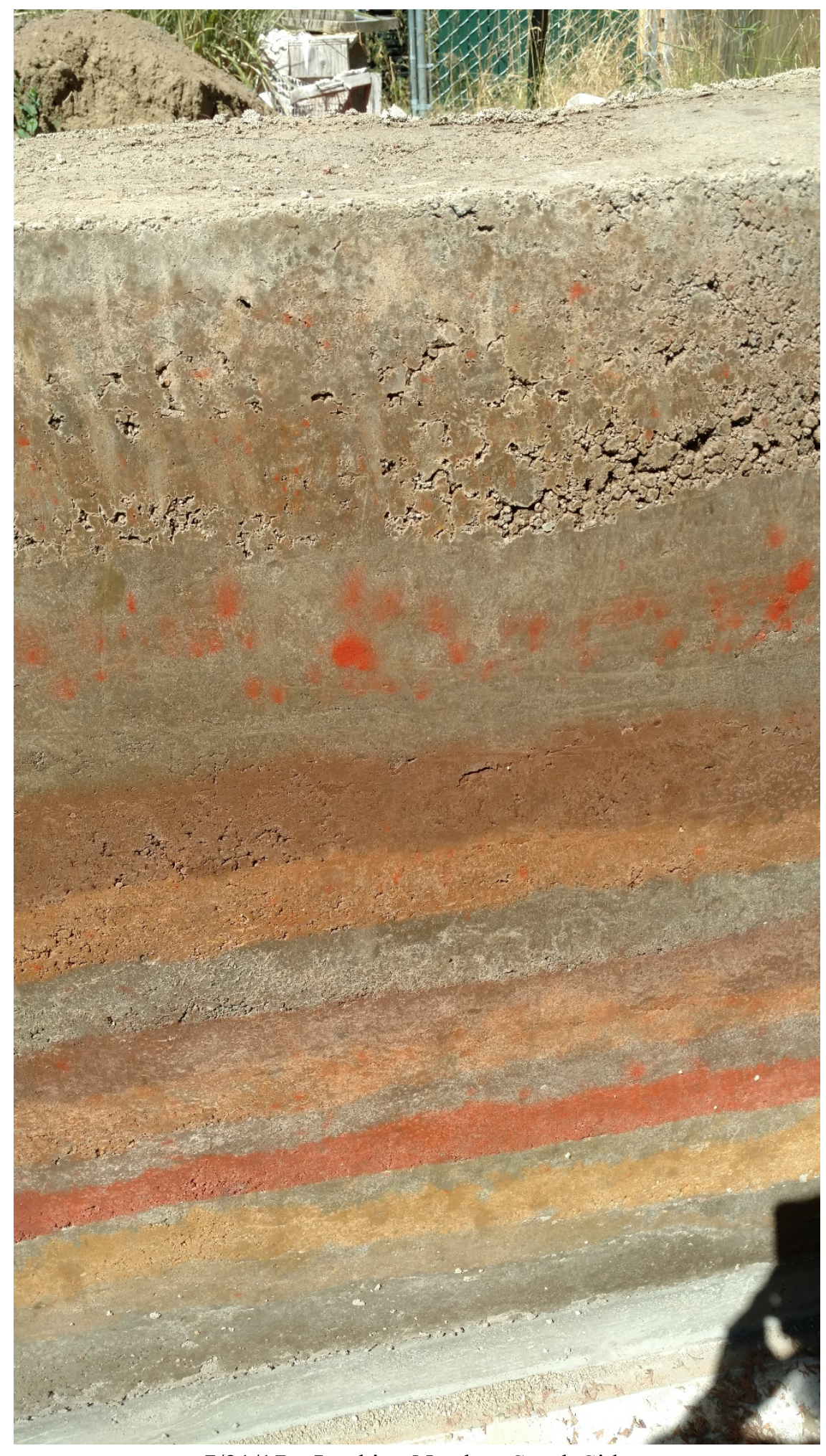

7/21/17 - Looking North at South Side 


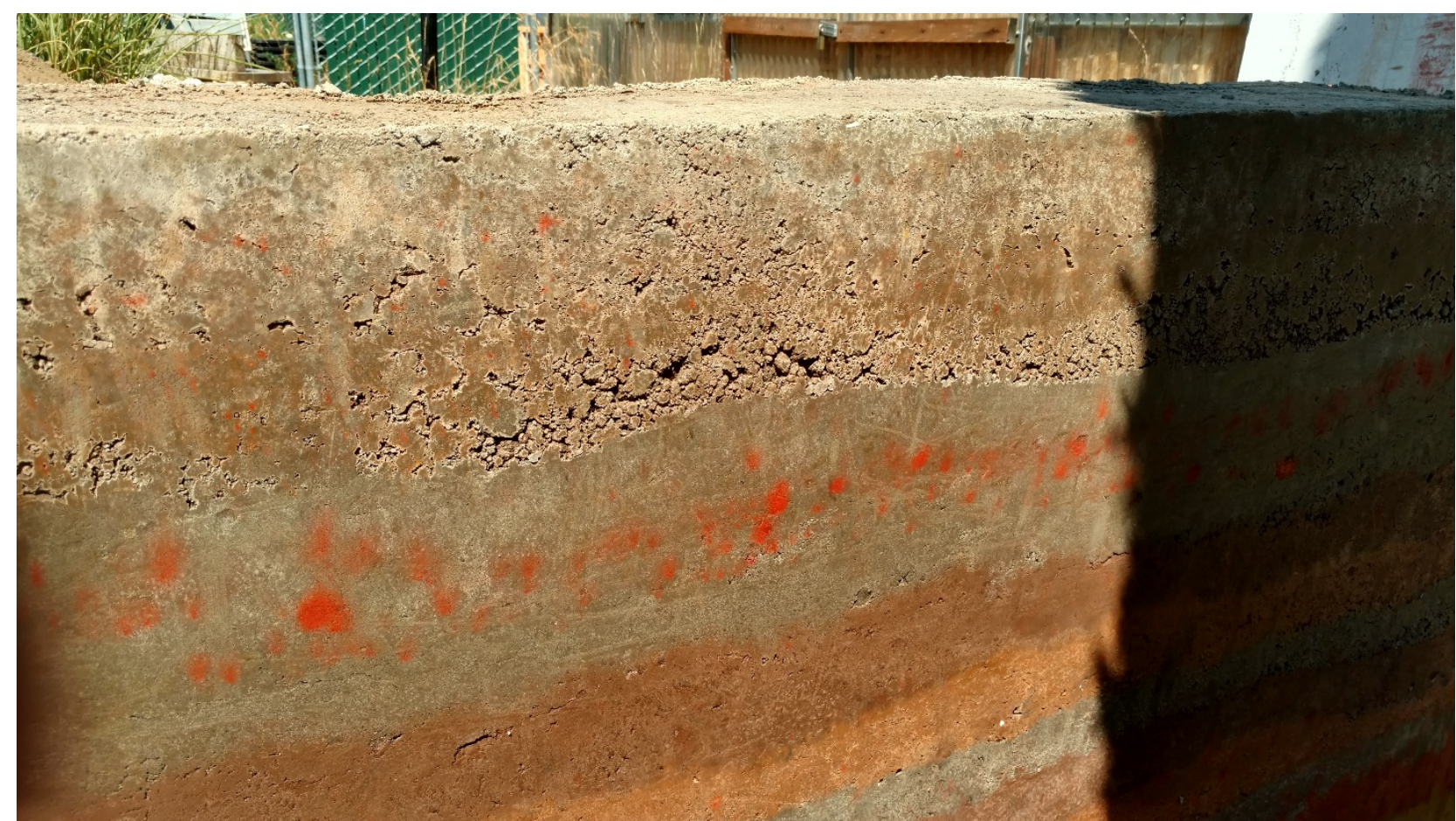

7/21/17 - Looking North at South Side

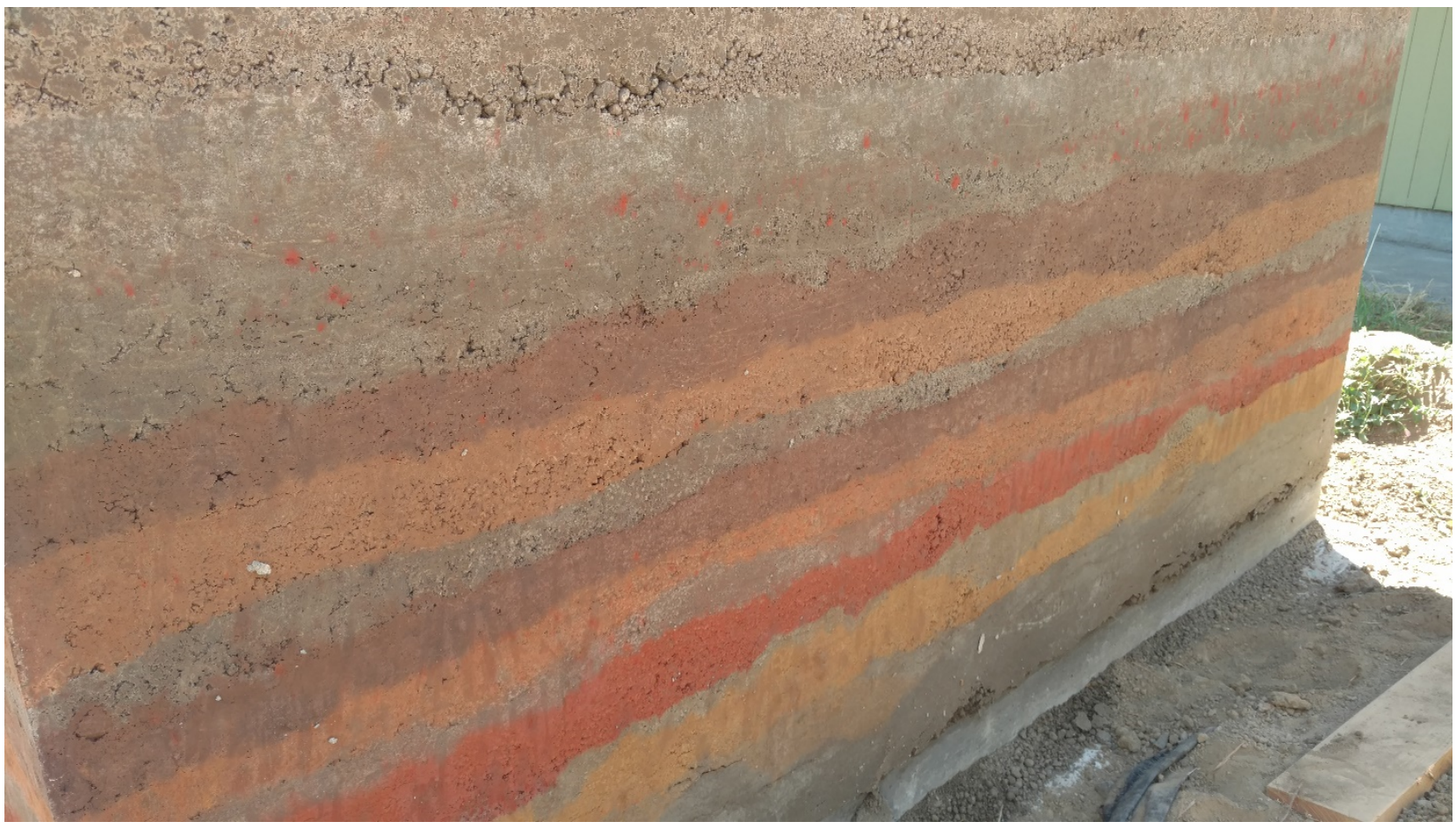

7/21/17 - Looking Southwest at North Side 


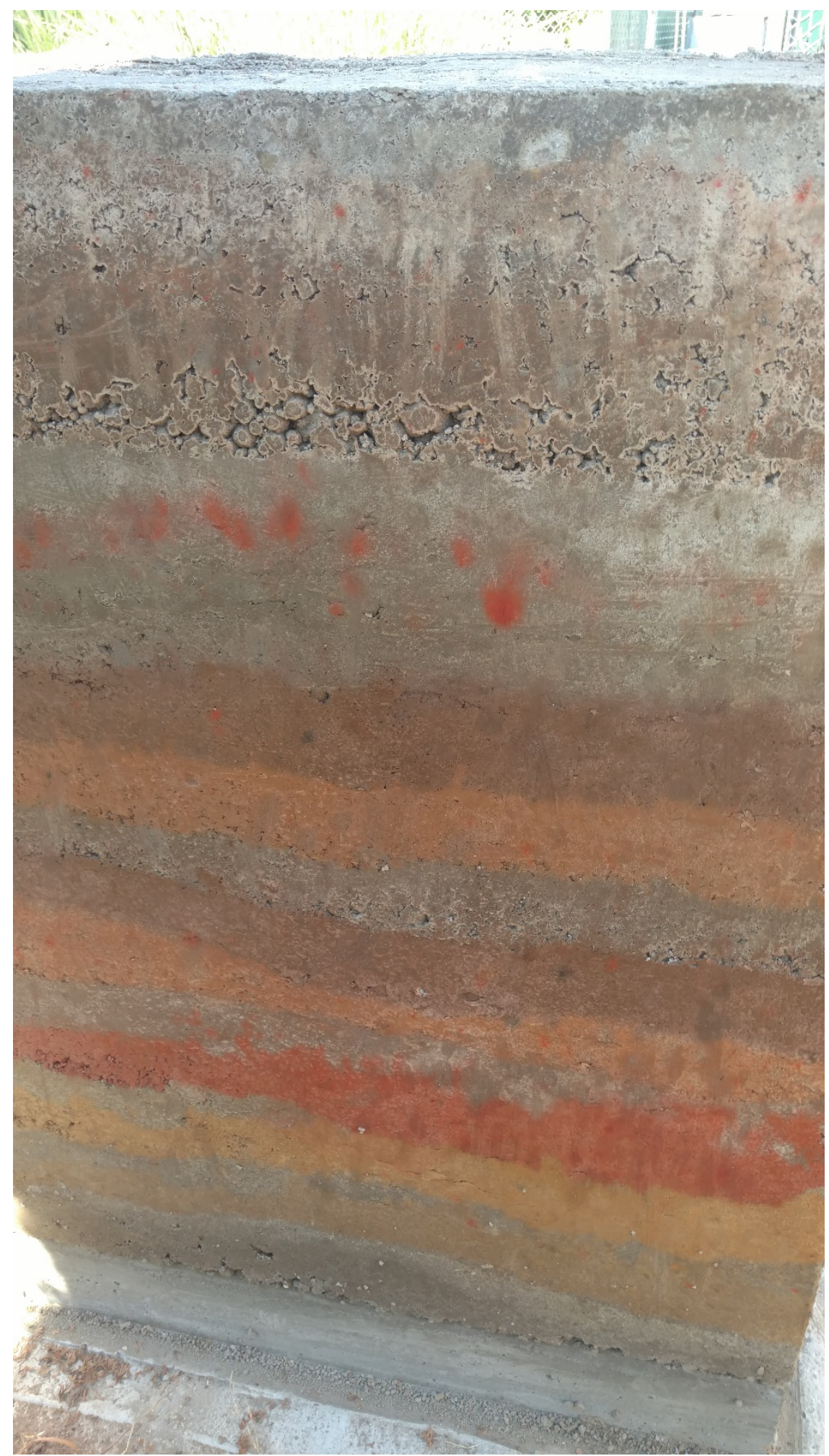

7/21/17 - Looking North at South Side 


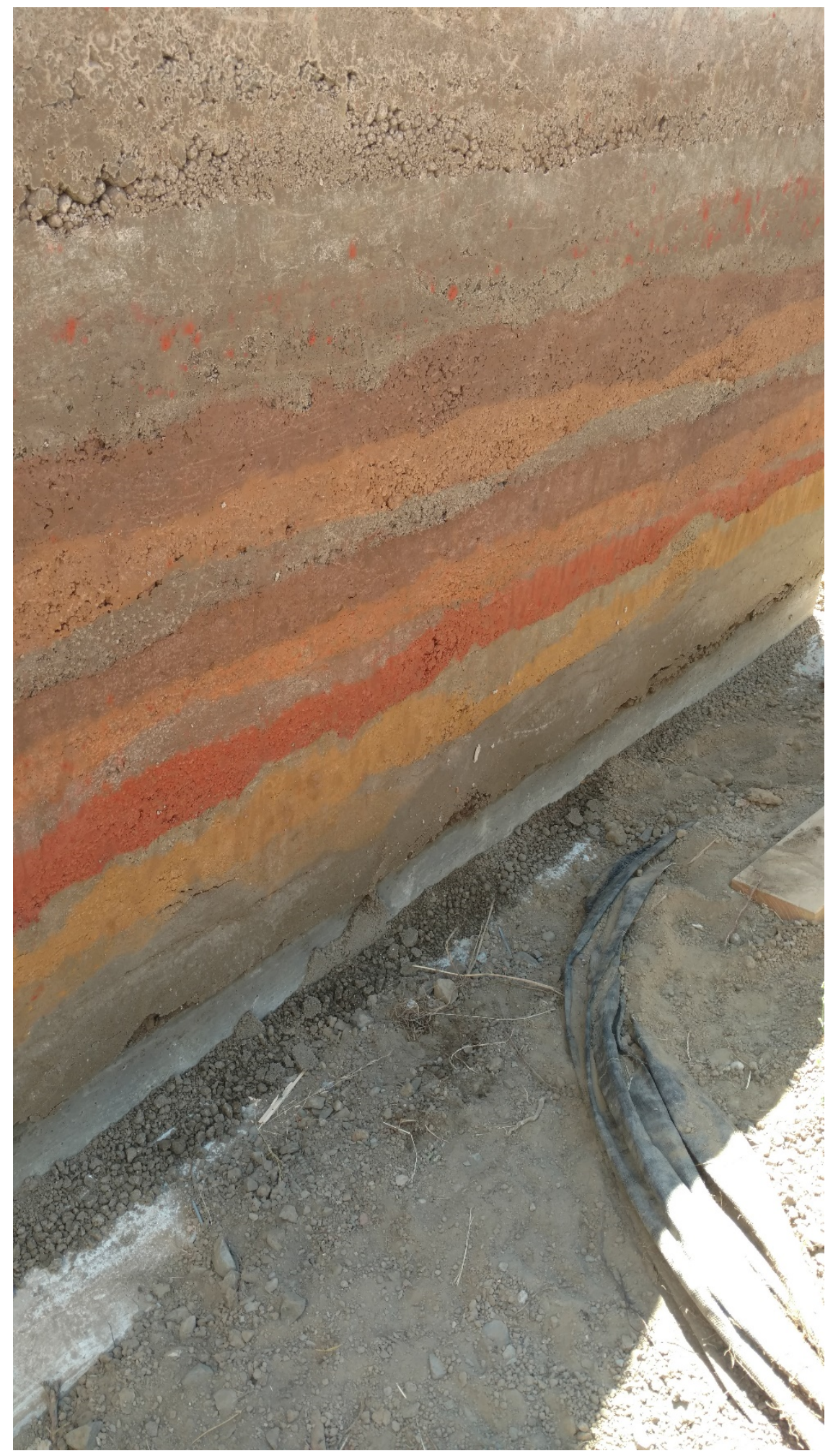

7/21/17 - Looking Southwest

D - 8 


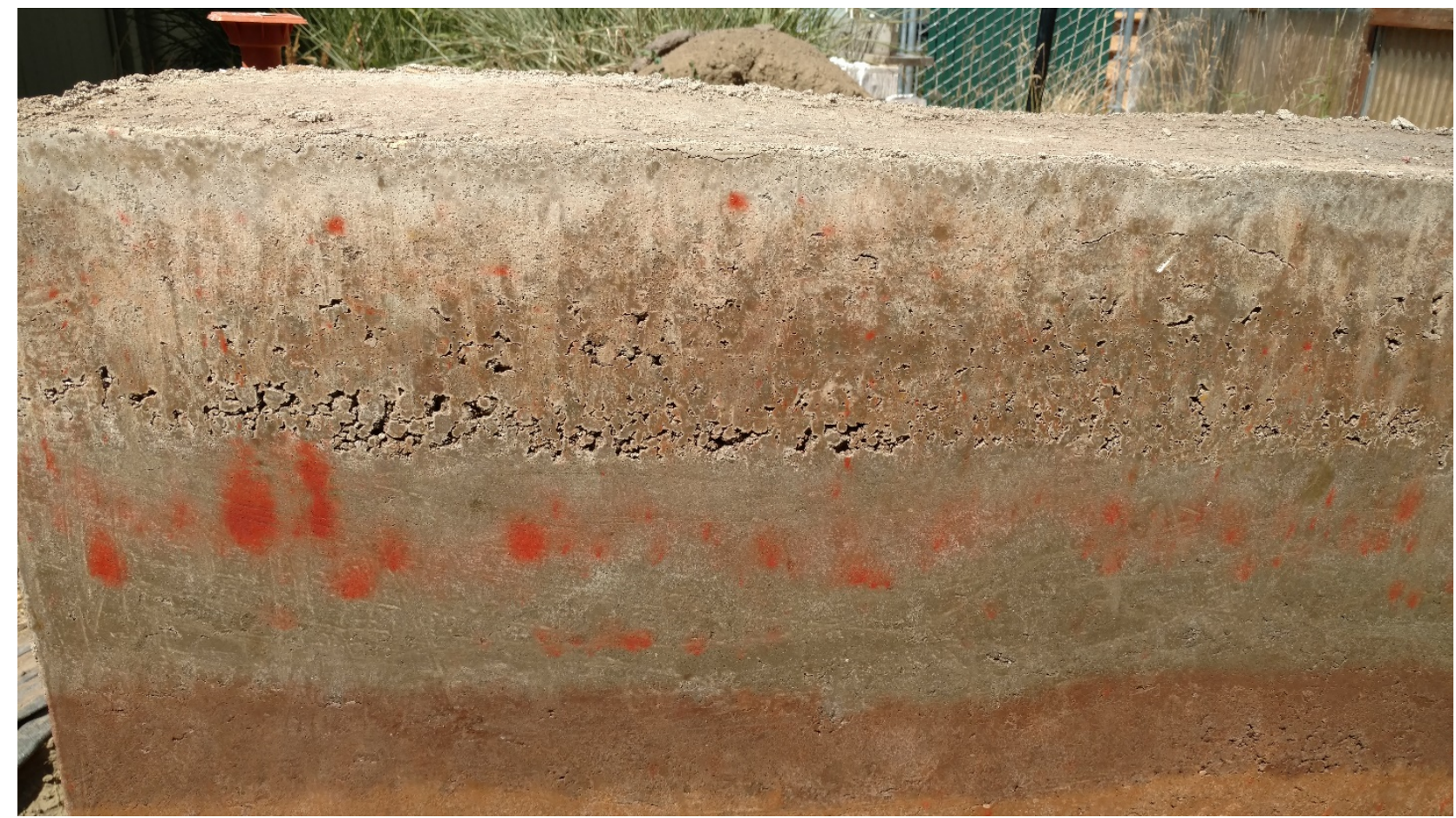

7/21/17 - Looking North at Upper Layer

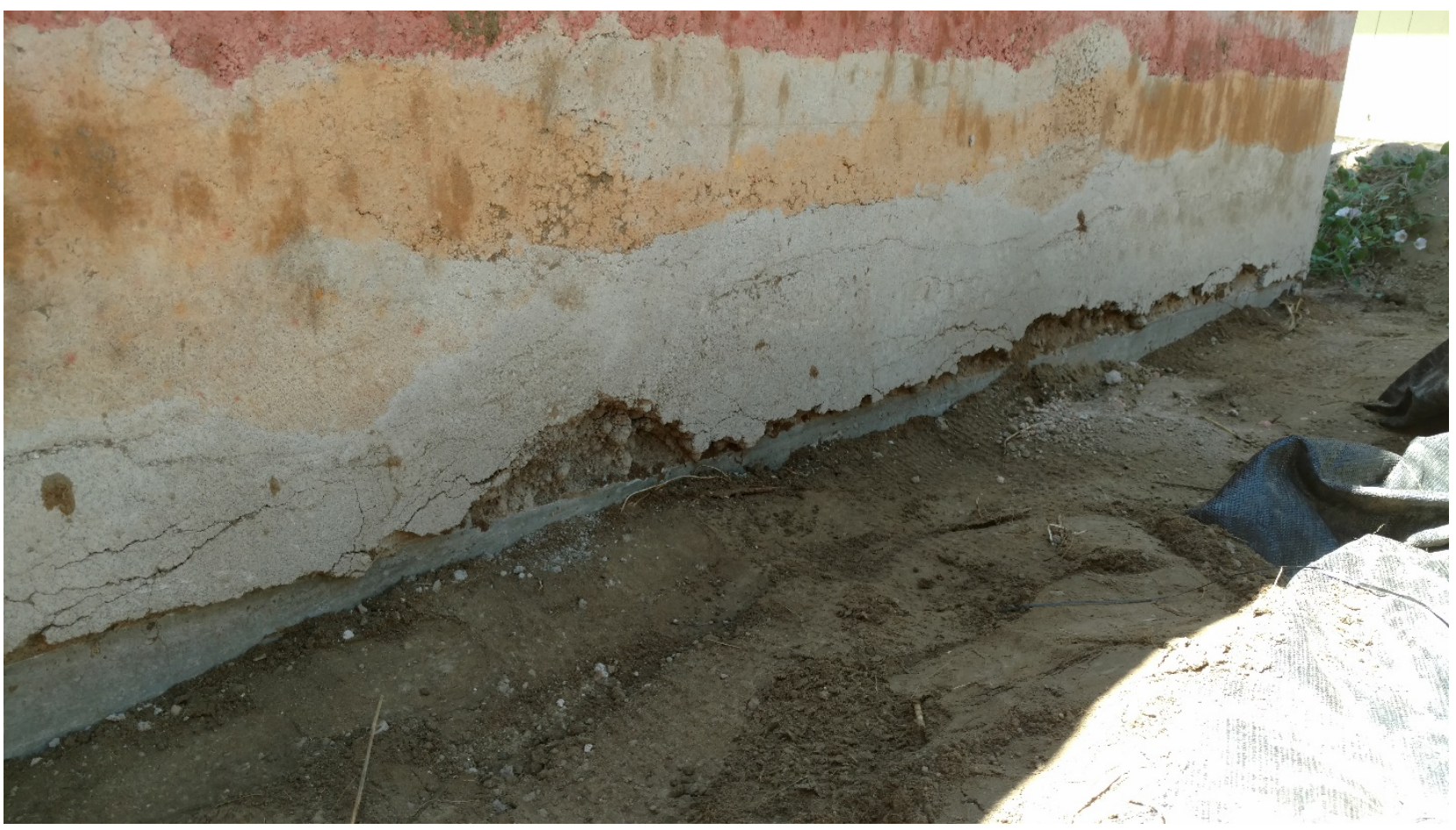

7/21/17 - Looking at Base of North Side 


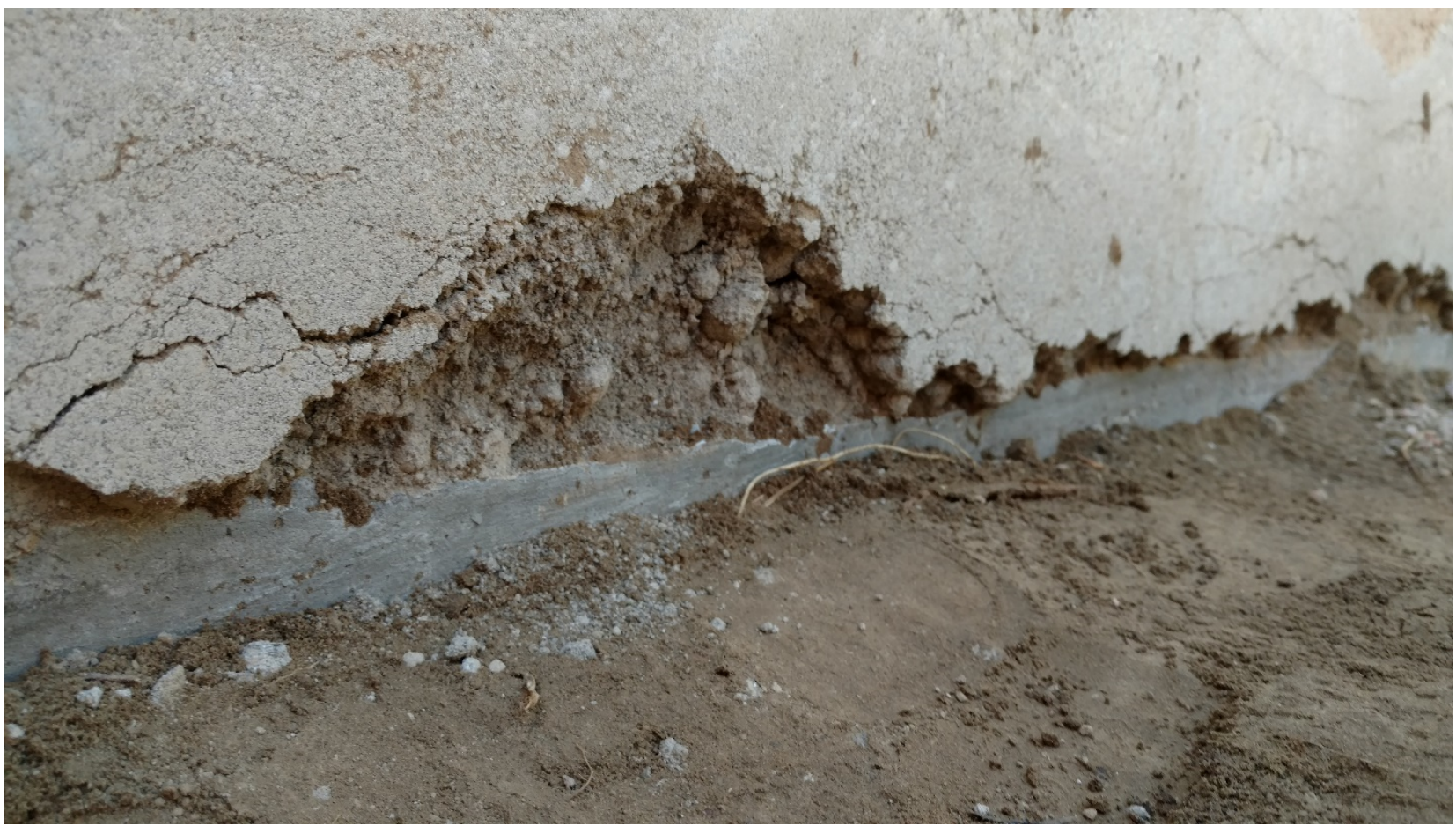

7/21/17 - Close up of Crumbling at Base of North Side

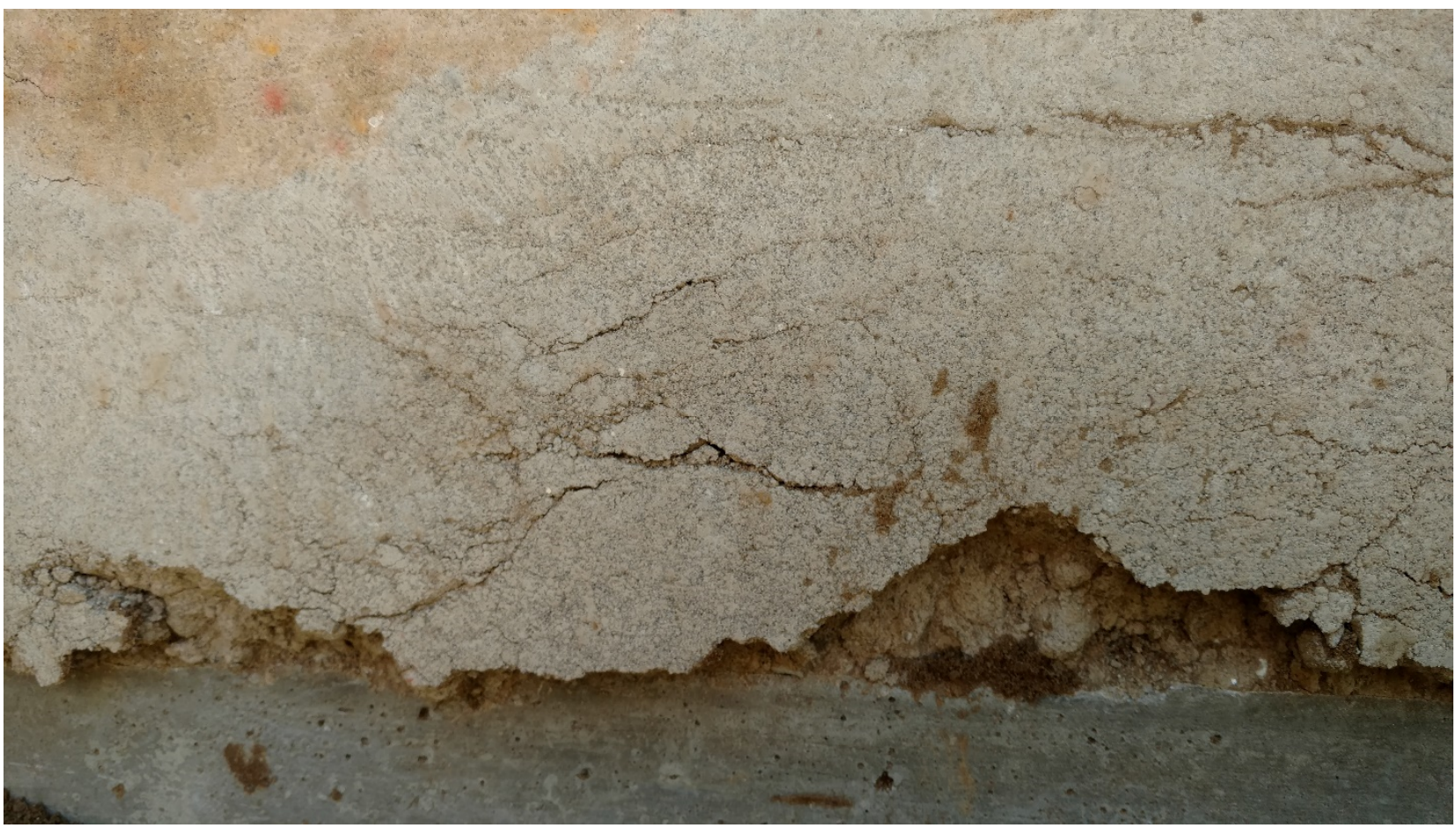

7/21/17 - Close up of Crumbling at Base of North Side 


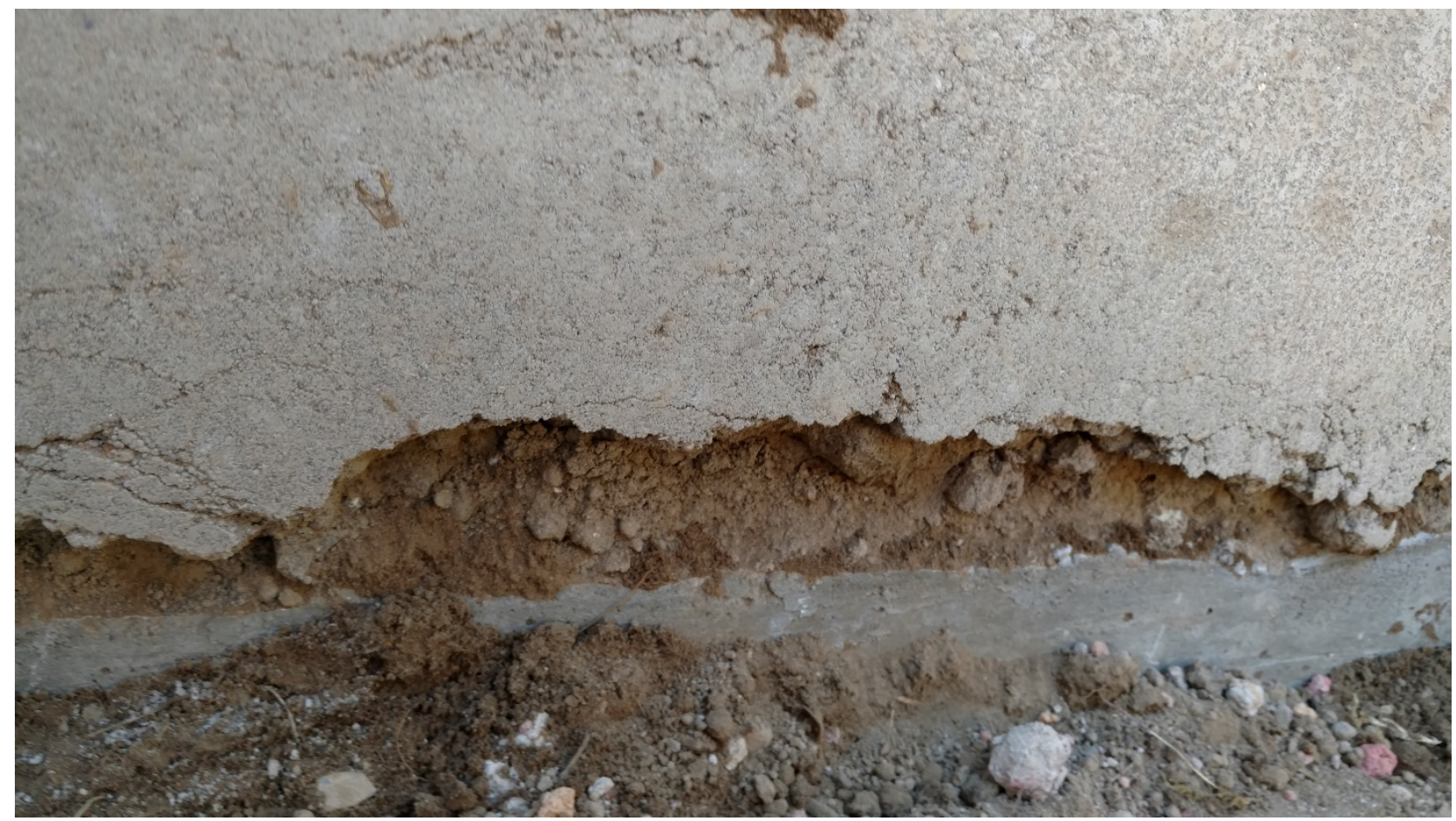

7/21/17 - Close up of Crumbling at Base of North Side

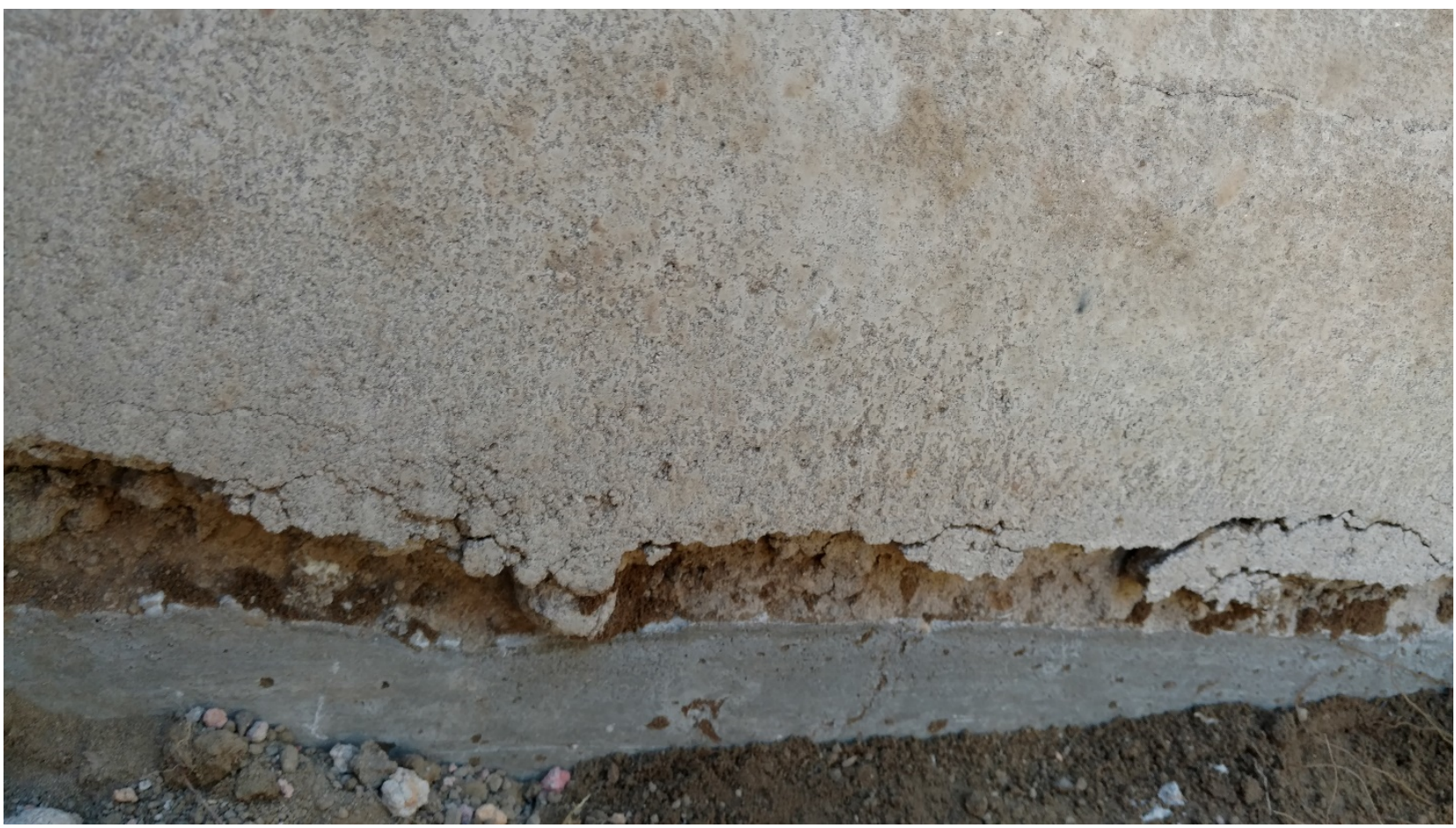

7/21/17 - Close up of Crumbling at Base of North Side 


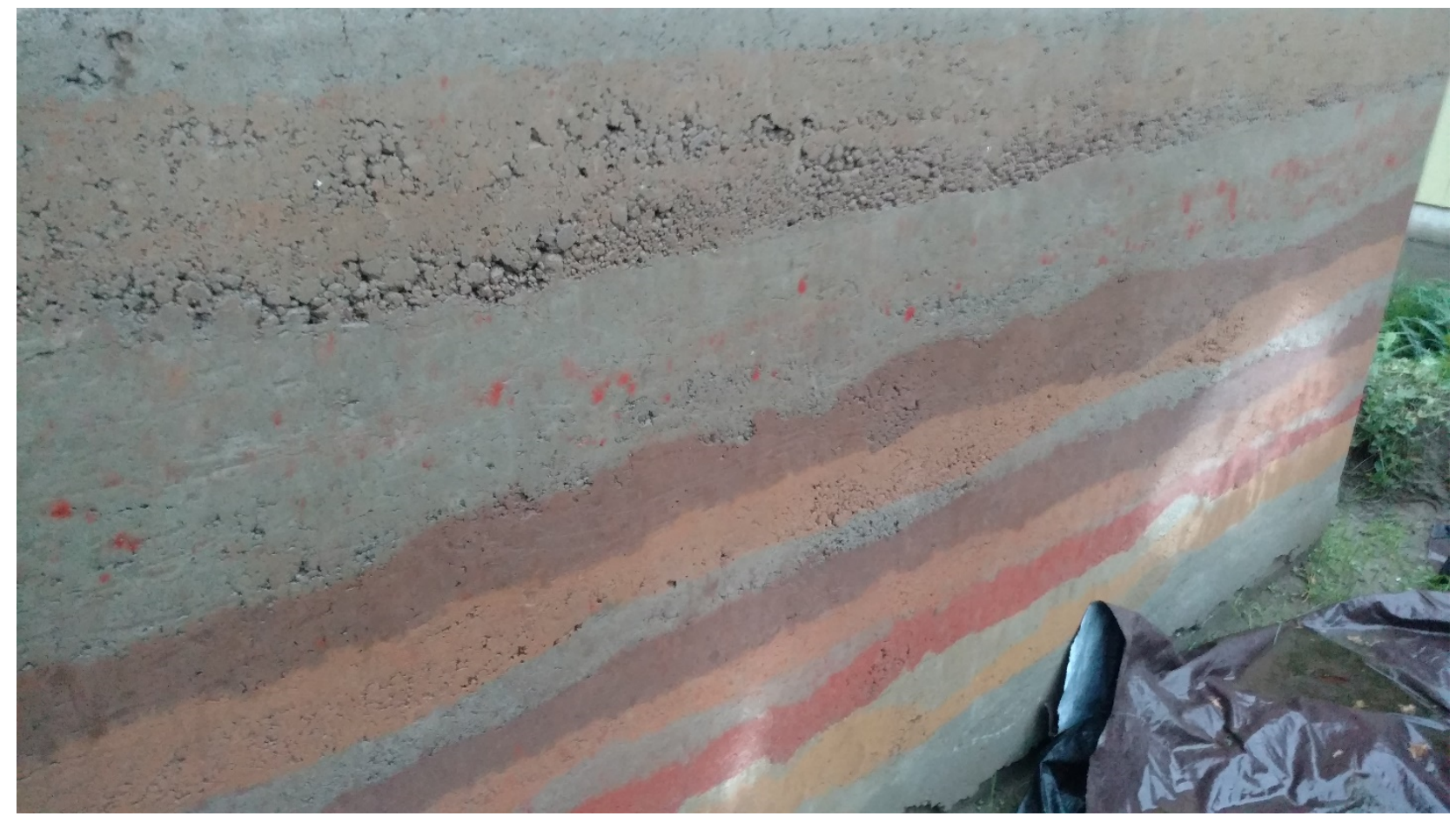

10/22/17 - Looking Southwest at North Side

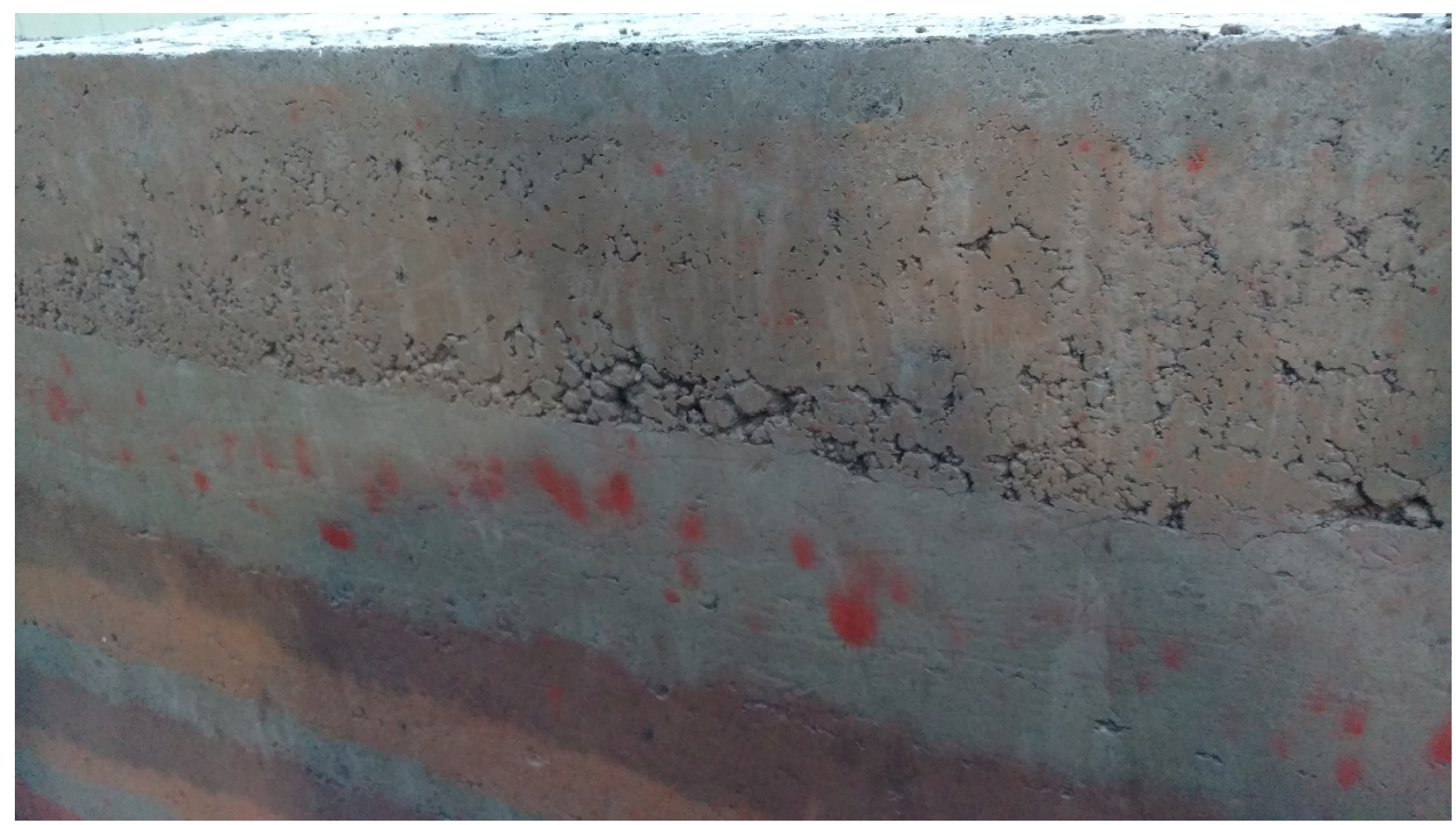

10/22/17 - Close up of Voids in Upper Layer

D - 12 


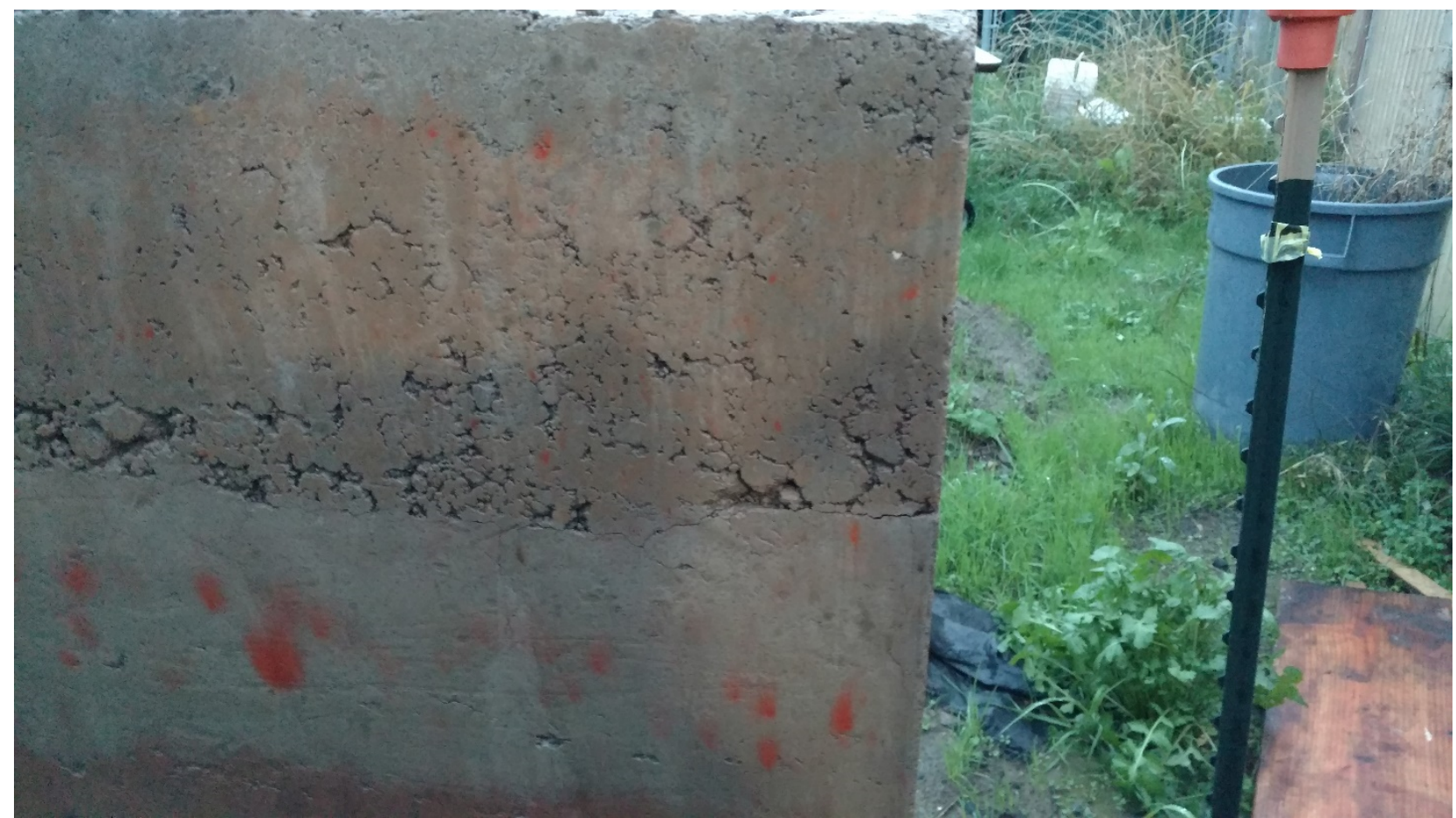

10/22/17 - Looking North at South East Corner Upper Layer

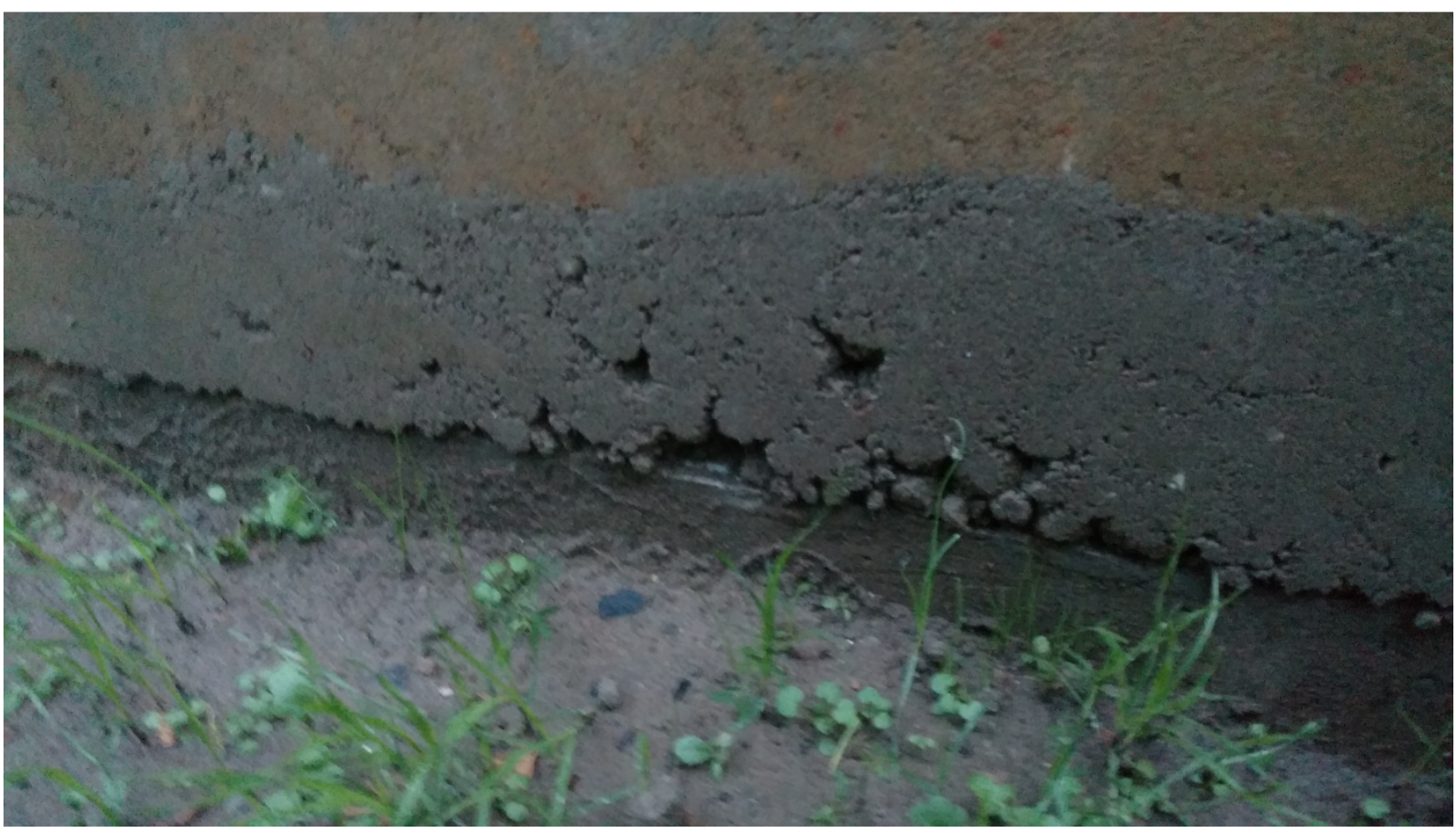

10/22/17 - Close up of Voids at Base of South Side 


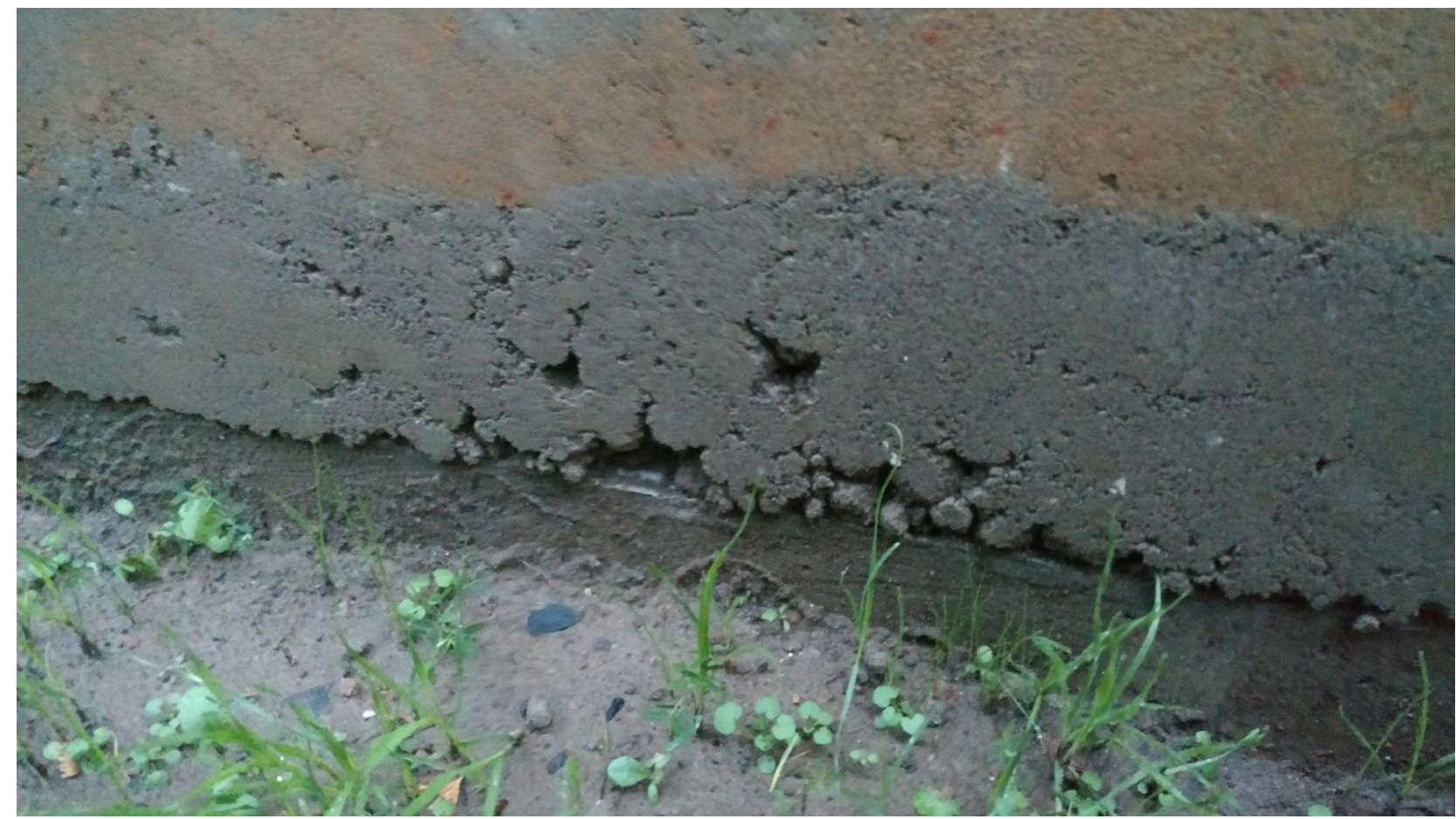

10/22/17 - Close up of Voids at Base of South Side

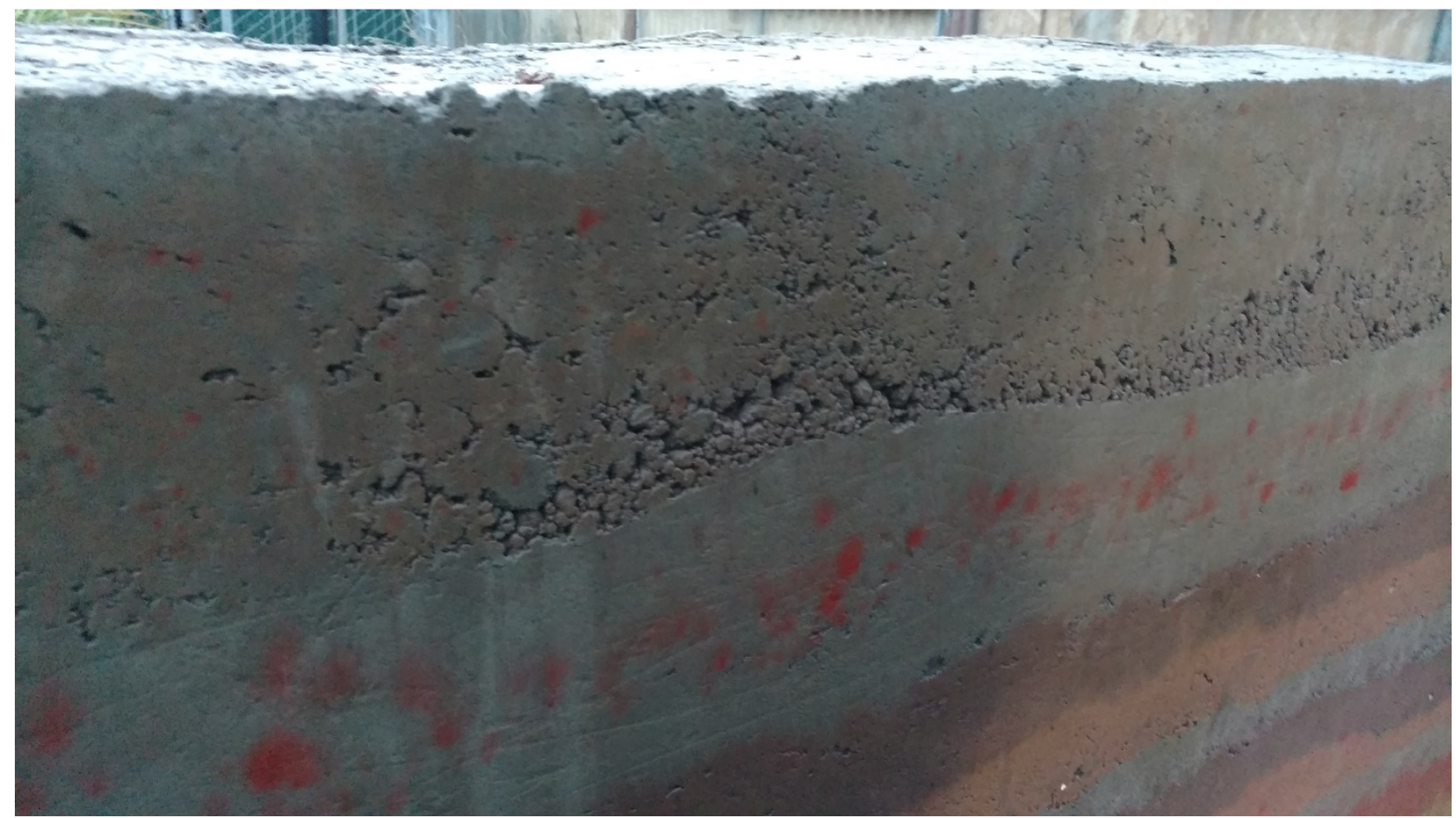

10/22/17 - Looking North at Upper Layer of South Side 


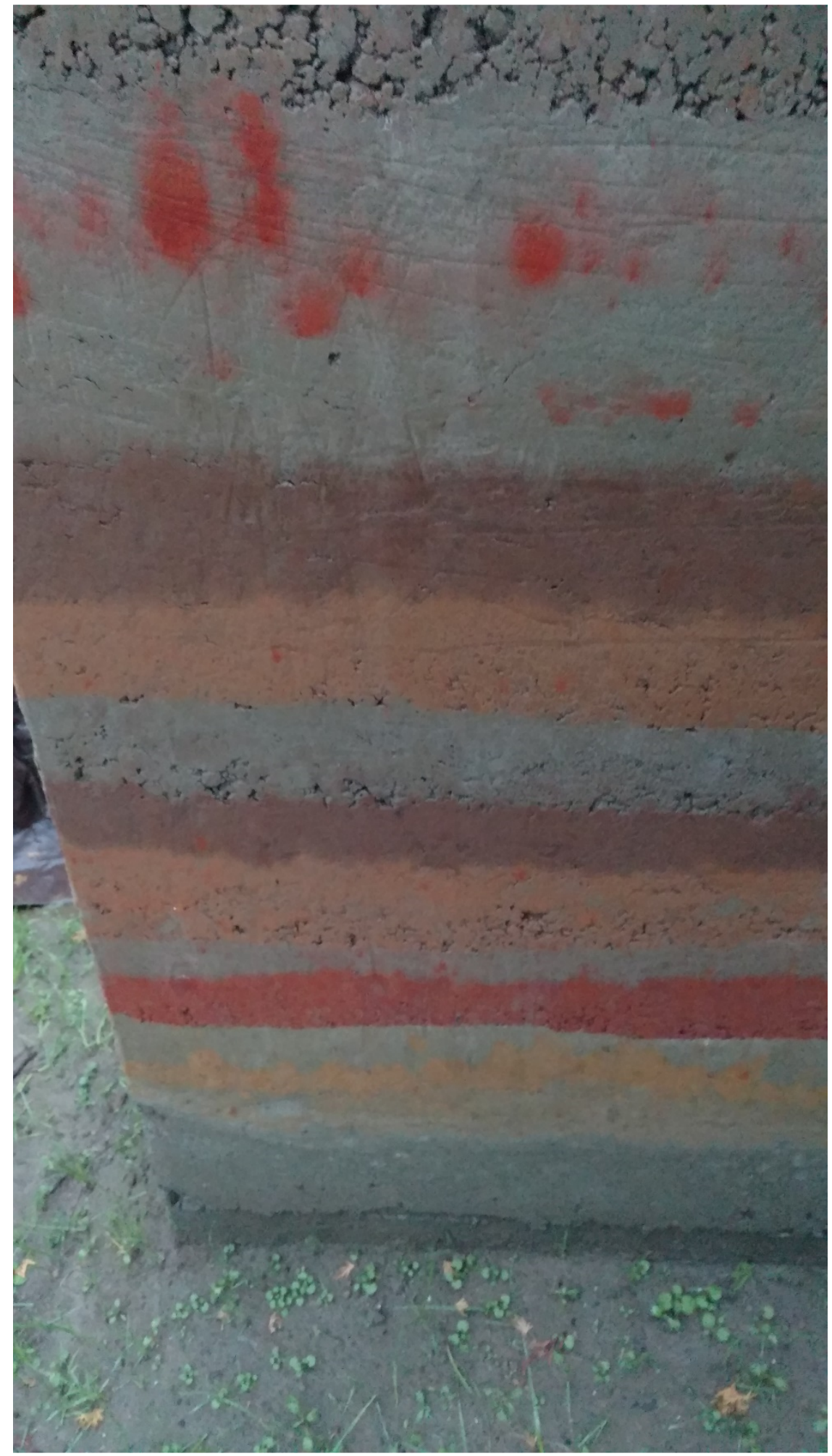

10/22/17 - Looking North at Southwest Side 


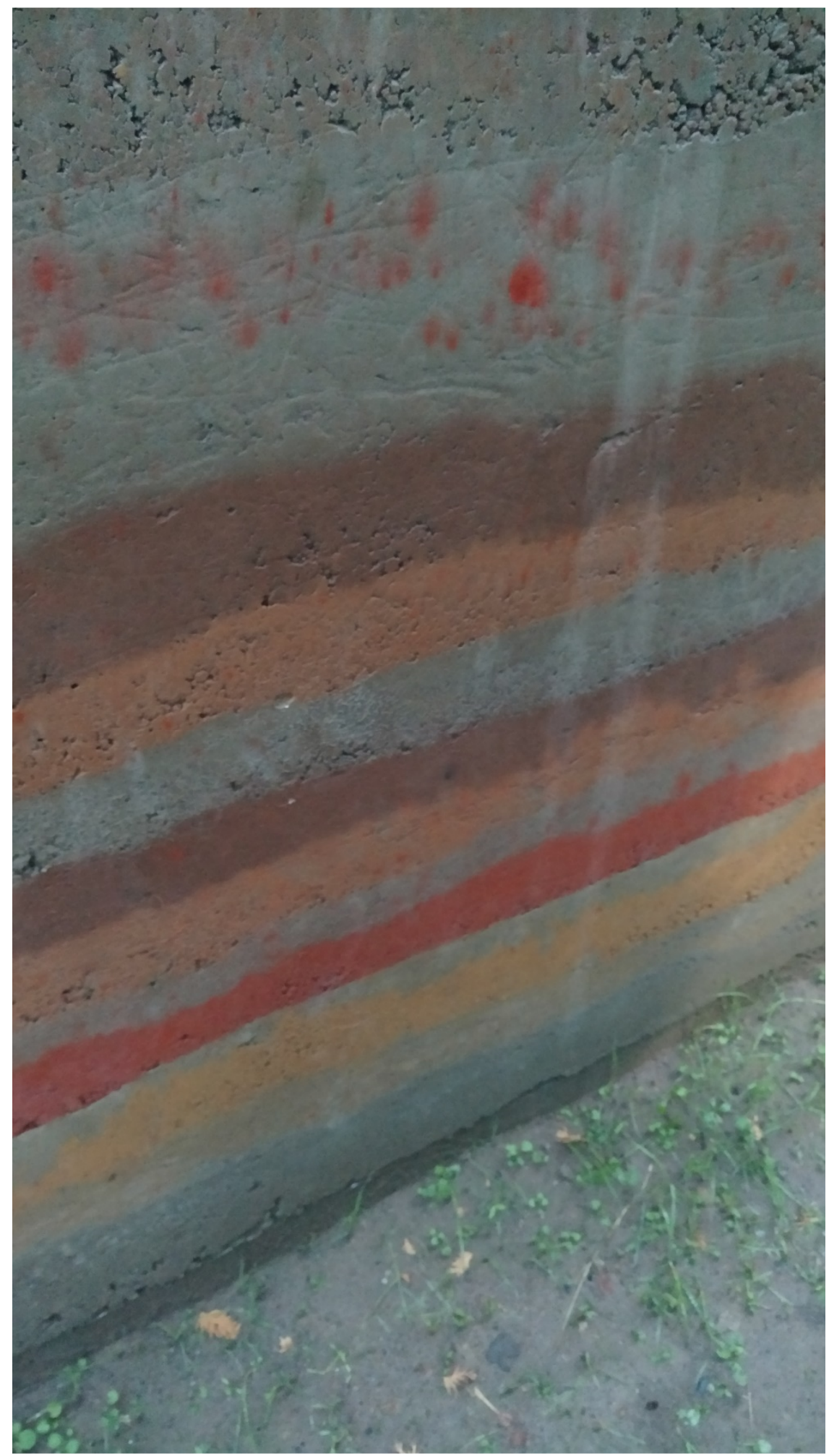

10/22/17 - Looking Northeast at South Side 


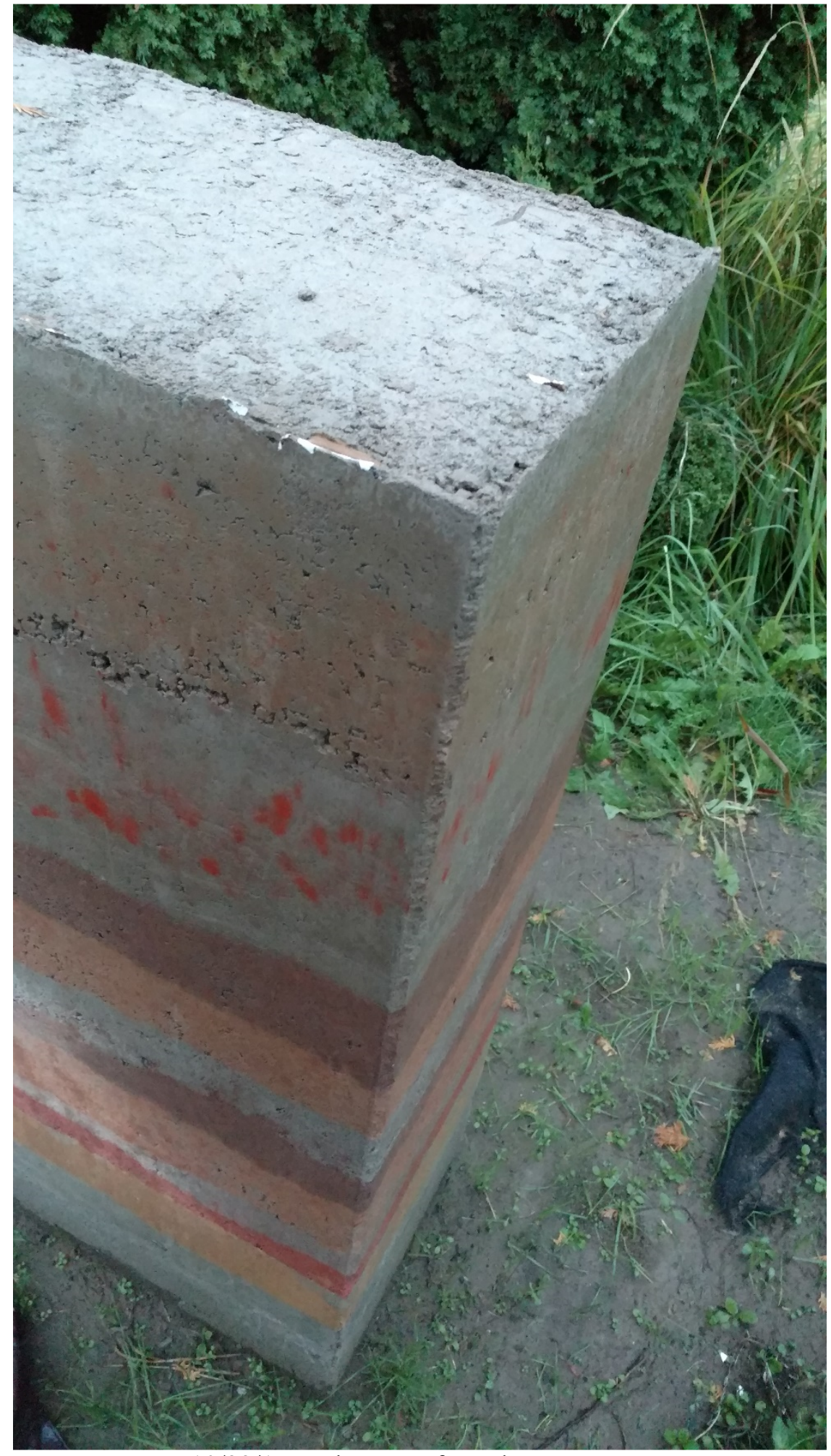

10/22/17 - Close up of Northwest Corner 


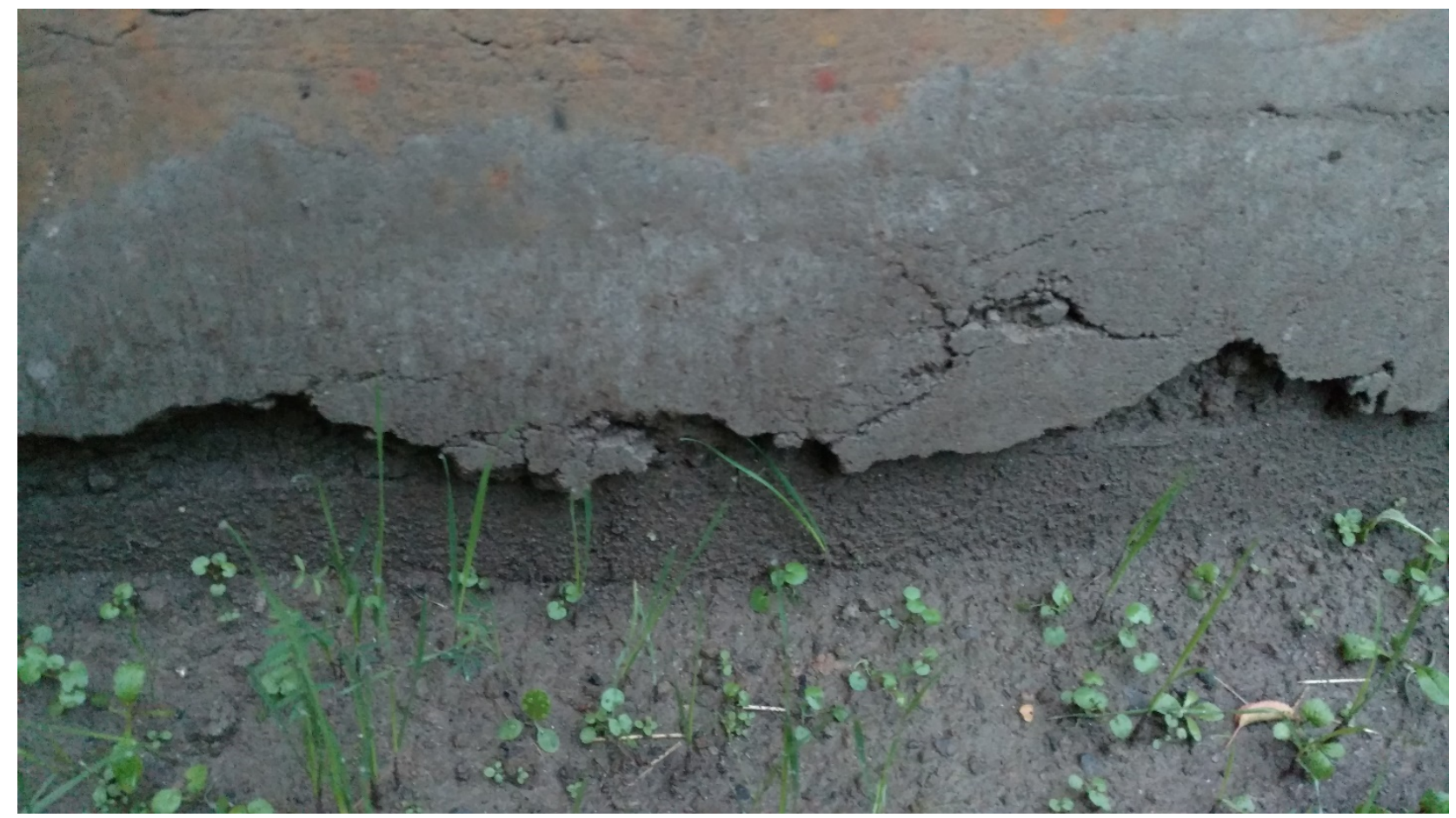

10/22/17 - Close up of Crumbling at Base of North Side

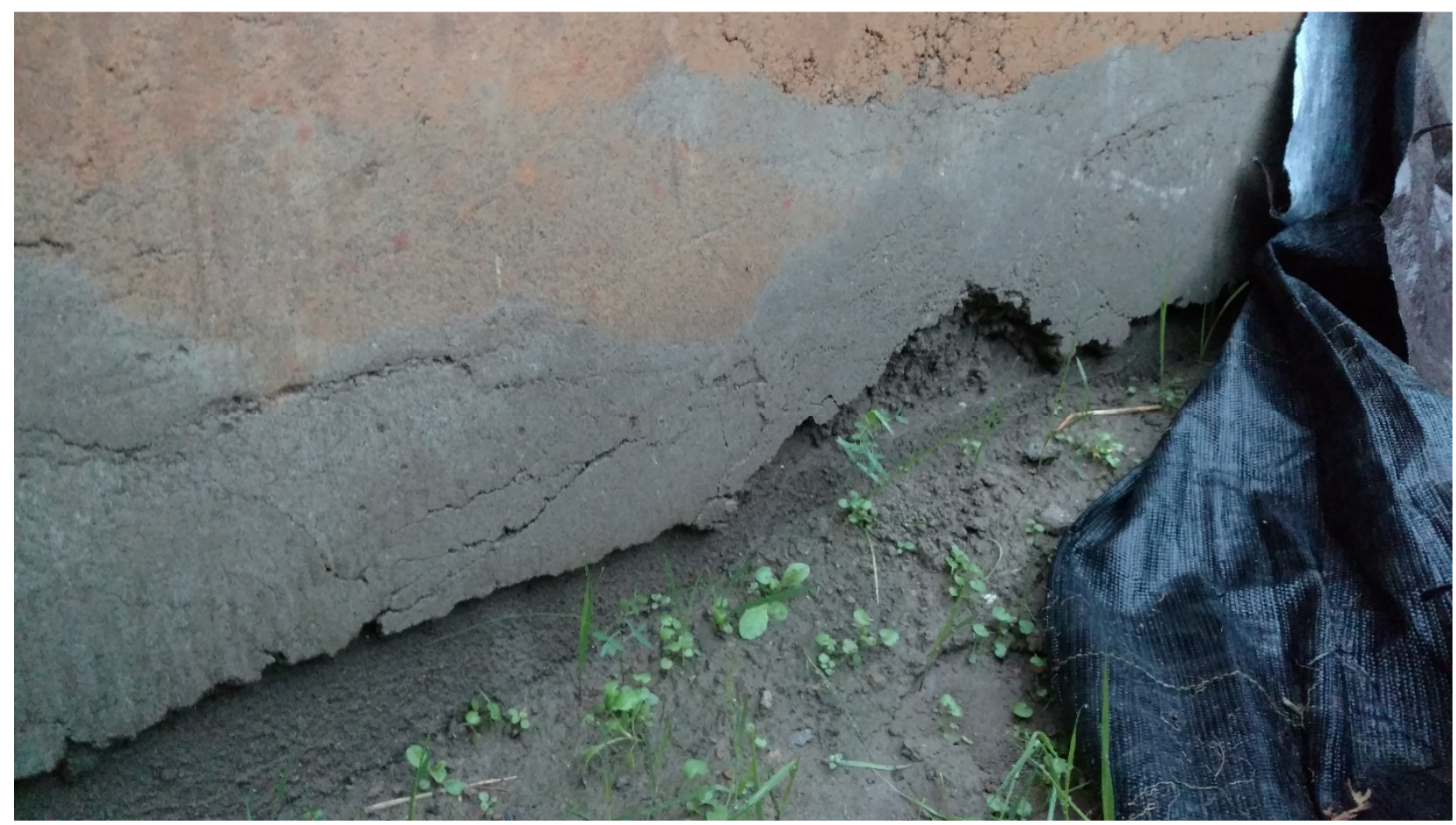

10/22/17 - Close up of Crumbling at Base of North Side 


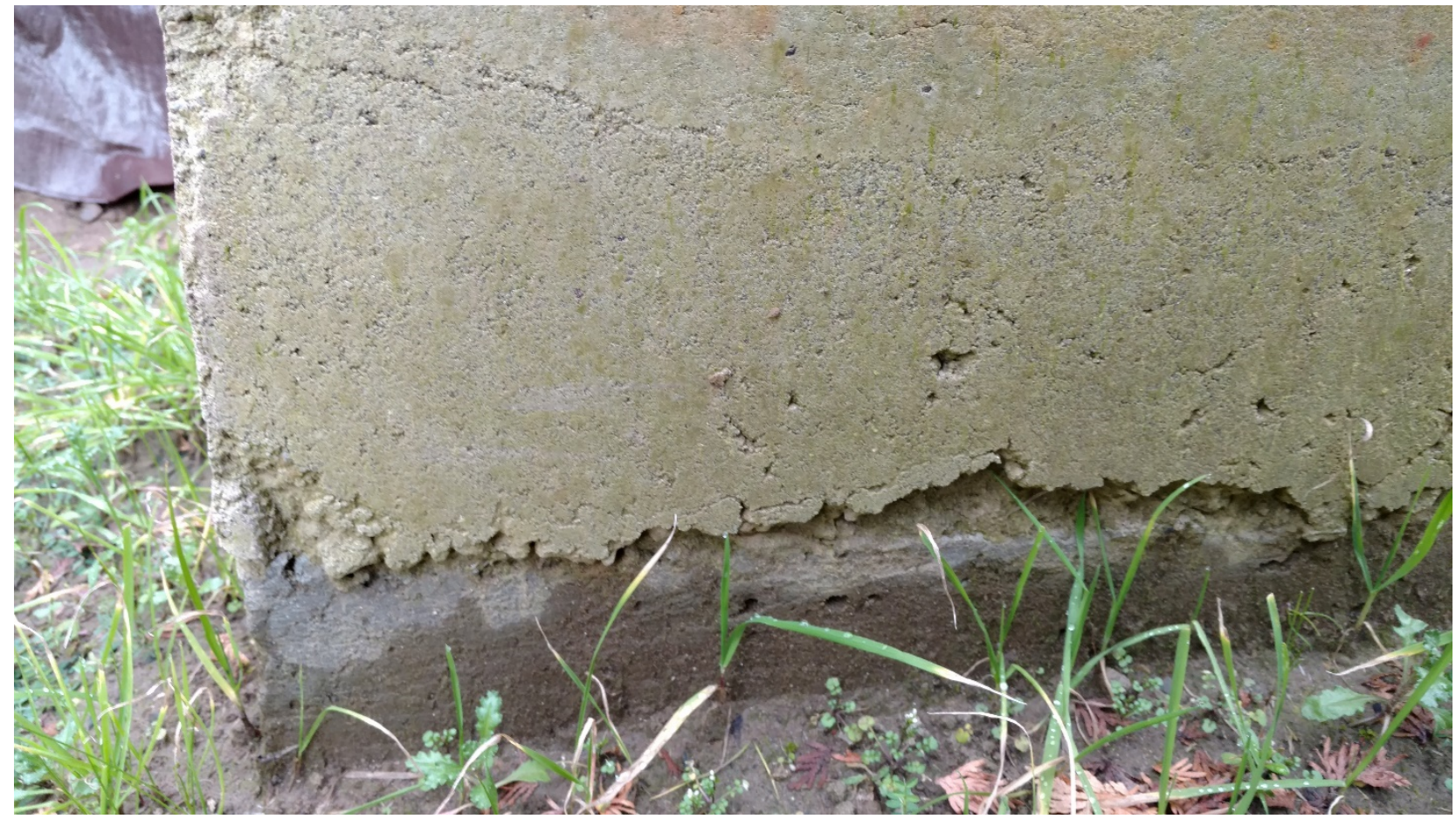

1/8/18 - Close up of Voids at Base on Southwest Corner

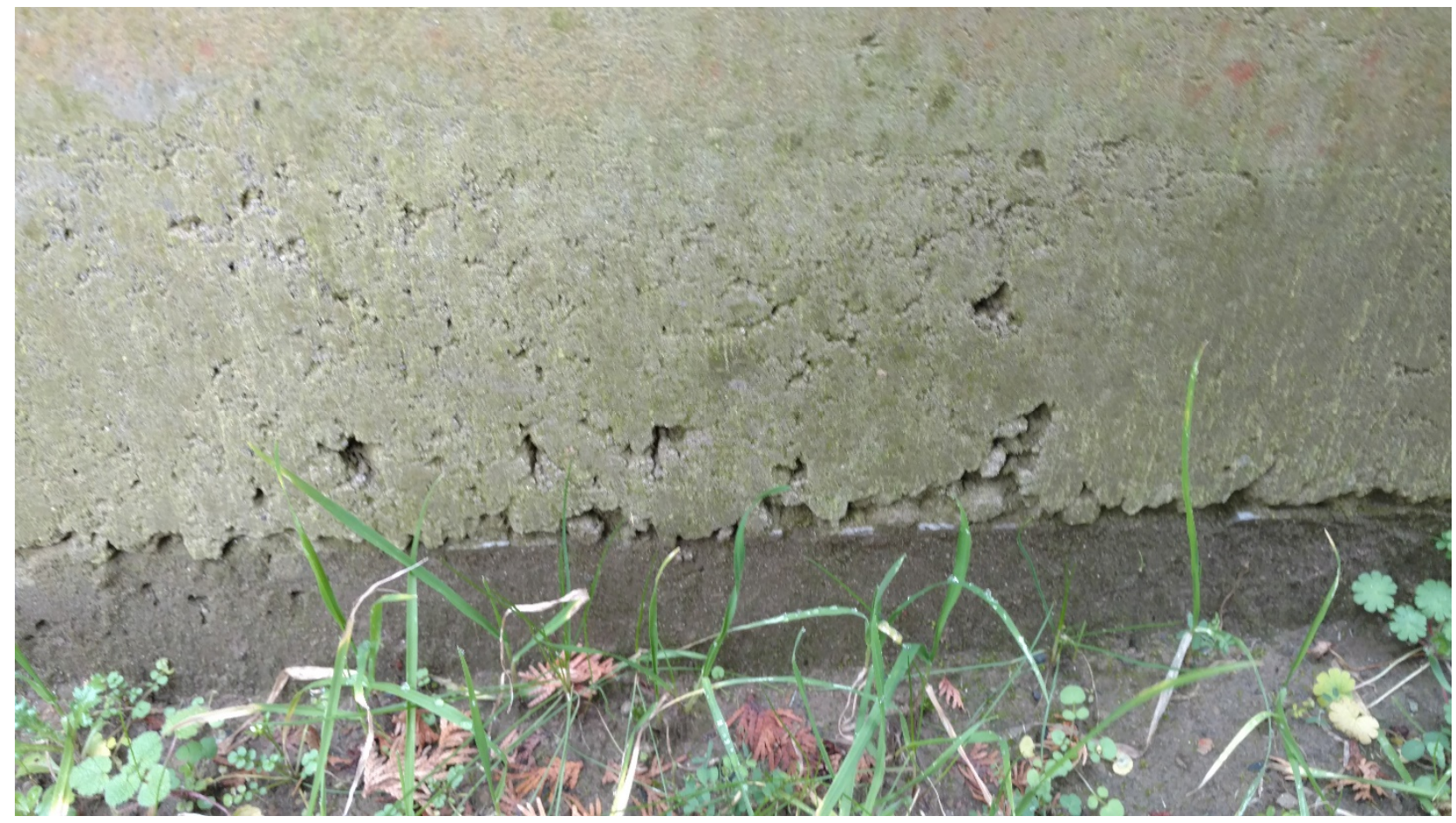

1/8/18 - Close up of Voids at Base 


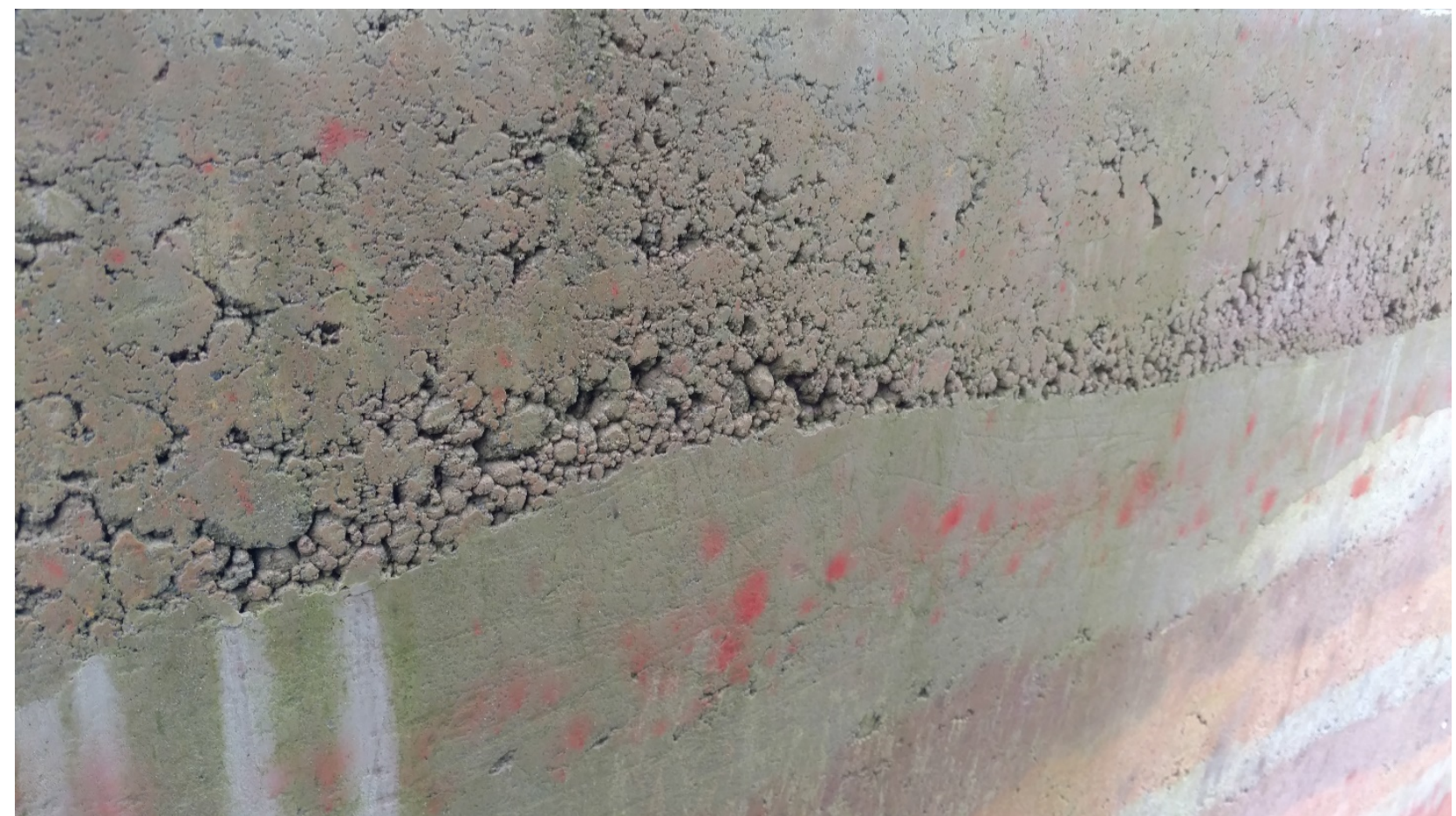

1/8/18 - Close up of Voids in Upper Layer

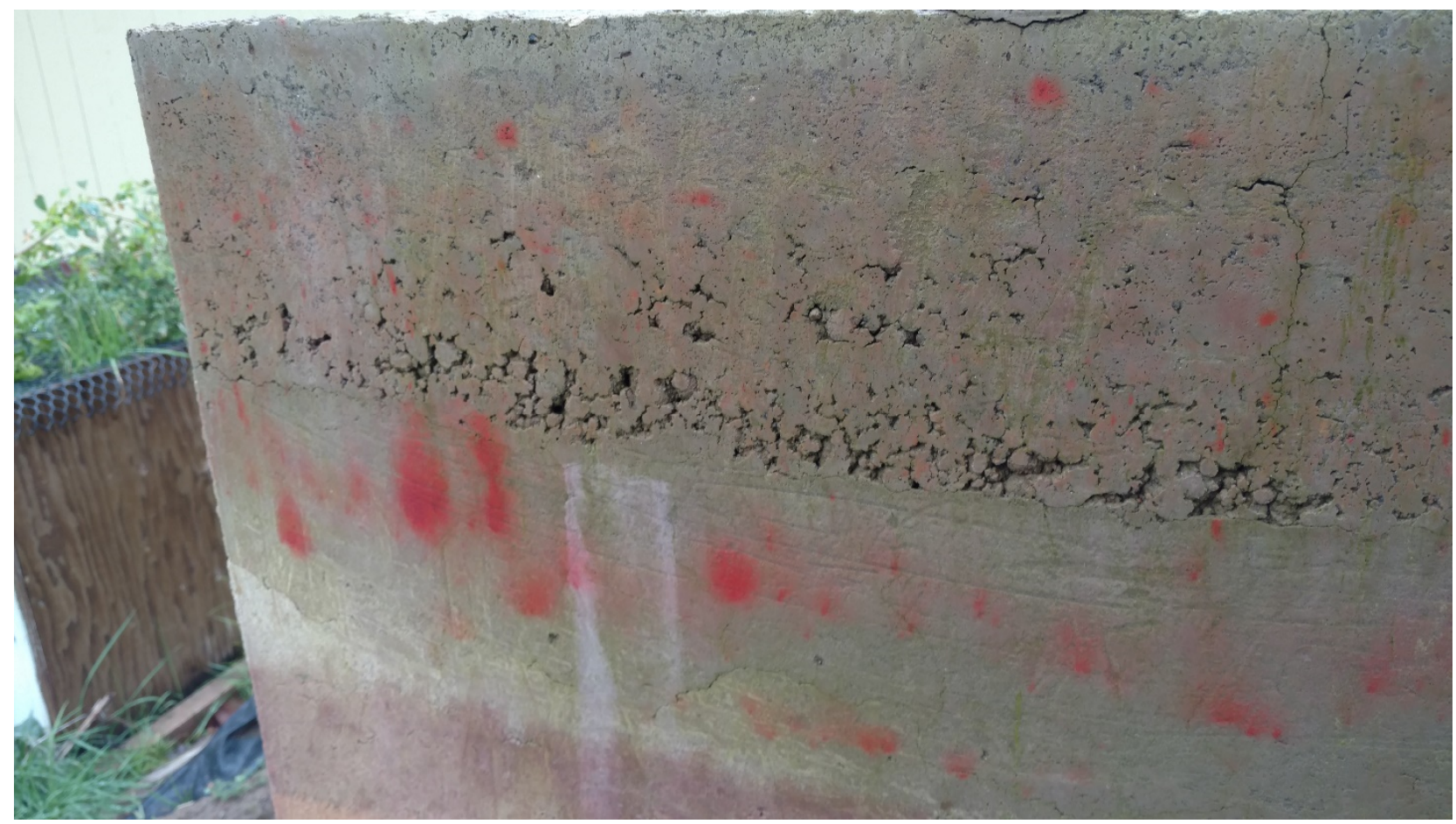

1/8/18 - Close up of Voids in Upper Layer on Southwest Side 


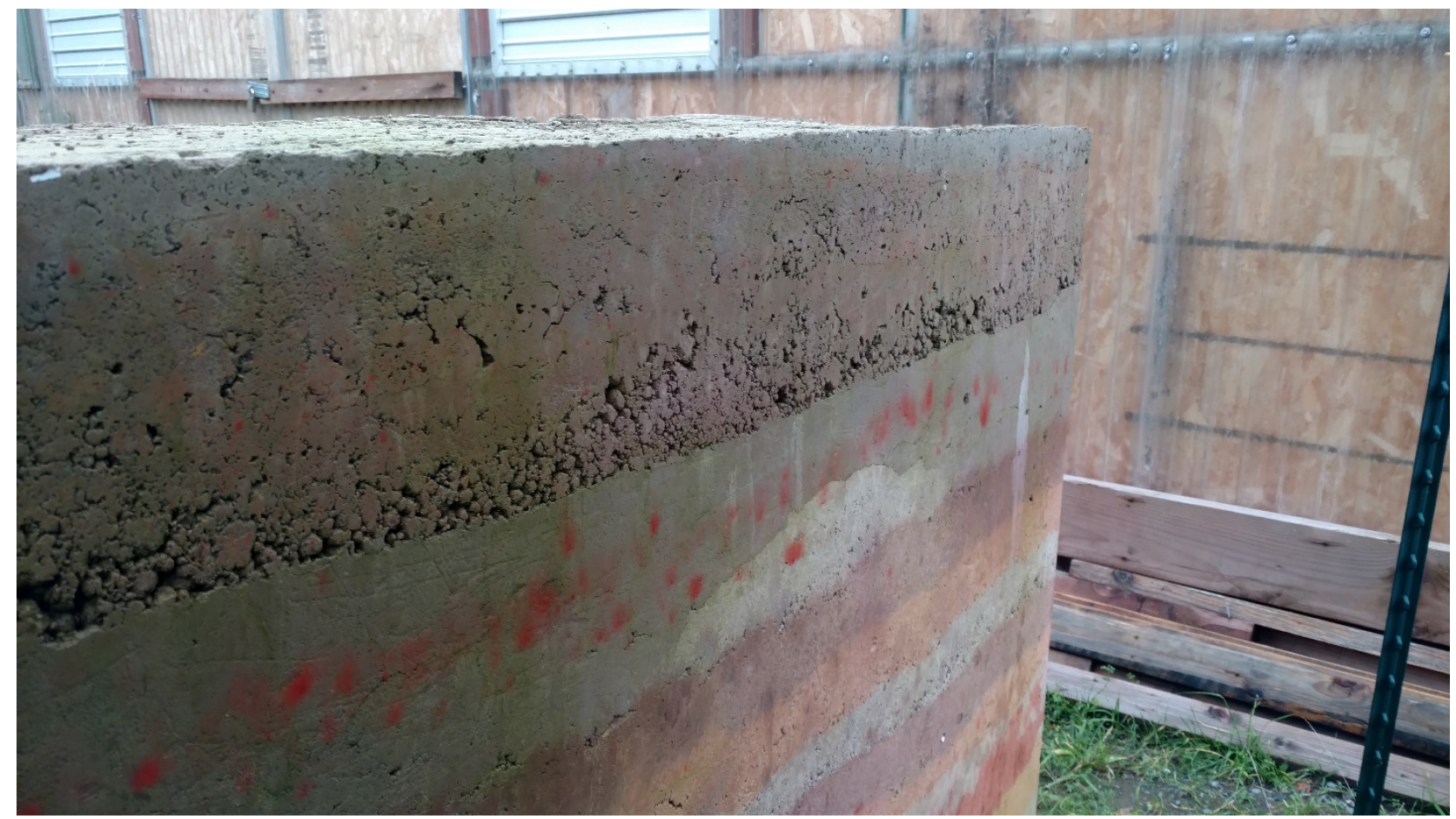

1/8/18 - Looking Northeast at Southeast Side

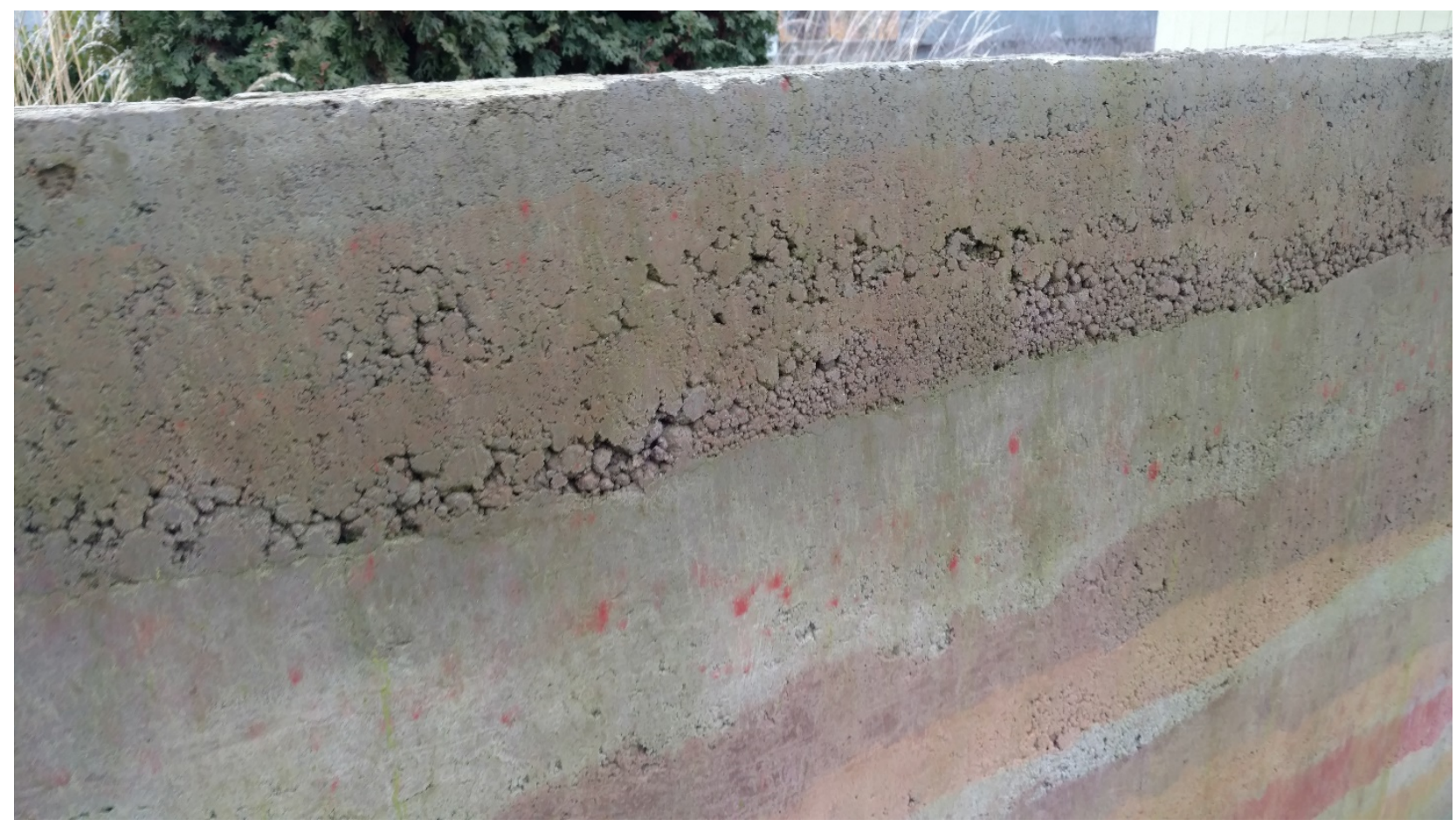

1/8/18 - Looking South at North Side 


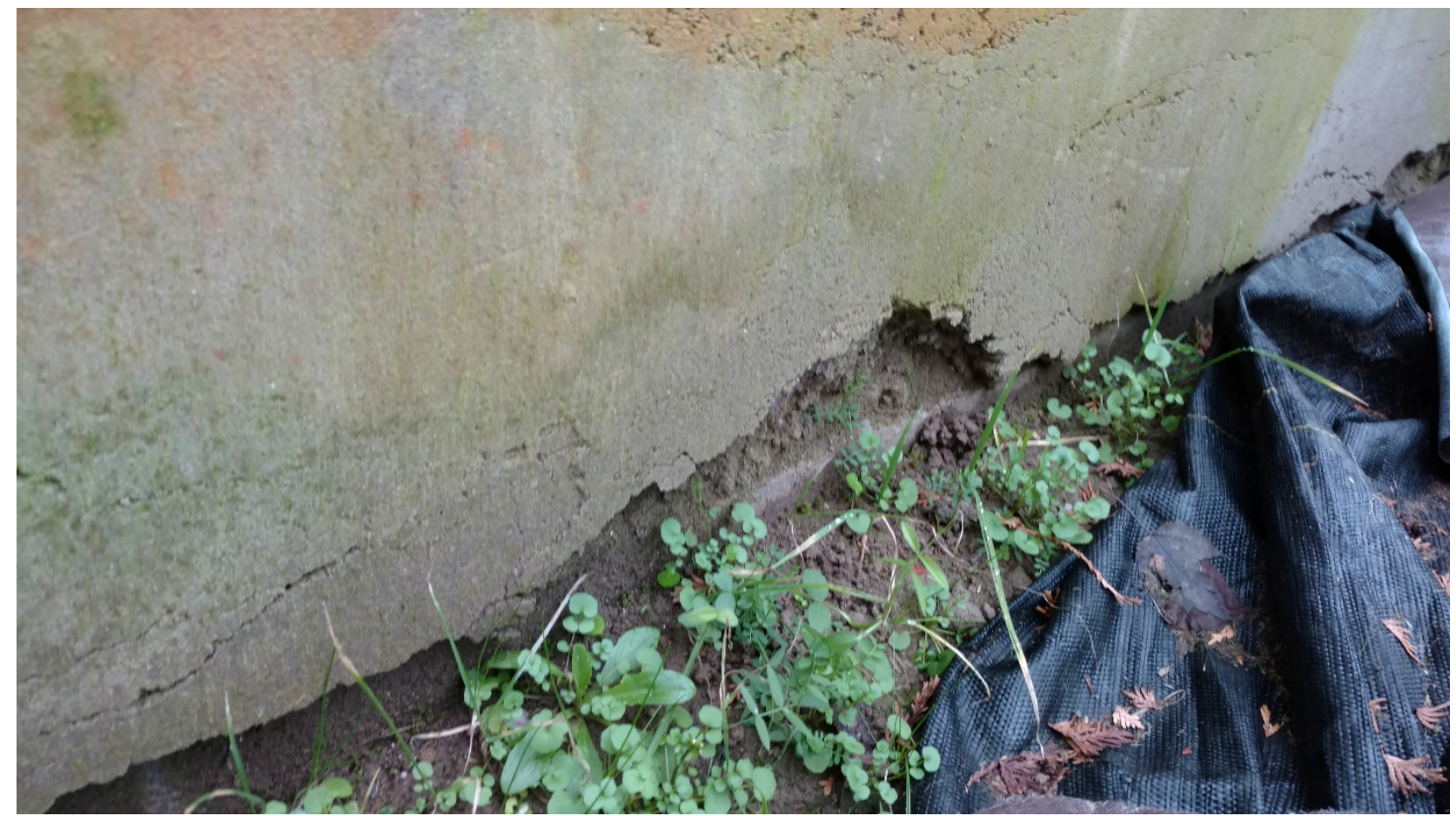

1/8/18 - Close up of Crumbling at Base on North Side

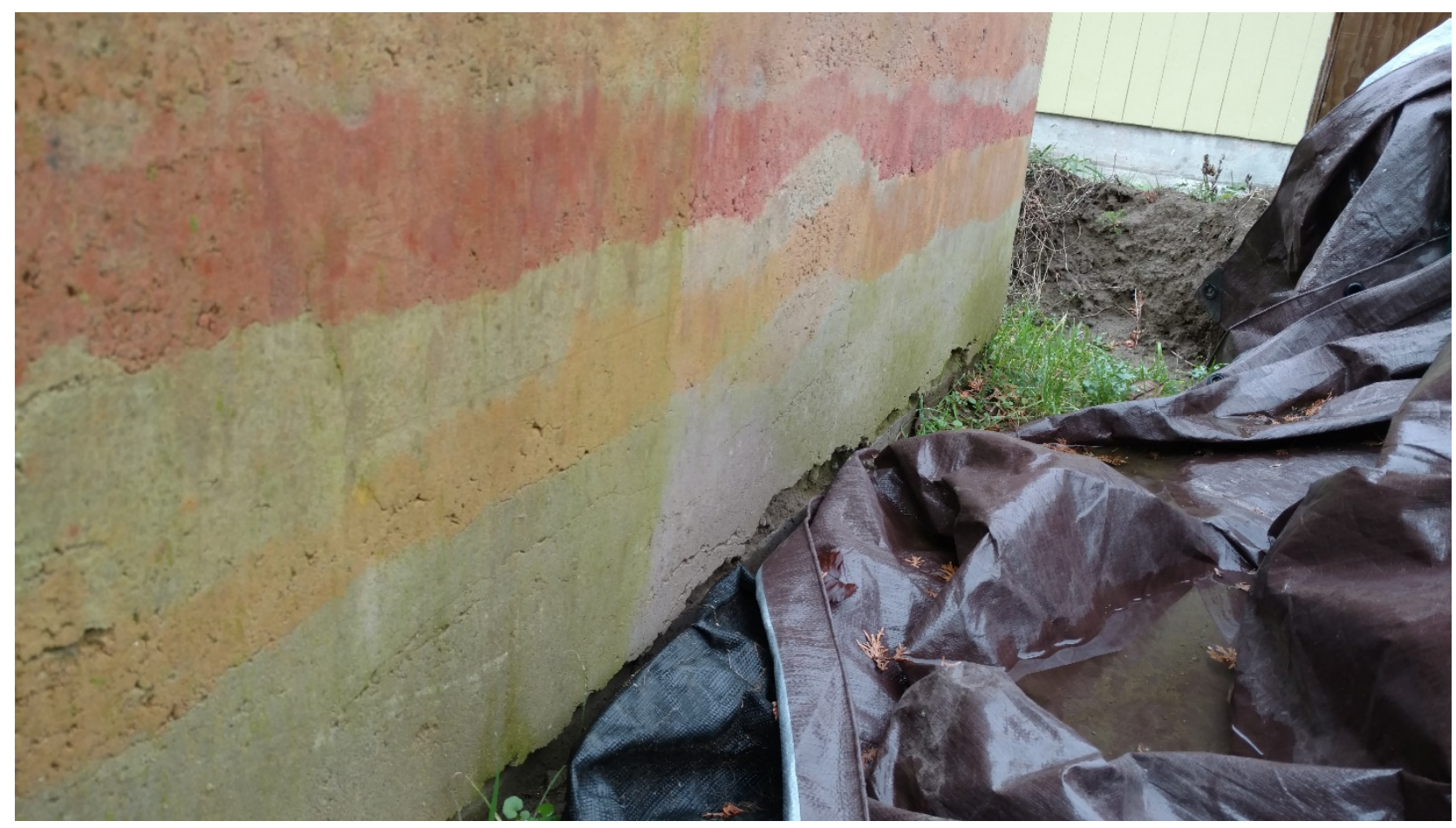

1/8/18 - Looking West at the North Side Base 


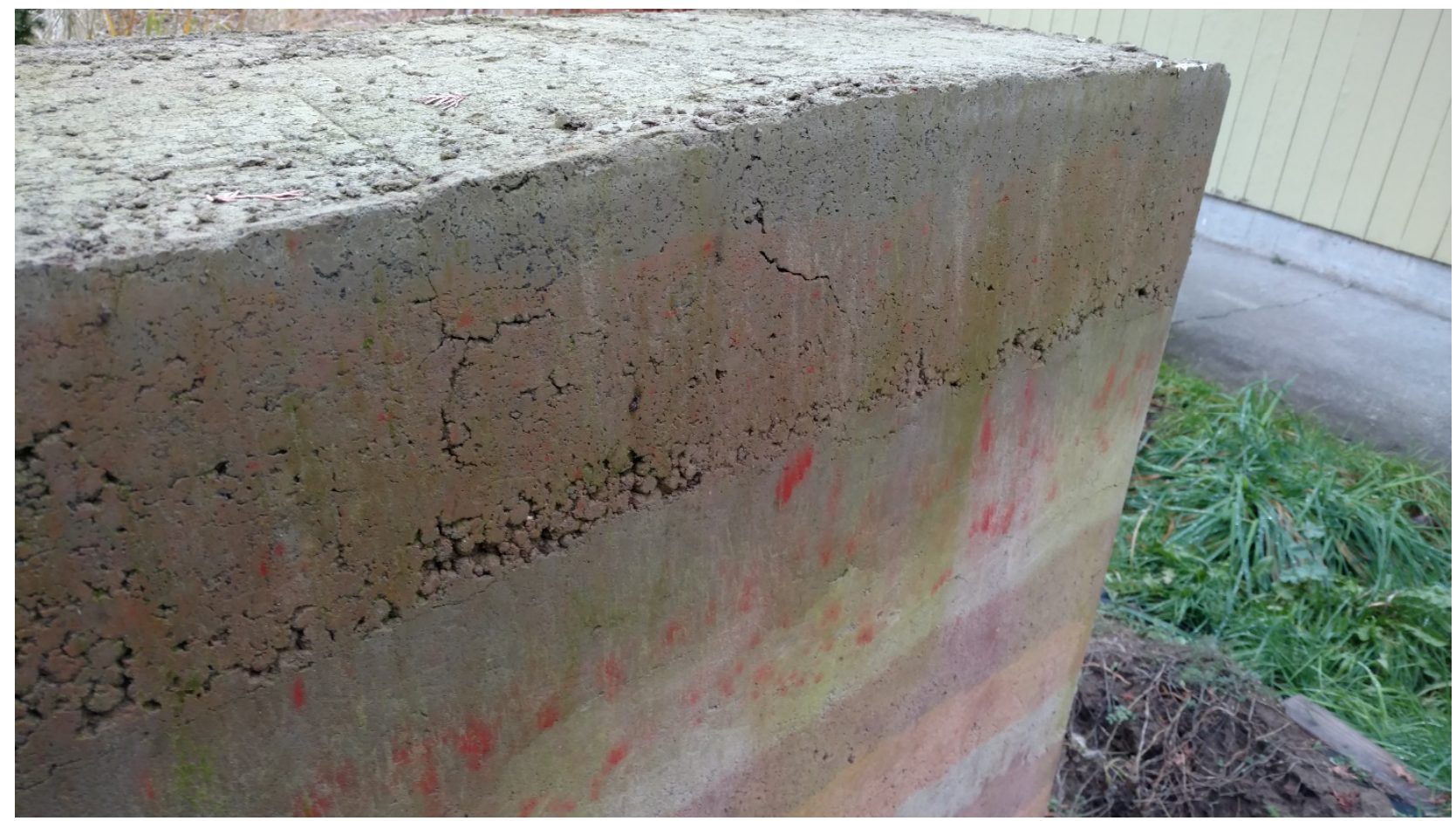

1/8/18 - Looking Southwest at the Northwest Upper Corner

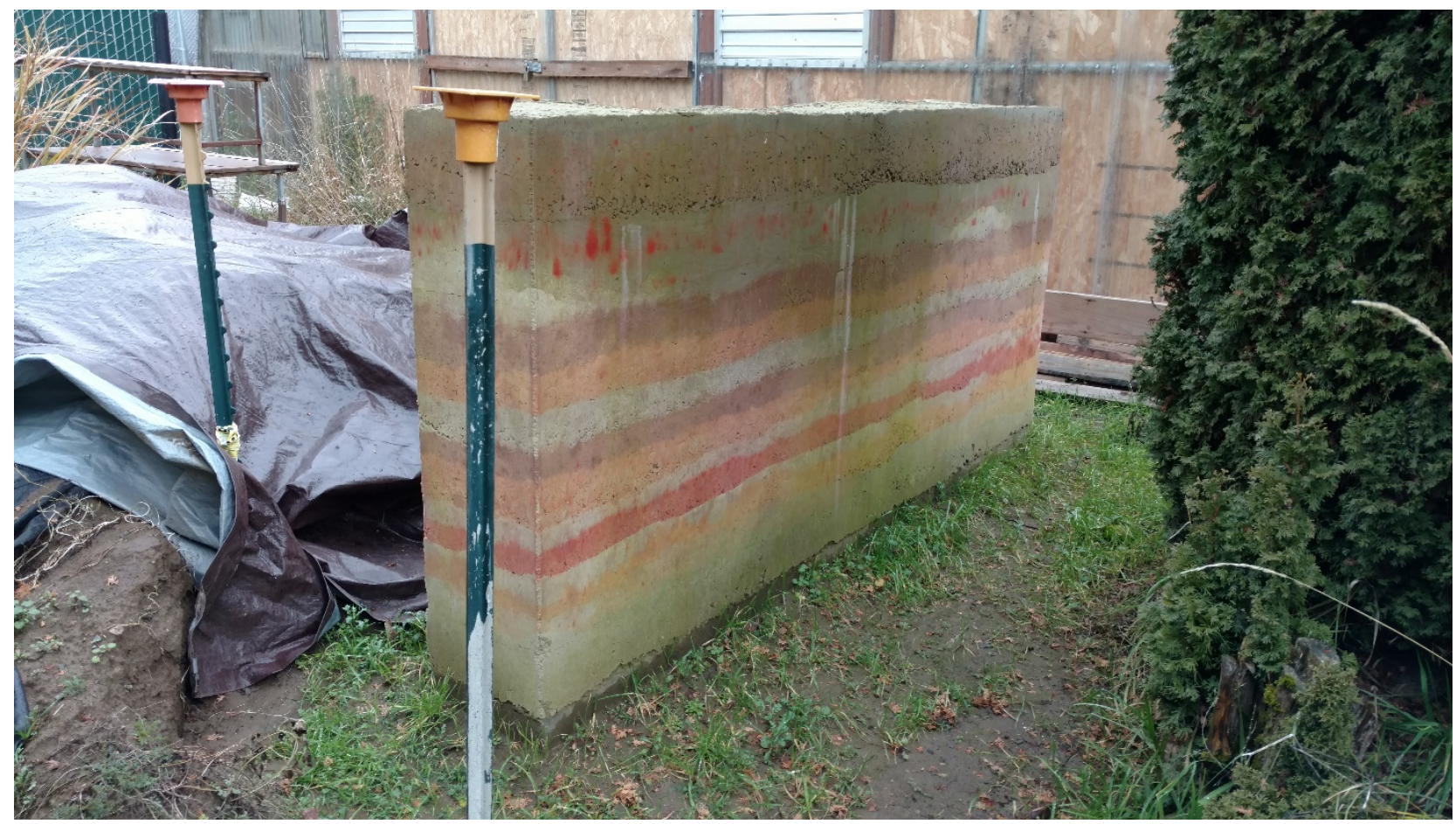

1/8/18 - Looking Northeast 


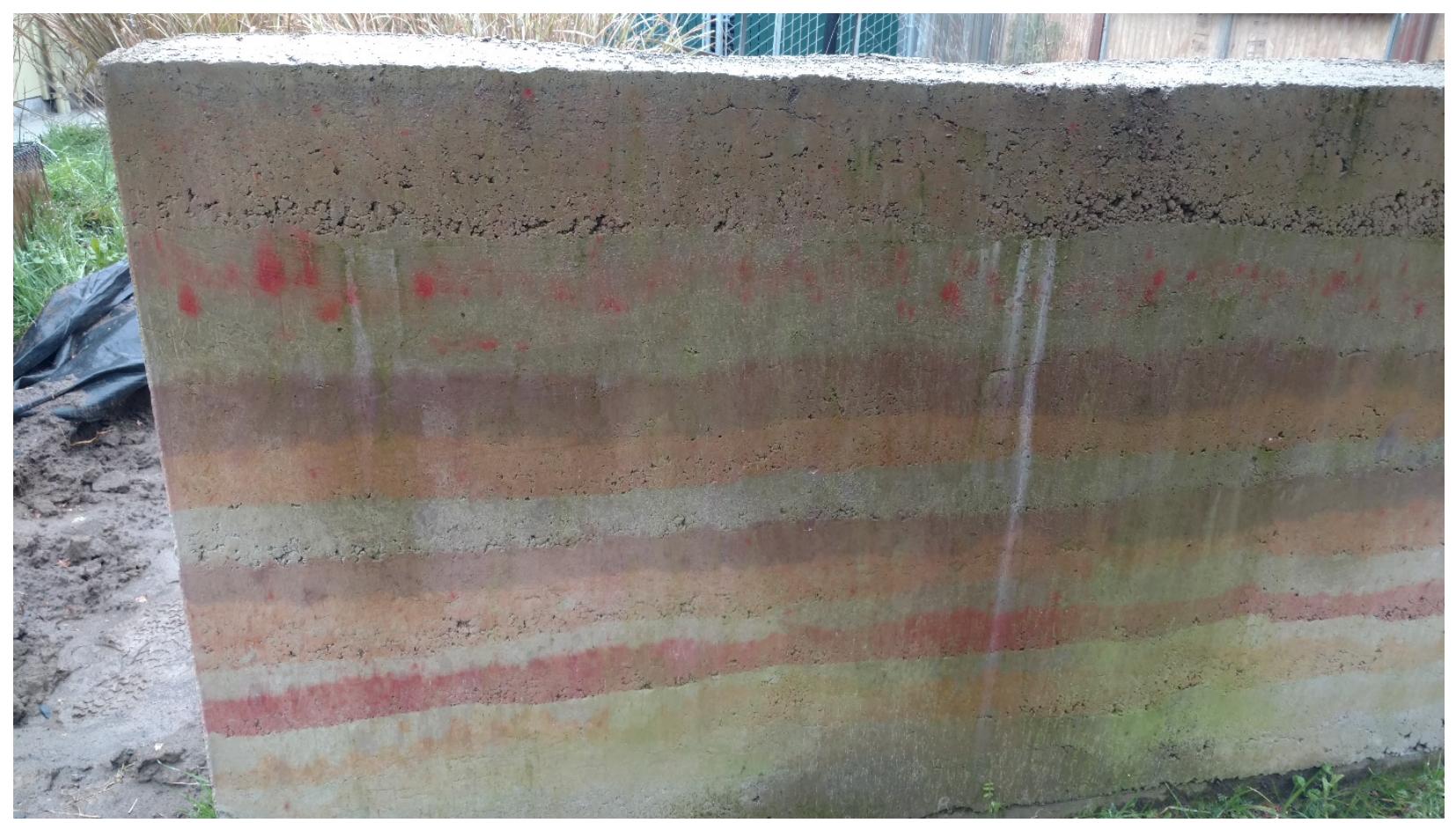

2/28/18 - Looking North at the South Side 


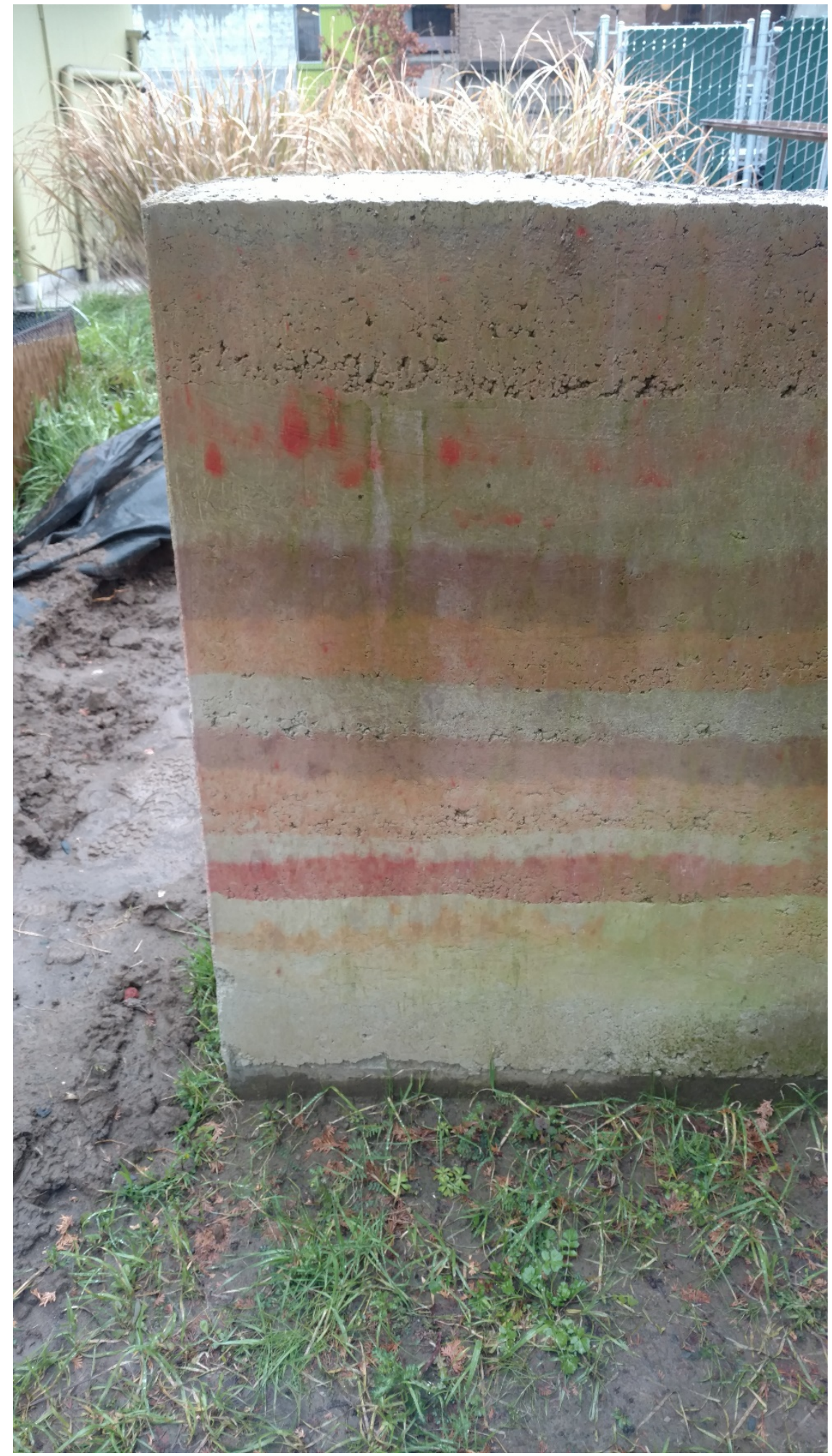

2/28/18 - Looking North at the West Side 

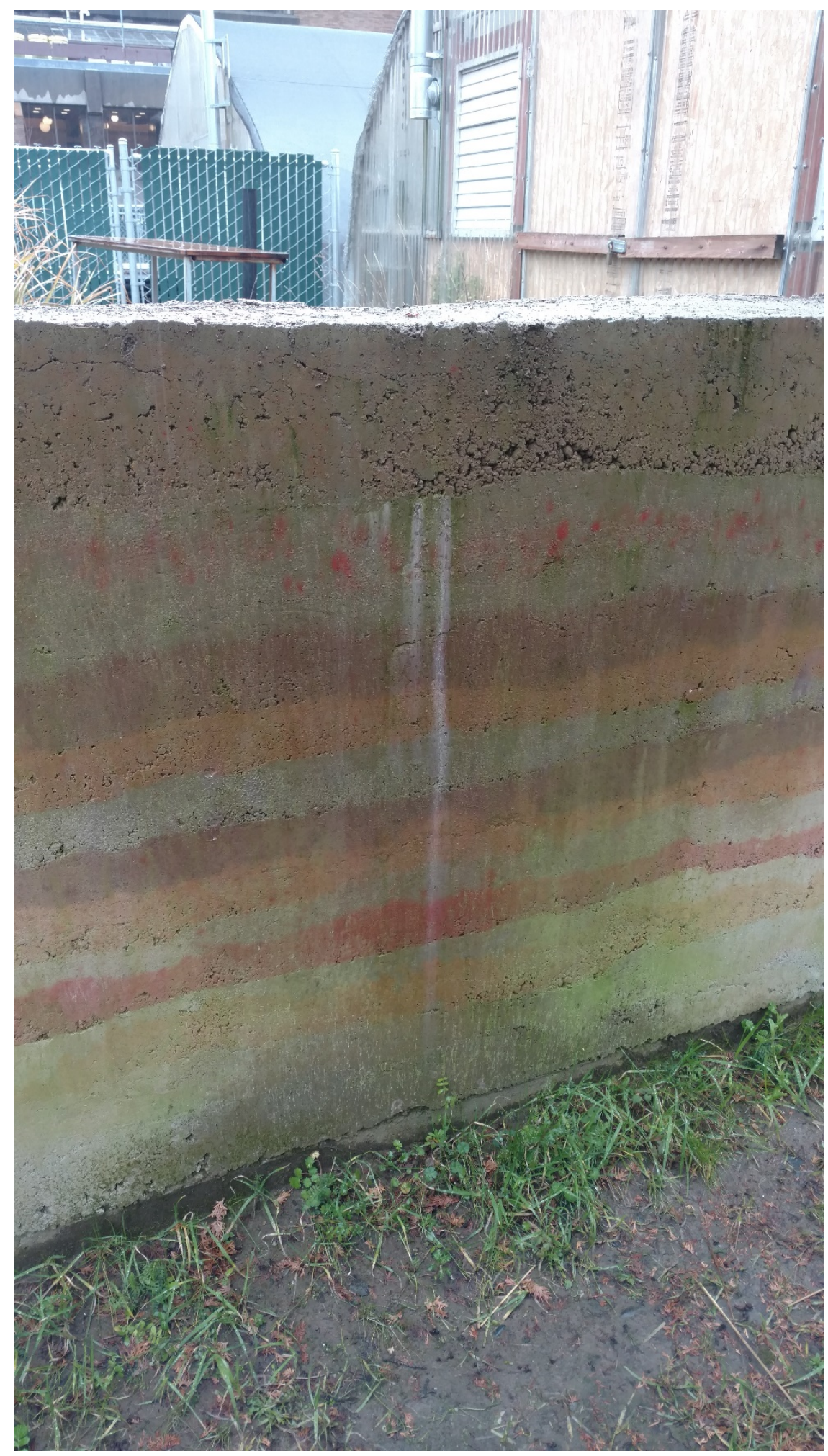

2/28/18 - Looking North 


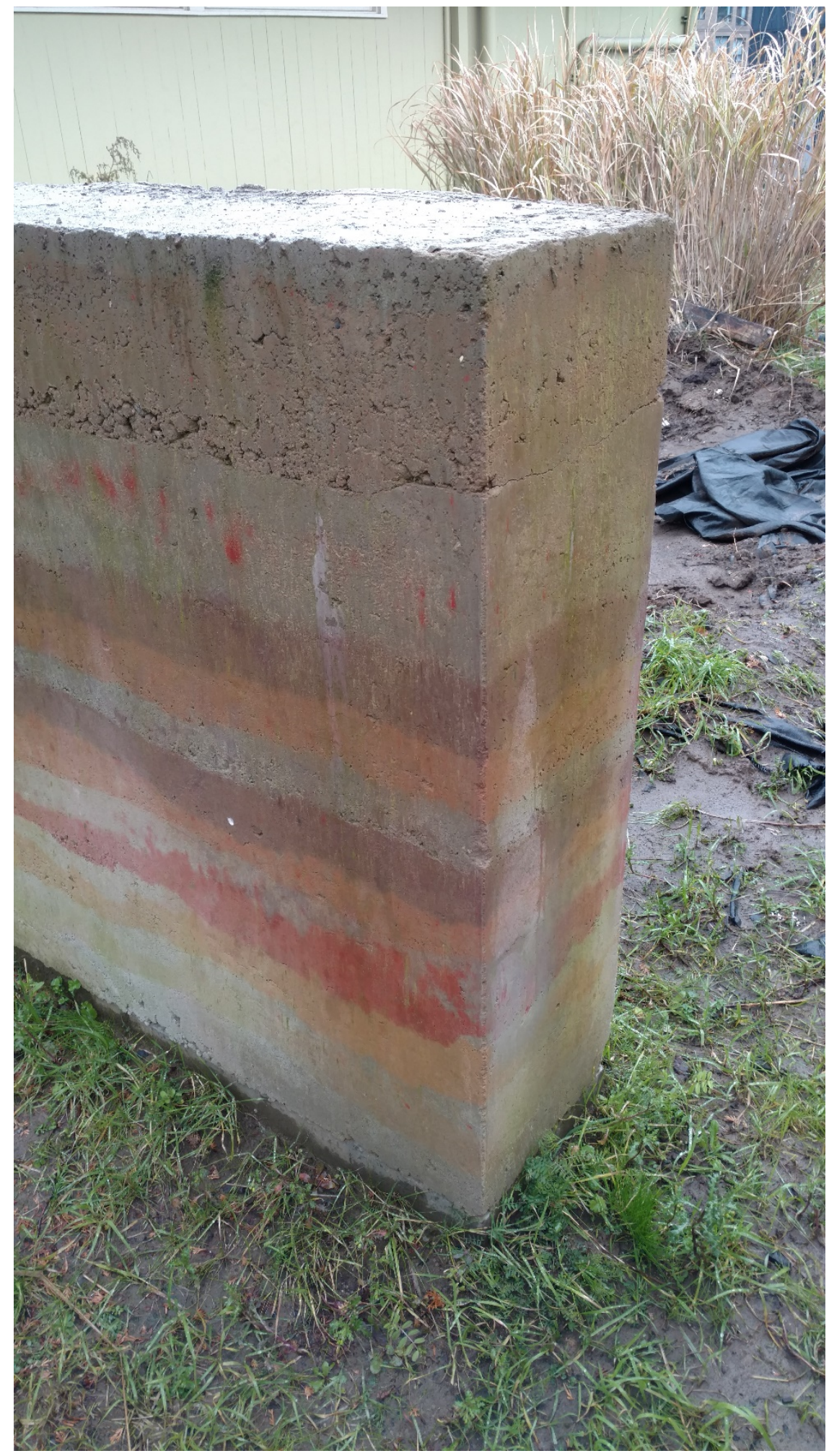

2/28/18 - Looking Northwest at the Southeast Corner 


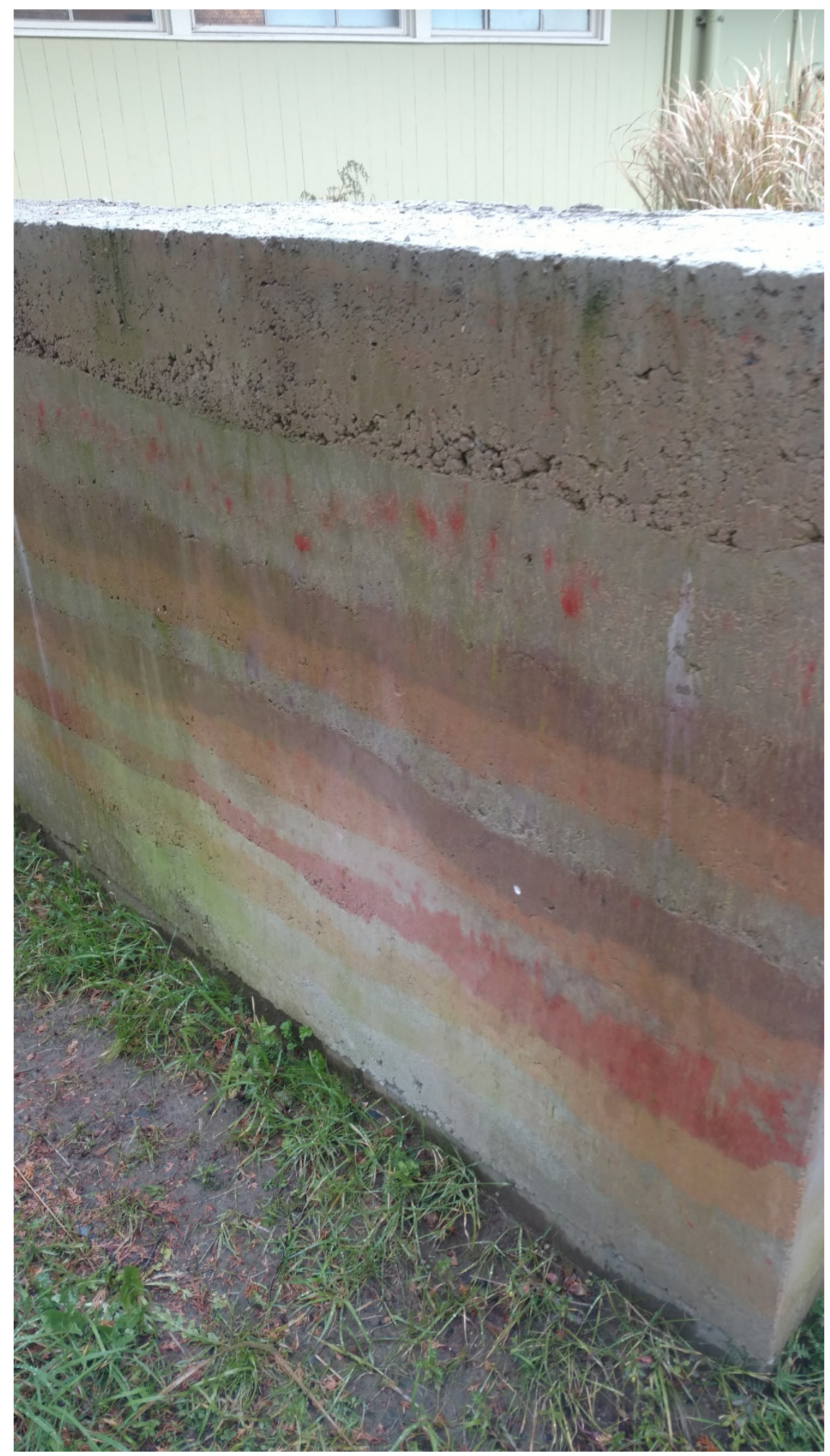

2/28/18 - Looking Northwest at the East Side 


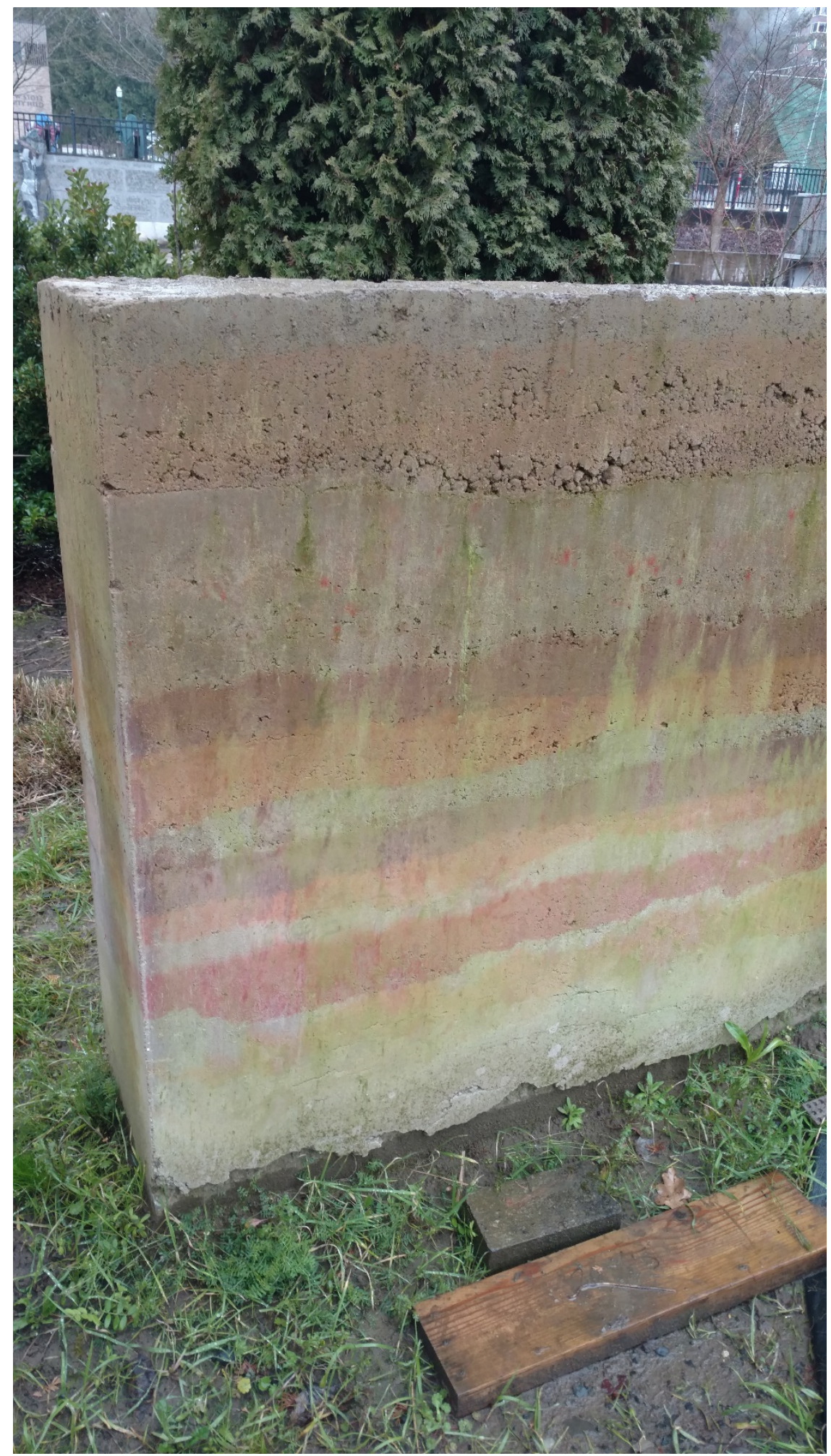

2/22/18 - Looking South at the East Side 